Linköping Studies in Science and Technology

Dissertations, No.1751

\title{
Health Care Customer Creativity
}

\section{Hannah Snyder}

Department of Management and Engineering Linköpings universitet, SE-581 83 Linköping, Sweden 
(C) Hannah Snyder, unless otherwise noted.

Health Care Customer Creativity

Linköping Studies in Science and Technology, Dissertations, No. 1751

ISBN: $978-91-7685-807-3$

ISSN: 0345-7524

Printed by: LiU-Tryck, Linköping

Distributed by:

Linköping University

Department of Management and Engineering

SE-581 83 Linköping, Sweden

Tel: +46 13281000

Linköping Studies in Science and Technology, Thesis No. 1751 


\section{Abstract}

Crafting and stimulating service innovation is considered a main research priority and remains a challenge for service providers. One suggested component of stimulating service innovation is customer creativity. Customers who adapt, modify and transform services or products to better suit themselves are increasingly being recognized as a source of competitive value and innovation. It has been proposed that understanding and supporting the customer's value creating practices is the key to creating and sustaining value over time in health care. Health services directly address a customer's well-being and have a significant impact on his or her quality of life. In these types of services, the service outcome is highly dependent on the activities of the individual customer. Health care services often require customers to participate extensively, over long periods of time, with limited support and control. Health services also stretch far beyond the particular service setting into the customer's daily life. While research, policy, and legislation have all emphasized the active role of health care customers, such customers have traditionally had few opportunities to design their health care services. Nevertheless, health care customers solve health-related problems and engage in self-care and medical decision-making on a day-to-day basis, although this creativity is often unknown to the service provider.

To understand how health care customers can enable service innovation, this thesis seeks to conceptualize and investigate the concept of customer creativity in health care. The thesis focuses on customer creativity, not only as an outcome, but also as a dynamic and contextualized process that can be enhanced. The thesis combines insights from health care research with service and innovation research to provide build a framework for health care customer creativity. Building on five papers, the research develops an understanding for health care customer creativity. The individual papers are based on systematic literature reviews as well as empirical data in the form of customers' ideas for service innovation collected through diaries.

The results of the thesis suggest that despite the negative nature of the service, health care customers are creative. Given the opportunity, health care customers can provide creative ideas and solutions on a multitude of aspects, both within and outside the health care setting. This provides the potential to view the health care experience through the customers' eyes and take part in their creativity in spheres where the service providers have not traditionally had any access. This thesis contributes to the literature by providing a framework for health care customer creativity that recognizes the concept as a complex interplay of factors operating at the individual, contextual, and situational levels. The proposed framework specifies the health care specific factors upon which customer creativity depends, with the intention of positing potential research directions and developing an enriched theory of health care customer creativity. 


\section{Sammanfattning}

Att skapa och stimulera tjänsteinnovation är en förutsättning för konkurrenskraft och för att möta de krav som finns från marknaden och kunder. En viktig del i detta är kundkreativitet. Istället för att vara passiva mottagare kan kunden ses som en aktiv resurs som anpassar, ändrar och omvandlar produkter eller tjänster för att skapa mer värde. Detta är speciellt viktigt i sjukvård. Sjukvårdstjänster har en stor betydelse för kunders välbefinnande och livskvalitet. Hälso- och sjukvård är en kategori av tjänster där resultatet till stor del är beroende av den individuella kunden. Tjänster kopplade till sjukvården ses som "negativa", alltså något som kunden behöver men egentligen inte vill ha. Trots detta kräver denna typ av tjänster ofta att kunden deltar aktivt och tar ansvar under längre perioder med relativt lite stöd och kontroll. Dessutom är detta en typ av tjänst som ofta har påverkan på kundens vardag. Även om vikten och nyttan av att stödja en mer aktiv kundroll har förts fram både i forskning, policy och lagstiftning, så har kunder fortfarande relativt liten möjlighet att bidra till utformningen och utvecklingen av vården. Trots detta så engagerar sig kunder i problemlösning, egenvård och medicinskt beslutsfattande, ofta på en daglig basis, men denna kreativitet är ofta osynlig för andra än kunden själv.

För att förstå hur kunder kan bidra till tjänsteinnovation i sjukvården, är syftet med den här avhandlingen att konceptualisering och öka förståelsen för kundkreativitet. Avhandlingen fokuserar inte på resultatet av kundkreativitet, utan också på processen och faktorer som influerar kundens möjlighet att vara kreativ. Avhandlingen bygger på fem individuella artiklar, som alla syftar till att öka förståelsen för och utveckla ett ramverk kundkreativitet specifikt för sjukvården. Detta görs genom att kombinerar teorier och insikter från vårdforskning med tjänste- och innovationsforskning samt empiriskt testa vissa delar av ramverket. Artiklarna bygger därför både på systematiska litteraturer genomgångar samt empirisk data i form av kundidéer för tjänsteinnovation som samlats in genom dagböcker.

Resultat från den här avhandlingen visar att trots att sjukvård ofta är någonting som kunden inte egentligen vill ha, så är kunder ändå kreativa. Om de ges möjlighet, kan kunder inom sjukvården bidra med kreativa idéer och lösningar inom en mängd olika områden, både inom sjukvården men också relaterat till den privata sfären. Detta kan ses som en potentiell resurs som kan användas för att förstå hur kunder använder tjänster och skapar värde och synliggöra deras kreativitet. Avhandlingen bidrar till forskning och praktik genom att utveckla ett teoretiskt ramverk som ser kundkreativitet som ett komplext samspel av faktorer som påverkas av både av individ, kontext, och situation. Detta ramverk redogör för vårdspecifika faktorer som influerar kundens möjlighet att vara kreativ och syftar till en utökad teori om kundkreativitet i sjukvården och hur kunder kan vara en resurs for innovation. 


\section{Acknowledgements}

I love everything about research, and I therefore feel very grateful for these past few years. However, this research would not have been possible without support from a number of important people to whom I would like to express my appreciation.

First of all I want to acknowledge that I am highly aware that I am not the easiest person to supervise. Therefore, I want to start off by expressing my warmest gratitude to my supervisor, Professor Mattias Elg. Thank you for all the help, insights, and support and for giving me lots of space to develop my own ideas. I also want to thank perhaps the most important person in this process, my co-supervisor, Professor Lars Witell. You represent what I feel are some of the best qualities: curiosity, generosity and intelligence. Thank you for the endless support, engagement, fun discussions, and for always motivating me to aim higher. This work would not have been possible without you.

Besides my supervisors, I have been lucky enough to be greatly supported by other fantastic scholars. Professor Anders Gustafson very patiently answered my endless research questions and always supported and encouraged me. Professor Janet McColl-Kennedy at the University of Queensland hosted me during a most rewarding semester. Thank you for sharing so much of your experience and time, and for inspiring me to be a better researcher. Besides these persons, I am also very grateful for having had the chance to work with such excellent coauthors from three different continents. In addition, I wish to offer my very special thanks to Elina Jaakkola who gave me valuable comments on earlier drafts of this thesis.

I also want to thank all of my colleagues at the Division of Logistics and Quality Management for providing such an excellent and fun work environment. In particular, I want to thank Elisabeth for being such a good friend and for all the laughs. You have really been a lifesaver during the last years and I have been lucky to always have you two offices away. Thanks to Per and Daniel for all fun discussions on methodology, philosophy, and music. To my new logistics colleagues, I must admit that I was initially skeptical, but this merge was probably the best thing that could ever happen. Special thanks to Maria and Fredrik for being such excellent sources of distraction from writing this thesis, and to Kristina Dalberg for assisting me with proofreading.

Finally, I am most grateful to my family and friends for putting up with me spending so much time away. Thanks to my parents Lars and Carol, who loves me and support everything that I do. Many thanks to my sister Sarah and brother Timothy for being so much fun and giving me the best little people in my life - Agnes, Martin, Lotus, and Looie. To my best friend Lisa, to have spent so many hours on the road with you this year and then finally stand on the finishline of Paris-Brest-Paris has been incredible - except for that one time you left me in the dark all alone after 1100 kilometers between Villaines-la-Juh and Mortagne-au-Perche. Thanks to Moa for all the dancing in the kitchen, for making sure that there is always coffee and for 
texting when I am not home in time. To Jens and Saga for putting up with me coming and going and being patient with my various requests to move to Australia, the United States, the south of France, or to buy a pony (often in the same week). Thank you Jens for never stopping me, and for being the most intelligent and funniest person I know.

Brisbane, February 2016

Hannah Snyder 


\section{Contents}

Abstract
Sammanfattning
Acknowledgements
Contents.
List of papers
Tables and figures
Introduction

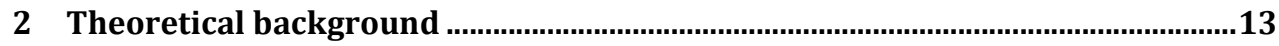

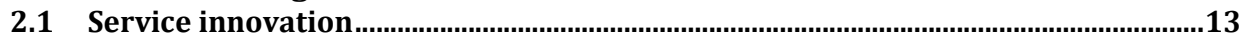

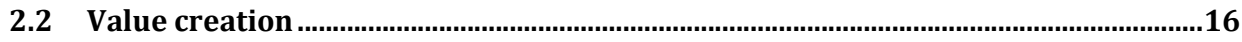

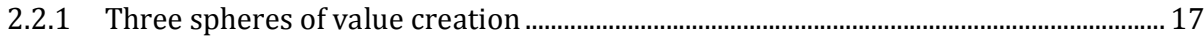

2.2.2 Extending beyond the service provider-customer dyad ............................................. 18

2.2.3 Value-creation practices ..................................................................................................... 18

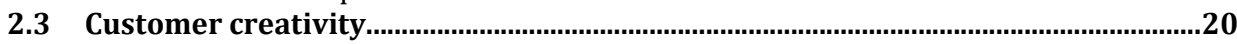

2.3.1 An integrative approach to creativity ......................................................................... 21

2.4 Relating service innovation, value creation, and customer creativity ......................22

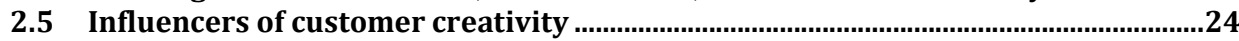

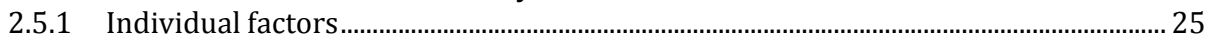

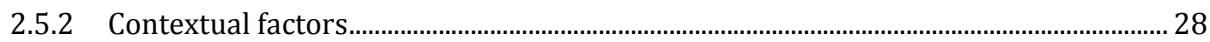

2.5.3 Situational factors.................................................................................................................. 31

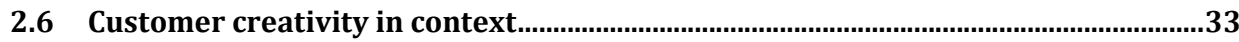

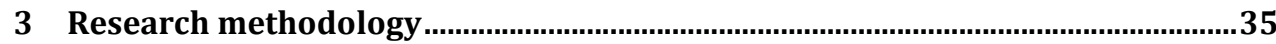

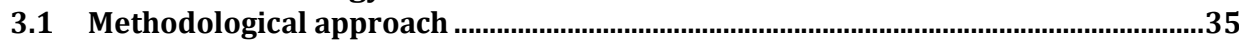

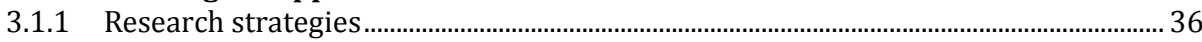

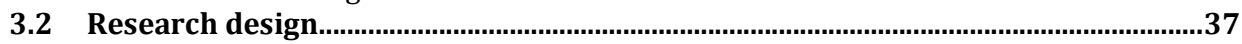

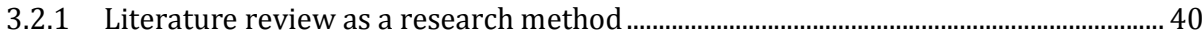

3.2.2 Different approaches to conducting a literature review ..................................................... 40

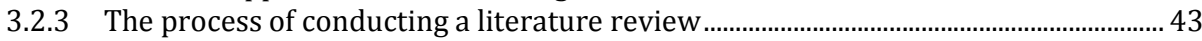

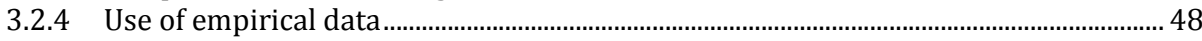

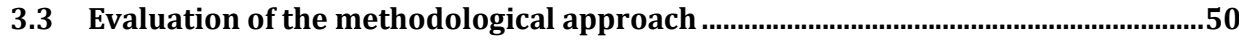

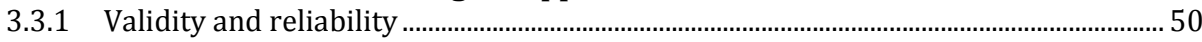

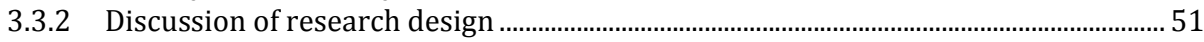

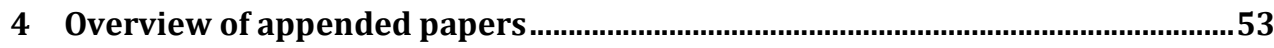

4.1 Paper 1: The Antecedents, Forms and Consequences of Patient Involvement: A

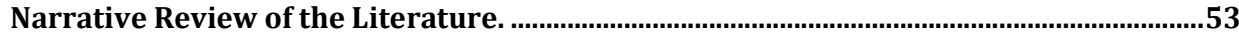

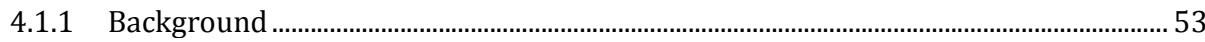

4.1.2 Findings and contributions............................................................................................ 53

4.2 Paper 2: Identifying categories of service innovation: A review and synthesis of the literature 


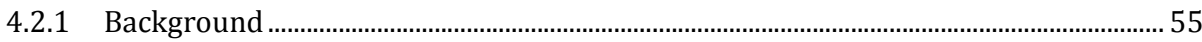

4.2.2 Findings and contributions............................................................................................ 55

4.3 Paper 3: Changing Role of the Health Care Customer: Review, Synthesis and

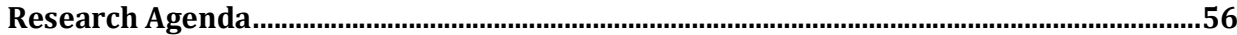

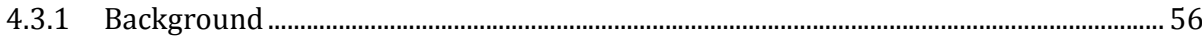

4.3.2 Findings and contributions.............................................................................................. 56

4.4 Paper 4: Customer Creativity: Exploring the Influence of Type of Service and

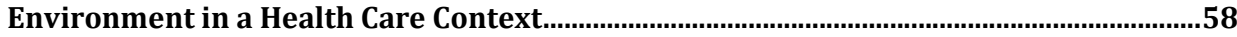

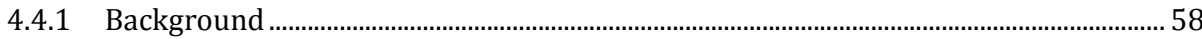

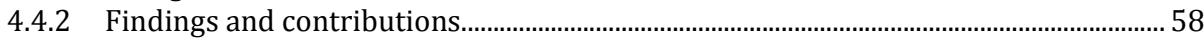

4.5 Paper 5: Health care customer creativity: The role of physical and social context 59

4.5.1 Background 59

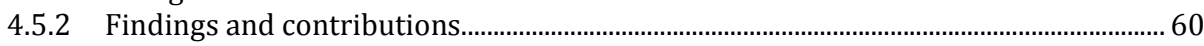

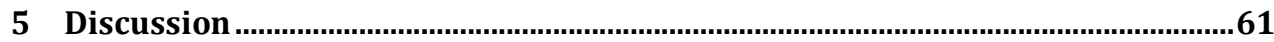

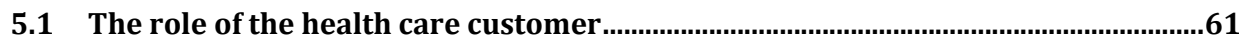

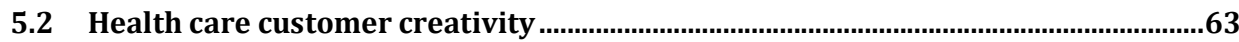

5.3 Towards a framework for health care customer creativity .......................................64

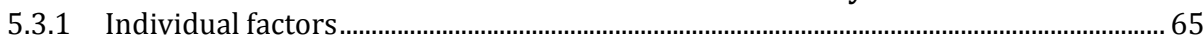

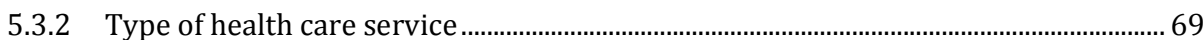

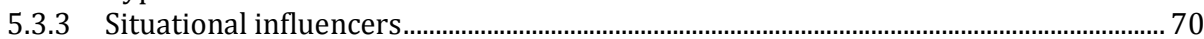

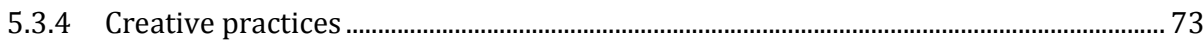

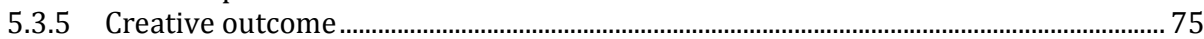

5.4 Health care customer as enablers for service innovation ............................................76

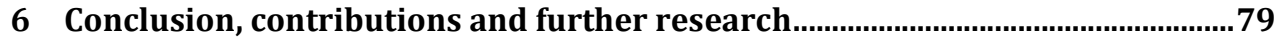

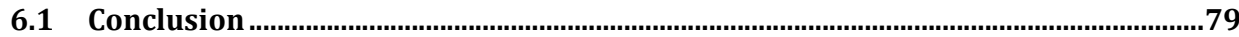

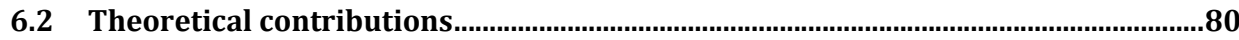

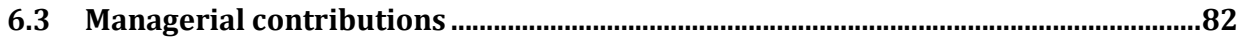

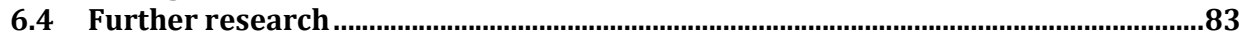

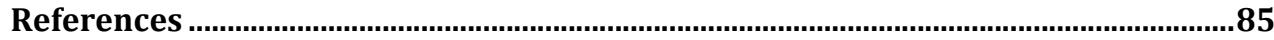




\section{List of papers}

1. Snyder, Hannah, and Jon Engström (2016). "The Antecedents, Forms and Consequences of Patient Involvement: A Narrative Review of the Literature." International Journal of Nursing Studies 53 (January): 351-78.

2. Snyder, Hannah, Lars Witell, Anders Gustafsson, Paul Fombelle, and Per Kristensson (2016). "Identifying Categories of Service Innovation: A Review and Synthesis of the Literature." Journal of Business Research.

3. McColl-Kennedy, Janet, Hannah Snyder, Anu Helkkula, Mattias Elg, Lars Witell, Sue Hogan and Laurel Anderson. "Changing Role of the Health Care Customer: Review, Synthesis and Research Agenda". In review of the Journal of Service Management.

4. Engström, Jon, Hannah Snyder, Mattias Elg and Lars Witell. 'Exploring the Influence of Type of Service and Environment in a Health Care Context". Submitted to the Journal of Services Marketing.

5. Snyder, Hannah, Lars Witell, Mattias Elg, and Janet McColl-Kennedy. "Health Care Customer Creativity: The role of physical and social context" In review of the Journal of Service Management. 


\section{Contributions}

This thesis builds upon the research of five papers that I have co-authored with colleagues. Below, I have summarized my contribution to the papers with regards to research idea, research design, data collection, data analysis, synthesis and writing. I have been actively involved in all of the papers in close collaboration with different constellations of co-authors.

1. Research idea, research design, data collection, data analysis, synthesis and writing.

I was actively involved in the research idea and designing the review strategy, as well as conducting the review and selecting the articles for inclusion. My co-author and I conducted the analysis and synthesis and we were equally involved in writing the article. I was responsible for the submission to the journal and served and took the main responsibility for addressing revisions from reviewers and resubmission.

2. Research idea, research design, data collection, data analysis, synthesis, and writing.

I was actively involved in the research idea and the design of the review strategy. I conducted the literature search and was responsible for selecting articles. Together with my co-authors, I was involved in the analysis and synthesis of the literature. I was also highly involved in the writing, as well as addressing and responding to the reviewer's comments.

3. Research idea, research design, data collection, data analysis, synthesis, and writing. I was involved in the research idea and was responsible for the research design, as well as for collecting, analyzing, and synthesizing the literature. The writing was done in collaboration with my co-authors.

4. Research idea, research design, data analysis, synthesis, and writing.

I was actively involved in developing the research idea, the research design, and the data analysis, as well as writing in collaboration with my co-authors.

5. Research idea, research design, data collection, data analysis, synthesis, and writing.

I was active in developing the research idea and design. While part of the data was collected from an earlier project, I was responsible for arranging the workshop and evaluating customer ideas. In addition, I performed all data analysis and did most of the writing. I was also responsible for submitting the article to the journal. 


\section{Tables and figures}

\section{Tables}

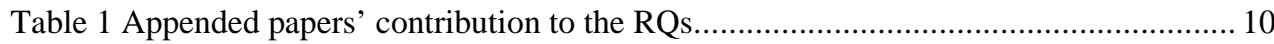

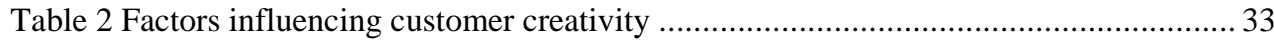

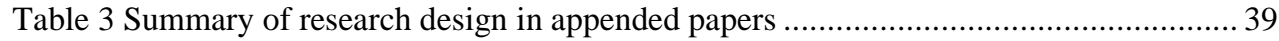

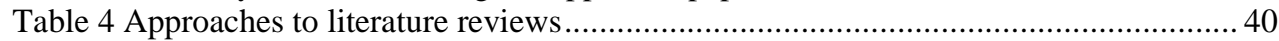

Table 5 Overview of the categorizations of service innovation ......................................... 55

Table 6 Illustrations of health care customer practices ................................................ 75

\section{Figures}

Figure 1 A model for understanding the value-creation process (Grönroos and Ravald, 2011)

Reprinted with the permission of Emerald Group Publishing (C) 2011

Figure 2 A system model of creativity (adapted from Csikszentmihalyi 1999; Kerrigan 2013)

Figure 3 Connections between theoretical concepts .................................................. 23

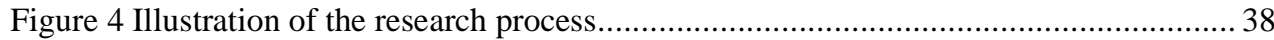

Figure 5 Process of conducting a literature review...................................................... 44

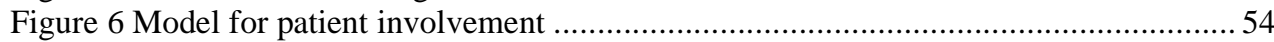

Figure 7 Health care customer practice approaches ......................................................... 57

Figure 8 An overview of customer co-creation roles in service innovation ........................ 59

Figure 9 Physical and social contexts for health care customer creativity (adapted from

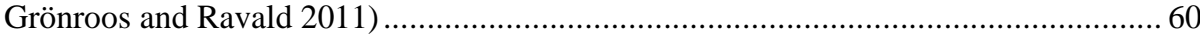

Figure 10 Conceptual framework of health care customer creativity ................................. 65 


\section{Introduction}

Both scholars and management practitioners have acknowledged that service innovation is essential for the future competitive strength and growth of modern economies (Agarwal and Selen 2011). Therefore, crafting and stimulating service innovation is considered a central research priority (Gustafsson et al. 2015; Ostrom et al. 2015). Increasingly, the value of alternative sources, such as customers, to drive innovation has been recognized (Burroughs et al. 2008; Hoyer et al. 2010; Kristensson et al. 2004). Traditionally, customers have been viewed as passive receivers of products and services, who consume and use finished offerings with little or no further adaptation or change (Payne, Storbacka, and Frow 2008). However, this view is starting to change and customers are being recognized as key actors who co-create value with service providers and others (Vargo and Lusch 2015; McCollKennedy et al. 2012). In line with this changing view of the customer, the phenomenon of customer creativity has attracted interest. Creative customers - defined as customers who adapt, modify, or transform a product, service, or idea - are now being recognized as a source of competitive value and innovation (Berthon et al. 2007).

The propensities of customers to adopt and modify offerings to better suit themselves plays an important role in theories of innovation and consumer behavior (Hirschman 1980). The concept of customers as a source of service innovation has received widespread attention in service research (Gustafsson, Kristensson, and Witell 2012; Alam 2002; Edvardsson et al. 2012). It has been suggested that by involving customers actively, new service and product ideas can be generated that are more likely to be valued by customers (Hoyer et al. 2010). However, most customer creativity is unknown to the service provider as it occurs in use, rather than in formal development processes. It can be argued that all customers are active to various extents through an array of different activities connected to the process of consumption (Hirschman 1980). That is, on an individual level, everyone adapts and modifies products and services in ways that are new for them, and that allow them to create more value for themselves. Nevertheless, even if customers are creative, this is not always considered positive. Berthon et al. (2007) concluded that firms often view creative consumers as threats to their business revenues and damaging to the reputation of their product brands, and consequently respond by ignoring or suppressing their activities. Even though a growing number of today's companies are paying close attention to the customers' experiences and role in innovation (Edvardsson et al. 2010), the phenomenon of creative customers remains a paradox. At the same time as it is a significant opportunity for innovation, creativity in consumption (when the customer uses the product or service) is often unobserved and outside of a firm's control.

Even though it is not explicitly encouraged, customers are increasingly able to innovate for themselves (von Hippel 2005). New technology and advancement has enabled the rapid spread of customer-driven innovation in all areas that are beyond the control of service 
providers. This challenges the boundaries of the origins, development, and ownership of ideas and innovations (Kawashima 2010), and also challenges the monopoly of expertise within professional service organizations. The rapid growth of apps and connected devices used by public or private companies enables and supports customers to be more creative and active in using and modifying services. For example, in health care, apps can enable people to control their weight, develop or sustain healthy habits, plan physical activities, or monitor their medication (Mifsud, Cases, and N'Goala 2015).

Customers are key actors in the production, delivery, and use of services (Bitner et al. 1997). While customer participation and engagement is essential for the successful outcome of many services, it is particularly important in prolonged and complex services. Health care services often require customers to participate extensively, over long periods of time, and with limited support and control from the service provider (Spanjol et al. 2015). In addition, they stretch far beyond the particular service setting into the daily lives of health care customers and their surrounding network (McColl-Kennedy et al. 2012; Lorig and Holman 2003). While most literature on customer creativity has implicitly assumed that creativity and creative practices, when engaged in, are desired by customers, little attention has been given to negative, prolonged, and complex services; that is, services that are necessary, yet often unwanted and stressful (Berry and Bendapudi 2007; Spanjol et al. 2015). A better understanding of the dynamic and contextualized creative practices in the customer sphere is especially important for health care services where customer effort and problem solving is crucial for value creation. Therefore, health care service is a particularly interesting context for customer creativity. Thus, by studying a "negative" service where customers are "sick" and reluctant (Berry and Bendapudi 2007), we can advance theories and test whether they can explain how customer creativity works in such a context.

\subsection{Customer creativity as an enabler of service innovation}

Research on service innovation has proceeded in many academic fields, with incomplete links across those fields (Witell et al. 2016). For example, research typically has not connected the diffusion of innovations with the creative design of new products. Without creativity, there would be no potential for service innovation (Howard, Culley, and Dekoninck 2008). Overall, there is a strong positive link between creativity and innovation (Sarooghi, Libaers, and Burkemper 2015); this is also reinforced by that fact that companies considered as innovative generate 75 percent of their revenues from products and services that did not exist five years ago (Howard, Culley, and Dekoninck 2008). While it is clear that creativity is important for service innovation, little research has been dedicated to how it can actually be reinforced (Zeng, Proctor, and Salvendy 2009; Giannopoulou, Gryszkiewicz, and Barlatier 2014). Thus, it is crucial to understand which practices and capabilities are actually needed to strengthen creativity in service innovation, especially when, in practice, "creativity gets killed more often than it gets supported" (Amabile 1998, p. 77). 
Creativity is commonly defined in terms of outcomes (for example, products, services, solutions, or ideas) that are novel and valuable in the given context (Amabile 1983; Oldham and Cummings 1996). To be identified as creative, not only must an idea be new or novel, it must also be appropriate, valuable, and actionable, and benefit some actor, thereby facilitating the value-creation process (Zeng, Proctor, and Salvendy 2009). In this sense, innovation can be distinguished from creativity in relation to the implementation, rather than the mere generation, of ideas. Therefore, in this thesis, service innovation is defined as a new offering that is put into practice by, is adopted by, and creates value for one or more actors. Implied in this view is that value creation plays a significant role in explaining both creativity and service innovation. Creating value in any form can be seen as the goal of creativity and service innovation. However, this can also be viewed as a motivator for creativity because people do not do things unless they are important - unless they are of value.

Customers can be a rich source of creativity and provide an alternative to internal new service and product development projects (Kristensen 2004; Kristensson, Magnusson, and Matthing 2002). Across a range of domains, customers develop their own solutions by finding and connecting the necessary components to meet their specific goals (Moreau and Dahl 2005). Customer creativity can be defined as "the problem solving capability possessed by the individual that may be applied toward solving consumption-related problems" (Hirschman 1980, p. 286). It has been suggested that, on an individual basis, all customers are (to some extent) creative in that way that they think, act, and interact when solving problems and adopting new ideas and changes in behavior. In this sense, customer creativity can be seen as the capacity to create some novel content that the customer finds valuable (Hirschman 1980; Guilford 1967). The extent of creativity will depend on the nature of the problem, the capability of the individual, and the surrounding context and situation.

The concept and understanding of customer creativity has developed from and across a number of research disciplines. With this emerging change in the view of the customer, researchers have addressed how organizations can use customer creativity in new product and service development and have suggested, developed, and tested a number of methods to do this successfully. This includes methods to identify creative customers (e.g., von Hippel 1986), developing methods for involving customers in new service and product development (e.g., Elg et al. 2012; Alam and Perry 2002), and to understand the effects of customer creativity (e.g., Witell et al. 2011; Poetz and Schreier 2012). Surprisingly, limited attention has been given to customer creativity in consumption outside the boundaries of the firm. In addition, the research that exists on customer creativity in consumption has often focused on product development, rather than service development. While involving customers in development is often a formal process initiated and controlled by the firm, creative customers act independently and rarely ask permission to experiment with a firm's offering (Berthon et al. 2007).

Acknowledgment of creativity's importance on the customer level remains limited (Rosa, Qualls, and Ruth 2014; Burroughs, Moreau, and Mick 2008). While some studies have 
focused on evaluating the outcome of customer creativity - the creative product (e.g., Kristensson, Magnusson, and Matthing 2002; Magnusson, Matthing, and Kristensson 2003; Poetz and Schreier 2012) - others have suggested that customer creativity should be understood in the context and situation in which it occurs (Witell et al. 2011). Given that customers undertake the majority of their consumption activities outside the service setting, researchers need to do more to understand when creativity occurs and what factors influence the customer to be creative and engage in the consumption process. Instead of evaluating a specific outcome to determine its creativity, this thesis departs from the individual, contextual, and situational factors that influence creative practices during consumption.

To further develop a theoretical and practical understanding of customer creativity, the literature has called for studies that explore the concept in service settings with specific conditions and requirements (Voss et al. 2016). While thinking creatively is an integral part of customers' daily lives, little research has examined the factors influencing such processes, and how these factors vary depending on domain. Within the fields of service innovation, services marketing, and creativity research, researchers have increasingly emphasized the need for a theory of context (Baer 2014; Voss et al. 2016; Ostrom et al. 2015); that is, dealing with a phenomenon in relation to the specific context in which it occurs. In creativity research, it has been argued that domain specificity has huge implications for theory, and that researchers need to look at creativity domain by domain (Baer 2014). Instead of creating grand theories which imply that one size fits all, theoretical frameworks should be able to articulate multiple levels, or compare and contrast multiple domains (Glăveanu 2014).

\subsection{Challenges in health care services}

Medicine is remarkably conservative to the point of being characterized as sclerotic, even ossified. Beyond the reluctance and resistance of physicians to change, the life science industry (companies that develop and commercialize drugs, devices, or diagnostic tests) and government regulatory agencies are in a near paralyzed state, unable to break out of a broken model of how their products are developed or commercially approved. (Topol 2012 , vi)

The health care sector has experienced an explosion of innovations that have helped make astonishing progress in diagnostic and medical treatments, thereby enhancing life expectancy as well as the efficiency and cost-effectiveness of the health care system (Windrum 2014). Advances in health care have been concentrated around medical innovations, such as new tools, drugs, and technologies (Windrum and García-Goñi 2008), with less attention given to the subject of innovating health care services and enhancing patient experience. Generally, in the experience of using health care services, the packaging and delivery of treatment is often inefficient, ineffective, and consumer unfriendly (Bohmer 2009).

Health care is becoming increasingly complex. Not too long ago, health care was a science of curing infectious diseases by identifying the cause and taking steps to eliminate it (Wagner et al. 2005). Today's health-related problems have fuzzier boundaries as they are 
an interplay of genetic predisposition, environmental context, and lifestyle choices (Plsek and Greenhalgh 2001). These rapidly changing conditions mean that health care organizations are facing the laborious task of staying up to date in an environment in which government policy, medical evidence, and technology are constantly shifting (Cohen et al. 2004). In all Western countries, an ageing population, increasing prevalence of chronic and long-term conditions, and the need for complex health services are testing the health systems ability to deliver high-quality care (Cottam and Leadbeater 2004). In 2014, 19.5 percent of the Sweden's population was 65 or older, which means that, proportionally, the country has one of Europe's largest elderly populations (OECD Health Statistics 2015). In parallel, there has been a shift in the nature of illness, from acute and infectious diseases to long-term and chronic diseases, such as cancer, diabetes, and heart disease (Cottam and Leadbeater 2004).

In Sweden, the goal of health care is to deliver health care on equal terms for the entire population (1982:763 $\S 2$ ). In addition, it has been stated that health care should be available, be based on respect for the patients' autonomy and integrity, promote contact between patients and medical staff, meet patients' need for continuity and security, and provide interventions for the patient that are coordinated in an effective way (1982:763 $\S 2$ ). During recent decades, from government policies and a number of theoretical concepts, practical approaches have emerged that all support, to varying degrees, a more consumer-friendly approach to health care. There have been a variety of Swedish health care reforms supporting policies for a stronger patient role, such as decentralization, concentrating hospital services, privatization, and responsiveness to patients' needs (Anell et al. 2012; Axelsson 2000). For example, in 2005 Sweden introduced a waiting-time guarantee in its legislation, giving consumers the right to seek care from an alternative provider at no extra cost if they are not treated within the guaranteed time, and strengthening their right to a second opinion (Anell et al. 2012). In addition, mandatory patient choice of primary care provider and freedom of establishment for accredited private providers to improve access to primary care and extend opening times were introduced. Despite these changes in policy, Sweden, in comparison to other developed countries, is worse at educating patients and assisting them in making informed decisions about treatment; its patients are less encouraged to ask questions during consultations; its health care providers have a lower general knowledge about individual patients' past medical histories; and there is a lesser degree of coordination between different care providers (Commonwealth Fund International Health Policy Survey 2014). In an evaluation of the Swedish health care system by the OECD (2013), the report found that even though Sweden had excellent acute care services it was worse at supporting patients once they left the hospital, and was failing to coordinate between primary, secondary, and community health services.

\subsection{Health care customer creativity}

Health services directly address customers' well-being, and can have a significant impact on quality of life (McColl-Kennedy et al. 2012). In these types of services, optimal value creation depends upon customer participation and engagement with the service (Black and Gallan 2015). Therefore, the role and the practices of customers are especially interesting in 
health care. In this thesis, health care customer creativity can be defined as the process of creating solutions, which can be incremental adaptations or completely new solutions, that solve health-related problems (Henrike and Schultz 2014; Hirschman 1980).

Health care customers have always been creative at solving health-related problems and engaging in self-care. In fact, health care as we know it is a relatively new model. For most of its history, health care customers have been managing almost all health-related activities themselves or within their social network (Lorig and Holman 2003). However, in the last 100 years, health care customers have been viewed as having a relatively passive role, as merely being recipients of what health organizations do for them (Berry and Bendapudi 2007; Holman and Lorig 2000). Health care activities have moved from the individual, family, and community levels to health care providers and health care institutions (Lorig and Holman 2003). The customer in modern medical practices, to a large extent, has come to be viewed as a passive recipient of care and the role of the patient has been conceptualized as a subject that doctors can observe, and on whom they can operate and practice their medicine (Wagner et al. 2005). In essence, patients have been required to show up to medical consultations, cooperate with the doctors (answer questions), and follow the instructions for treatment. This view is supported by Morton (1937) who described the customer's role as "having consulted her physician and being willing to cooperate, the patient has done her part, in a manner of speaking. It is then up to the doctor to see that she gets the benefit of proper examination and care according to the principles set forth" (p. 225).

Recently, health care researchers have started to view the passive role of the customer as limiting for the further development of health care services (Hardyman, Daunt, and Kitchener 2015). There has been growing recognition that successful management of illness depends largely on the actions and activities of the health care customers themselves (Bodenheimer et al. 2002; Lorig and Holman 2003; McColl-Kennedy et al. 2012). Effective management of long-term illnesses such as diabetes or hypertension requires not only technical skills to perform treatment behaviors, but also problem-solving skills to manage daily barriers and make appropriate adjustments (Hill-Briggs 2003). Therefore, a new role for the customer in health care has been proposed in terms of contributing information, knowledge, and creativity in problem solving, and engaging in activities to improve their health and well-being. This implies a change in the role of the customer to becoming active in co-creating the service with health care professionals and others (McColl-Kennedy et al. 2012). This new view is reflected in both research and practice. A more active role of the health care customer is emphasized and manifested in concepts and practices such as patientcentered care (Mead and Bower 2000; Stewart 2001), shared decision making (Charles, Gafni, and Whelan 1997; Makoul and Clayman 2006), and patient participation (Haywood, Marshall, and Fitzpatrick 2006; Gallan et al. 2013). In addition, a number of models and practices for involving customers both in delivery and in the development of health care have been proposed (e.g., Elg et al. 2012; Soto et al. 2007; Boulos et al. 2014). Often, this literature has focused on the sphere of direct customer-provider interaction and the organization of care within the health field (Spanjol et al. 2015). 
While interaction with practitioners is important, most health care activities take place in the customer sphere (Creer and Holroyd 2006). Even if they receive excellent high-quality care when they are in the service setting, customers in health care often fail to manage their illnesses successfully once they leave the service setting (Bodenheimer, Wagner, and Grumbach 2002; Creer and Holroyd 2006). Therefore, in addition to improving health care service in the actual service setting (such as hospitals and primary care facilities), research should focus on understanding the actions, creative practices, and problem-solving abilities of customers in the customer sphere; after all, that is where almost all health-related activities take place (Creer and Holroyd 2006; Spanjol et al. 2015; Bodenheimer et al. 2002).

\subsection{Purpose and research questions}

Based on the above discuss, this thesis aims to provide insights of customer creativity related to health care services. In particular, this thesis focuses on customer creativity not only as an outcome, but also as a dynamic and contextualized process. In this thesis, I take an integrative approach that explicitly recognizes health care customer creativity as a complex interplay of factors operating at the individual, contextual, and situational level. This is consistent with perspectives that highlight a need for the use of multiple factors to explain the adoption of health behaviors, individual illness management, and problem solving (Creer and Holroyd 2006; Hill-Briggs 2003; McColl-Kennedy et al. 2012). In this thesis, I argue that understanding and supporting customer creativity and value-creating practices is key to creating and sustaining value over time in health care. Customers have always been a source of insight and inspiration in business. The new concept here is not to listen and adapt to what customers say, but to understand customer creativity as a strategic resource that is able to drive service innovation and enhance health care practices. This thesis builds on and combines research on value creation and customer co-creation in service innovation (Witell et al. 2011; Magnusson, Matthing, and Kristensson 2003; Grönroos and Ravald 2011), customer creativity (Burroughs, Moreau, and Mick 2008; Hirschman 1980), customer practices (Sweeney, Danaher, and McColl-Kennedy 2015; McColl-Kennedy et al. 2012), and health care research. Taking the perspective that customer creativity must be understood in relation to a specific context, this thesis aims to contribute to understanding of the concept of customer creativity in relation to health care. Therefore, the overall purpose can be articulated as:

To conceptualize and investigate the concept of customer creativity in health care to enhance understanding of how customer creativity can be used as a source to enable service innovation and health care practice.

To fulfill this purpose, the following broad research questions (RQs) are advanced:

1. How can the roles of the customer and customer creativity in health care be characterized?

2. What factors influence health care customer creativity?

3. How can customer creativity enable service innovation in health care? 
To answer these RQs, this thesis builds on five appended papers. While each paper has specified RQs and aims that communicate and contribute to different aspects and parts of the overall purpose, the idea is to synthesize and integrate, rather than summarize, the research findings from the individual papers.

To understand customer creativity in the health care context, it is essential to comprehend the role of customers in health care and how they differ from those of customers in other settings. Therefore, the peculiarities of health care customers and health care customer practices must be identified and explained in order to conceptualize and identify the factors influencing health care customer creativity. In addition, by understanding the concept and influencers of health care creativity, we can also increase understanding of how health care customer creativity can enable service innovation and health care practices.

While there are numerous empirical studies of health care customer practices and methods for involving and managing health care customers (e.g., Elg et al. 2012; Gagliardi et al. 2008; Street and Gordon 2006), there is a lack of studies synthesizing these findings. In addition, creativity among health care customers, with a few exceptions, has not previously been conceptualized. Therefore, this thesis aims to develop a conceptual framework for health care customer creativity. Because there have been only limited studies addressing the factors that influence customer creativity in health care directly, literature on creativity and customer creativity in other domains is used to identify potentially relevant factors that are then explored in the health care context. By considering these factors in relation to the health care customer role and specificities of the health care domain in general, this thesis aims to further the knowledge on such influencers.

\subsection{Positioning and scope of this thesis}

Traditionally, health care as a research discipline has been focused on a strict biomedical view of disease and illness where "sufficient deviation from normal represents disease, that disease is due to known and unknown natural causes, and that elimination of causes will result in cure or improvement in individual patients" (Ludwig 1975 p. 603). Knowledge in this sense can be defined as facts that can be empirically tested using biomedical methods, and is restricted to theory that can be controlled, measured, counted, and analyzed by statistical methods (Malterud 2001). According to this view, health care and medicine should be concentrated on disease and nothing more, and aspects outside of the biomedical sphere can be argued as being beyond the scope of medicine. However, increasingly, researchers within the medical sciences are realizing that medical issues stretch beyond the strictly biomedical to behavioral and psychological dimensions at the individual, group, and system levels (Malterud 2001). For example, how can biomedical knowledge and methods help us understand questions such as: Why do health care customers fail to take their medicines as prescribed? How do persons suffering from diabetes, for example, solve medical problems? Does the clinician's communication style affect health outcomes in customers with chronic diseases? When attempting to explain and investigate these types of issues, the biomedical 
perspective and associated methods have little explanatory power. While it could be argued that these issues are not connected to medical sience, Malterud (2001) stressed that a broad base of medical and scientific knowledge is needed if the research field of medicine is to remain founded on scientific knowledge in all aspects of care and health-related behaviors. Based on this position, it is reasonable to take a wider view of scientific knowledge within the context of health care.

Thus, in investigating the role of the health care customer and health care customer creativity, there can be advantages of taking an integrative view that combines theory from areas outside the medical field. This thesis is situated within the extant literature of services marketing, service innovation and customer creativity. In these research areas, the roles of the customer and customer creativity have been of interest for decades, both in regards to creativity in the consumption process (Hirschman 1980; Moreau and Dahl 2005) and creative customers as a recourse in developing new products and services (Magnusson, Matthing, and Kristensson 2003; Hoyer et al. 2010). Additionally, in these fields, the role of the customer has been conceptualized (Bitner et al. 1997) and discussed in relation to their contribution to value creation (Vargo and Lusch 2015; McColl-Kennedy et al. 2012; Grönroos and Ravald 2011).

This thesis has several delimitations. The analysis of creativity in relation to health care can be divided into different levels (Nelson et al. 2008). Foremost in this thesis, I focus on the micro level of health care; that is, creativity in relation to individual customer practices. Taking this perspective, I emphasize the practices (activities and interactions) of the individual health care customer in relation to health care professionals, processes, interactions, and recurring patterns. In some cases, the levels of analysis overlap, as I take the view that the individual health care customer's creativity must always be understood in relation to the broader social, physical, and situational contexts in which it occurs (Akaka, Vargo, and Schau 2015; Vargo and Lusch 2015). My intention is not to argue for the superiority of one or another approach to the theory or level of analysis regarding customer creativity and value-creation practices; all make important contributions.

Additionally, this thesis does not aim to cover all aspects of how to successfully plan health care customer creativity, or provide a comprehensive guide for turning creativity into innovation. Instead, I focus on circumstances that enable or reinforce creative practices, rather than analyzing the whole process from individual creativity all the way to a successful outcome that is used and considered as an innovation. Finally, rather than departing from a creative outcome, such as a new product or service, I focus on the customer practices that enable creativity and the contextual and situational influencers of such practices. 


\subsection{Appended papers' contribution and connection to the purpose of this thesis}

As stated above, this thesis builds on the findings of five appended papers. Each paper has specific RQs and aims that communicate and contribute to different aspects and parts of the overall purpose and the chapters included in this dissertation. The main contribution of each paper and connection to RQs is summarized in Table 1.

Table 1 Appended papers' contribution to the RQs

\begin{tabular}{|c|c|c|c|c|}
\hline Paper & Focus & $\begin{array}{l}\text { Type of } \\
\text { paper }\end{array}$ & Main contribution & Related RQ \\
\hline 1 & $\begin{array}{l}\text { Health care customer } \\
\text { involvement }\end{array}$ & $\begin{array}{l}\text { Literature } \\
\text { review }\end{array}$ & $\begin{array}{l}\text { Identifies antecedents, practices and } \\
\text { consequences of customer involvement }\end{array}$ & RQ1 and RQ2 \\
\hline 2 & Service innovation & $\begin{array}{l}\text { Literature } \\
\text { review }\end{array}$ & $\begin{array}{l}\text { Identifies and synthesizes the current } \\
\text { research on service innovation }\end{array}$ & RQ3 \\
\hline 3 & $\begin{array}{l}\text { The role of the } \\
\text { health care customer }\end{array}$ & $\begin{array}{l}\text { Literature } \\
\text { review }\end{array}$ & $\begin{array}{l}\text { Conceptualizes the role of the health } \\
\text { care customer }\end{array}$ & RQ1 and RQ2 \\
\hline 4 & $\begin{array}{l}\text { Health care customer } \\
\text { creativity }\end{array}$ & Empirical & $\begin{array}{l}\text { Explores how customer creativity is } \\
\text { influenced by the type of health care } \\
\text { services and environment }\end{array}$ & $\begin{array}{l}\text { RQ1, RQ2 and } \\
\text { RQ3 }\end{array}$ \\
\hline 5 & $\begin{array}{l}\text { Health care customer } \\
\text { creativity }\end{array}$ & Empirical & $\begin{array}{l}\text { Investigates how health care customer } \\
\text { creativity is influenced by physical and } \\
\text { social environment }\end{array}$ & $\begin{array}{l}\text { RQ1, RQ2 and } \\
\text { RQ3 }\end{array}$ \\
\hline
\end{tabular}

Paper 1 provides an extensive review and overview of health care practices for involving customers in the delivery of health care. Although this article is mostly descriptive, it highlights the shortcomings in the current research regarding activation of customers in health care. In addition, the paper identifies a number of health care practices and influencers of such practices and provides insights into conceptualizations of the role of the health care customer. As such, it connects closely to RQs 1 and 2. Paper 2 provides a systematic review of the concept of service innovation, specifically focusing on defining service innovation through categories. While this paper does not explicitly focus on health care, it provides insight into the shortcomings of the research in service innovation and has a significant influence on the theoretical framework (Chapter 2) and the positioning of this thesis, and connects to RQ3. Paper 3 extends further by focusing on health care customers' roles and practices as portrayed in health care and service and marketing research. This paper identifies, relates, and discusses a number of conceptualizations of the customer role used in research, and identifies health care customer practices connected to different customer roles. In addition, Paper 3 provides suggestions for potential research directions within the area to enhance existing knowledge. This paper primarily connects to RQs 1 and 2.

In Paper 4, we investigate how type of service and environment influence health care customer creativity by analyzing the characteristics of customer-generated contributions (ideas) to service innovation. In this paper, we used different groups of customers (orthopedic and chronic pain) and allowed them to generate ideas in different environments, 
in the specific health care setting, and in their private sphere. The analysis indicates that there were differences between customer groups, but also between different environments. However, this evaluation was based on the characteristics of the ideas, rather than an objective measure of creativity. Therefore, in Paper 5, we use expert panels to evaluate the creativity of health care customers' ideas. In Paper 5, we focus on how both social and physical contexts influence customers' creativity and evaluate this effect using expert panels. Both Papers 4 and 5 are connected to RQs 1, 2, and 3.

\subsection{Outline of this thesis}

The remainder of this thesis is structured as follows. First, the theoretical framework presents and discusses the main theoretical concepts and presents factors influencing customer creativity. This is followed by a description of the research methodology underlining the thesis. After that, the five appended paper are presented and summarized briefly. The discussion presents the research findings and the proposed framework for health care customer creativity. The thesis ends with some conclusions and highlights the theoretical and managerial contributions, as well as possible further research. 


\section{Theoretical background}

The following chapter aims to present and discuss the theoretical background, perspectives, and concepts that underlie this thesis. This chapter discusses and complements the theoretical perspectives used in the papers, and aims to define and explain relationships between concepts. Three main concepts and theoretical areas are presented: service innovation, value creation, and customer creativity.

In this thesis, it will be argued that the concept of customer creativity is closely linked with the concept of service innovation, value creation, and value creation practices. In this sense, service innovation can be considered a result of creative activities, performed by individuals, groups, organizations, or markets, that enables value creation in a specific context. Value in this sense can encompass economic value (for one or all actors), but also value-in-use. Following this logic, the concept of service innovation is not a root activity in and of itself, but rather the outcome of creative performances. Therefore, understanding creativity and value creation are essential components to understanding service innovation.

\subsection{Service innovation}

The debate about what is an innovation and how to define it goes back almost a century (Schumpeter 1934). Independent of perspective or theoretical outlook for addressing and analyzing service innovation in research, the term "innovation", and how it is defined and what it entails, varies. Most commonly, service innovation is referred to as either an outcome or a process. However, it should be noted that authors often do not make clear whether they are using the concept of innovation to refer to the innovation process or the outcome of this process (Toivonen and Tuominen 2009). Viewing service innovation as a process is common in new service development (NSD) research, which refers to innovation as a planned and formal process. Here, researchers do not separate the development process from the outcome of the process. Often, the terms "NSD" and "service innovation" are simply used interchangeably (Menor, Tatikonda, and Sampson 2002), without further characterizing the differences. For example, Biemans, Griffin, and Moenaert (2015) concluded that NSD and service innovation should be viewed as synonymous, defining both concepts as a "process of devising a new or improved service, from idea or concept generation to market launch" (p. 2). They suggested that key questions within the area of service innovation are for example how to create and manage a successful NSD process. This implies a strong internal focus on activities of the service provider. Other studies taking a process view of innovation have argued that the process of developing new services, and the implementation and value creation of these new services, cannot be separated and should be seen as stages or components of service innovation (e.g., Skålén et al. 2014; Carlborg 2015). In this sense, they have extended the definition of service innovation to include development and realization, as well as the outcome of the new value proposition. Nevertheless, this creates confusion when discussing successful service innovation, as it is 
not clear whether it refers to the successful process or the outcome of the process, or what determines whether the service innovation is successful.

Schumpeter (1934) viewed innovation as a novel combination of new and existing knowledge, which should be clearly distinguished from inventions. While an invention can refer to any new product, service, process, or idea, for an invention to become an innovation it must be introduced in the market and make a substantial profit, as inventions themselves have no inherent value (Schumpeter 1934). Therefore, Schumpeter (1934) argued, we must differentiate the process of developing a new offering from the process of its commercialization and evaluation of its outcome. Building on the Schumpeterian approach (Toivonen and Tuominen 2009, p. 893) defined service innovation as "a new service or such a renewal of an existing service which is put into practice and which provides benefit to the organization that has developed it; the benefit usually derives from the added value that the renewal provides the customers". In addition, to be an innovation the renewal must be new not only to its developer, but in a broader context. This indicates three things. First, the definition of service innovation is separated from the process of development; second, for something to be defined as an innovation it must be used and put into practice; and third, it must have created value. Put simply, it is something new that is put into practice and creates value.

There have been interesting differences in the interpretation of "new". Schumpeter argued that true innovation not only creates value for the firm that developed it, but also changes the market in such a way that other companies imitate and follow, which leads to development of market as a whole (Schumpeter 1934). While this definition of "new" is relatively strict, recent developments within the service innovation literature have departed from this restrictive definition of innovation to claim that innovations can be categorized based on degree of newness or novelty. Defining innovation in this way is a common approach to categorizing innovation (Sundbo 1997; Toivonen and Tuominen 2009). Innovations can be divided into "radical" and "incremental", where radical usually refers to innovations that are new to the world and incremental innovations are new to the market (Sundbo 1997). Sundbo (1997) emphasized that even if an innovation is not new to the world, in comparison to continuous development, improvement, and adaptation, the term "innovation" implies a larger degree of change. Therefore, following this definition, advancements that are only new to the firm that adapts them should not be considered innovations. Toivonen and Tuominen (2009) argued that this "leads to the strange conclusion that backward companies make innovations when they adopt well-known practices" (p. 892). They argued that newness should be viewed in a geographical or sectorial context. In this view of service innovation, value is often seen from an economic point of view, where the outcome is measured in terms of economic value for the developing firm. In contrast, those that consider service innovation in terms of outcome or change instead define value according to customer-perceived value-in-use (Lusch and Nambisan 2015; Michel, Brown, and Gallan 2008). 
Taking this further, recent views of service innovation have put forward the idea that service innovation emerges within networks. Kindström and Kowalkowski (2014) suggested that value should be determined by benefits received by customers, developers, and others in the business network. In the same view, Lusch and Nambisan (2015) argued that service innovations can be seen as novel resources that are of value to any actor in the network. In this view, innovations or ideas for innovations are not developed from within the borders of a firm, but evolve from the joint achievement and integration of resources of a network of actors including service providers, partners, customers, and independent inventors.

Even if a new service creates significant benefits for customers, it might not generate revenue for the developer. Kindström and Kowalkowski (2014) argued that firms cannot simply develop service after service without considering the outcome of these services. This is certainly true, and a valid argument from a firm's perspective. Nevertheless, defining innovation in the form of economic value for the developer provides a limited view of what an innovation is. For example, innovation in social services such as health care might actually lead to increasing costs for the developer or society, but can still dramatically affect well-being and provide substantial value to individuals and society. In addition, there is a growing trend of innovations, developed by individuals or groups of non-professionals or customers, that others can use free of charge, where the benefit for the developer is the enjoyment of creating and social acknowledgment from peers, rather than monetary value (von Hippel 2005). Therefore, the definition of service innovation depends on what perspective is used. Helkkula (2010) stated that companies and other external actors alone cannot judge whether something is an innovation. Instead, it has been suggested that innovation should be understood as an experience, where some actors will experience the new offering as an innovation and others will not.

Following this debate on the definition of service innovation, it can be argued that service innovation is likely to be the result of a number of components, contextual aspects, actors and interactions (Toivonen and Tuominen 2009). Consequently, innovation research should adopt a broad perspective of the process and how to determine what an innovation is. A better understanding and deeper knowledge of the creation of innovations is essential both for companies wanting to innovate, and for theory that builds on understanding, and the mechanisms, of service innovation. However, this does not imply that the outcome of this process is less important to consider and define. In order to generate new knowledge and enable theory building, it is important to understand a variety of aspects - including the components of the creative process of creating new offerings, the diffusion of innovations, and the innovation in light of customers' and other actors' value-creation practices. Viewing service innovation as simply a matter of improving the development process of new products and services gives little explanatory power to the success of service innovation. Nor does a focus on the outcome in the form of economic revenue in determining whether an invention was successful provide an understanding of how innovation is created.

Based in the above discussion, there is potential in investigating service innovation in combination with other related concepts, such as value creation or the process of creativity. 
The relationship between service innovation, creativity, and value creation has not been a particularly explored area (Lepak, Smith, and Taylor 2007). However, value plays a significant role in explaining creativity and creative behavior, because people do not do things unless these things are important or of value (Runco 2007). Creating value in any form can be seen as the goal of creativity and service innovation. Consequently, in order to understand creativity and creative behavior, we must also understand the practices in which value is created.

\subsection{Value creation}

The question of what value is, how it is created, and what perspective should be used when determining value is a frequently debated topic. Holbrook (2002, p. 5) defined value as "interactive, relativistic preference experience". In this sense, value is not a possession, object, or product, but is instead an interactive experience. Traditionally, the creation of customer value focused on satisfying customer needs, often through manufacturing products (Smith, Maull, and Ng 2014). The traditional way to define value is as monetary exchange value, or value-in-exchange (Vargo and Lusch 2004). This view defines the customer as a buyer who has the ability to use resources and consume value, but does not enter the consumption process in an interactive way (Prahalad and Ramaswamy 2004). More recently, the view of what value is and how it is created has changed. Modern marketing has emphasized the relativistic, context-dependent features of value as created in use (Grönroos 2006), implying that value emerges in the customer sphere during consumption (Grönroos 2011). This view holds that customers are essential for value creation, and redefines customers from passive recipients of value to active contributors who co-create value with the service provider. In this thesis, value co-creation is defined as "benefit realized from integration of resources through activities and interactions with collaborators in the customer's service network.' (McColl-Kennedy et al. 2012, p. 370). This stretches beyond being customer-oriented and identifying customer needs to actively collaborating with, and learning from, customers to adapt to their individual needs (Vargo and Lusch 2004).

As with the case of service innovation, value creation is referred to as either an outcome or a process. Usually, marketing and marketing research primarily focus on the value perceptions of two actors: customers and/or providers (Hillebrand, Driessen, and Koll 2015). While traditional theories in marketing hold that value is created by the firm, it has been argued that value cannot be created, stored, and then delivered, but rather that value is created when the product or service is used (Vargo and Lusch 2004). This view emphasizes that value is ultimately perceived and determined by the individual customer on the basis of value-in-use. Value, in this sense, can be seen as being created in interaction between the customer and the service provider as well as during use, where the role of the provider is to facilitate and support the customer's value-creation process (Grönroos 2006). 


\subsubsection{Spheres of value creation}

Addressing the customer's perspective in a provider-customer relationship, Grönroos and Ravald (2011) argued that customer value is a multilane process consisting of two distinct subprocesses: (1) the provider's process of creating resources for customer use, and (2) the customers' process of turning service into value. This suggests that studying the valuecreation process as entirely under the control of a firm yields an imperfect understanding of how value is created. Although it can be argued that this model is restricted to the providercustomer dyad, it can be considered as a useful framework to analyze value in the form of spheres and context for value creation. Besides pointing out different sub-processes, Grönroos and Ravald (2011) also divided the process of value creation into three different spheres: provider, joint, and customer (see figure 1).

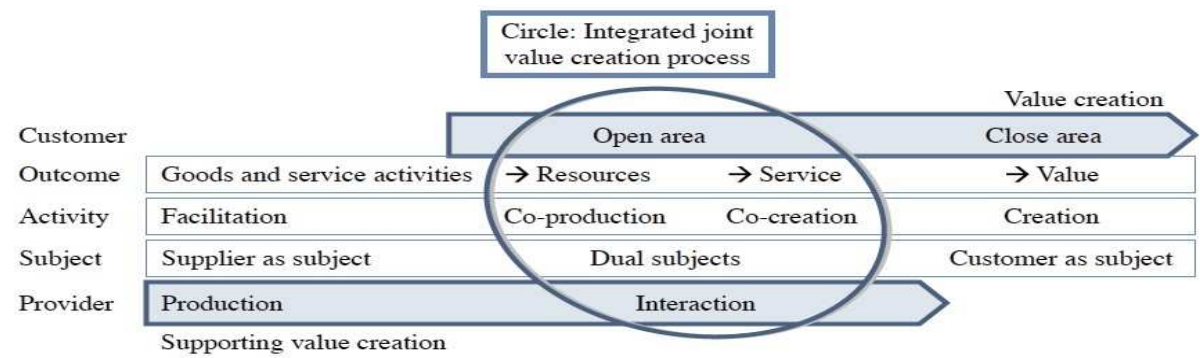

Figure 1 A model for understanding the value-creation process (Grönroos and Ravald, 2011) Reprinted with the permission of Emerald Group Publishing (c) 2011

In the provider sphere, production entails developing and designing the provider's offerings, and facilitating value creation for the customer (Grönroos and Ravald 2011). Payne, Storbacka, and Frown (2008) argued that service provider value creation is the processes, resources, and practices that the provider uses to manage its business and its relationships with customers and other relevant stakeholders. In general, this can be seen as a closed sphere for the customer (Grönroos and Ravald, 2011). In the joint sphere, the customer creates value with the service provider (such as in the case of medical consultations). Here, customers and service providers have opportunities to actively initiate actions and activities, and through such actions influence one another's value-creating processes (Grönroos and Ravald 2011). During interaction, the service provider can directly influence the customers' experience, and therefore also their value creation. Thus, high-quality interactions can be viewed as a central source of value creation for both customers and firms (Prahalad and Ramaswamy 2004). In the customer sphere, the customers create value in their everyday practices by integrating personal resources from the service provider and resources outside traditional service settings. This sphere is usually closed to the service provider and the activities and outcomes are beyond the service provider's control (Troye and Supphellen 2012). 


\subsubsection{Extending beyond the service provider-customer dyad}

While this logic implies a new view of value creation that stresses the importance of the customer, more recent developments have emphasized that value is not created only in the customer-provider dyad, but rather with a multitude of actors (Vargo and Lusch 2015; McColl-Kennedy et al. 2012). Therefore, analyzing value creation from the view of a specific service provider or the customer provides limited understanding (Jaakkola and Hakanen 2013; Vargo and Lusch 2015). However, even when acknowledging the importance of considering multiple actors, most of the research has not fully embraced this notion and has kept the customer or the provider-customer dyad in focus. As McCollKennedy et al. (2012) pointed out in their study of cancer patients, a significant number of value-creation practices take place outside the joint sphere of interaction. The benefits of receiving treatment and using health care services represent value-in-use, but the total value created depends on integrating other resources, such as family support and motivation to comply with treatment and engage in activities that positively influence health.

Vargo and Lusch (2015) argued that value co-creation should be considered in the context of specific rules, norms, and beliefs that enable or constrain actions and make life predicable, which represents value-in-context. This implies that value must be defined as assessed in accordance to context (Vargo et al. 2008). Value is not created individually, but rather within complex social and cultural networks (Akaka et al. 2015). Vargo and Lusch (2015) argued that consideration of the context of value creation is key to understanding and enhancing service experiences. This implies that value is not created at one point in time, but rather over time in relation to past, present, and anticipated future experiences (Helkkula, Kelleher, and Pihlstrom 2012). This reasoning is in line with the conceptualization of customer experience as evolving, dynamic, and collaborative (McColl-Kennedy et al. 2015), and includes cognitive, emotional, social, and affective factors associated with the customers' experience with the firm (Bolton et al. 2014).

Thus, the view of value and value co-creation should move further away from its rather restrictive focus on the provider-customer dyad towards a view that embraces value as created among actors over time (McColl-Kennedy, Cheung, and Ferrier 2015; Akaka, Vargo, and Schau 2015). In this thesis, value creation can be conceptualized not as being restricted to the provider or the customer, but as taking place in the form of practices that exist throughout a network on different levels and that cannot be understood accurately by isolating one actor. Thus, co-created value manifests when customer practices, network support, and contextual conditions are synergized (Aarikka-Stenroos and Jaakkola 2012).

\subsubsection{Value-creation practices}

Even though value creation and creativity involves a number of actors and contextual factors, it starts with individuals who think, act, and interact. Customer practices have been receiving increasing attention and can be seen as a combination of activities and interactions (McColl-Kennedy et al. 2012; Xie, Bagozzi, and Troye 2007). In this sense, practices can be understood as the way that individuals view the world and their roles, and the way 
individuals interact, behave, and do things (activities) in relation to their social and physical environment (Kjellberg and Helgesson 2007).

There has been considerable interest in investigating customers' roles and activities in service delivery and, more broadly, in their value creation; specifically, what drives these behaviors and their impact on customers themselves, employees, and firms' service outcomes (e.g., Gallan et al. 2013 McColl-Kennedy et al. 2012; Sweeney, Danaher, and McColl-Kennedy 2015; Dong et al. 2015; Moeller et al. 2013; Troye and Supphellen 2012). Nevertheless, "creating value" is a rather abstract practice. Often, value-creation roles and practices are described on a theoretical and non-specific level, and researchers have argued that the provider contributes by making a value proposition, with the customer's role being to actualize the value by using the resource that is offered. Even though the process of value creation has been extensively discussed in theory, the specific practices, such as behaviors, actions, and interactions, that underlie this process have received less attention and are thus not fully understood (Witell et al. 2011; McColl-Kennedy et al. 2012).

The new role of customers implies that they can and are allowed to engage in practices that were previously viewed as provider activities, creating value for themselves by, for instance, booking holiday trips or scheduling doctor's appointments online (Moeller et al. 2013). In health care, health information sites and forums allow users to perform self-diagnosis, develop treatment plans, find information, and get advice online. Rather than depending on the service provider, customers can access information and perform the service themselves. This implies that the outcome of a service or the value it generates is mostly beyond the service provider's control. It might have some influence on what the customers do, but has limited control on how they do it (Troye and Supphellen 2012). In a study of cancer patients, McColl-Kennedy et al. (2012) identified eight broad themes of customer co-creation practices linked to quality of life. These are connected to behavioral activities, such as cooperating; collating information; combining complementary therapies; co-learning; connecting with family, friends, doctors, other health professionals, and support groups; changing ways of doing things; co-production; and cerebral activates (such as positive thinking). Their typology is based on the different perceptions of the customer's role in relation to levels of activities and the number of interactions with different individuals in the firm, other market-facing and public sources, private sources, and self-generated activities in the service network.

At an individual level, Ford and Dickson (2012) argued that customers diverge in their ability to create value depending on their knowledge, skills, and motivation. This implies that customers have different personal and contextual prerequisites that can affect the value they create and perceive. In addition, customers can vary in their motivation regarding what they want to do and how they perceive their role (Ford and McColl-Kennedy 2015). While creativity is closely related to what customers do, not all customer practices that create value for the individual can be considered creative. Therefore, if we want to understand when customer practices are creative - that is, when customers solve problems or adapt their life 
situation in new ways that create value for themselves - simply considering customer practices is not enough. We must also include the dimension of creativity.

\subsection{Customer creativity}

Creativity is important at both the individual and societal level. At the individual level, creativity is relevant when one is solving problems in daily life, and on an organizational and societal level creativity is necessary to enable new inventions and new scientific findings (Sternberg 1999). Research of creativity is interdisciplinary, which is reflected in the present body of literature and its inclusion of behavioral, clinical, cognitive, economic, educational, organizational, personality, and social perspectives (Runco 2007). Although creativity has received attention since the time of the ancient Greeks, modern research on creativity dates back to middle of the twentieth century and the work of Guilford (1950) and his structure of intelligence theory, which focused on talent as the main driver of creativity. Since then, creativity research has focused on cognitive processes of creativity, personal characteristics of the creative person, and lately, contextual and situational factors associated with creative practices (Burroughs, Moreau, and Mick 2008; Simonton 2000).

Creativity is commonly defined as the ability to create something that is both novel (that is, original, unexpected) and useful (valuable, appropriate) in a given situation (Amabile 1983). This definition, with small differences in the words used, has become dominant in the theory of creativity. Basically, it refers to an original idea or expression that differs from the norm and is appropriate or valuable in the given context. Not surprisingly, creativity is connected with problem-solving and the creation if unique solutions to practical problems (Guilford 1967). However, what is defined as new and appropriate may be in reference to the creator, society, or the domain within which the situation occurs (Peter 2009). This means that what is defined as creative or not must always be judged in relation to a specific person, field, or culture.

In the consumer behavior literature, there have been streams of research focusing specifically on the concept of customer creativity. Hirschman (1980) defined customer creativity as "the problem solving capability possessed by the individual that may be applied toward solving consumption-related problems" (p. 286) and argued that on an individual basis, all customers are, to some extent, creative in the process of using services or products. From a traditional perspective on customer roles, the roles of "producers" and "customers" are distinct and separate (Vargo and Lusch 2008; Lusch and Nambisan 2015). The shift to a value-in-use perpective has resulted in a reconceptualization of the customer role. With this new development, the classical approach to service production and consumption becomes insufficient. Service providers make value propositions to customers, but the value-in-use, and thus service usage (such as frequency, variety), depends on the activities, interactions, and perceptions through which customers make the service their own and leverage its benefits (Mifsud, Cases, and N'Goala 2015). 
The focus of customer creativity research has been on individual traits or behaviors of specifically creative customers, as in the case with lead-users (von Hippel 1986) or early adopters of innovation (e.g., Chesbrough and Crowther, 2006). In addition, others have focused on customer idea generation (e.g., Kristensson et al. 2002; Magnusson et al. 2003) or the process of involving customers in new service or product development (e.g., Alam and Perry 2002; Elg et al. 2012). A different form of involving customers in the development of service offerings is referred to as "self-design" or "self-production", where customers are asked to design/customize products and services (Dong and Sivakumar 2015; Troye and Supphellen 2012). Instead of developing for others, this involvement is for the customer's own core-service consumption, where the customer becomes both producer and user. A third line of research concerns creative customers and innovations that come directly from customers, rather than from development departments (Burroughs, Moreau, and Mick 2008; Berthon et al. 2007).

\subsubsection{An integrative approach to creativity}

While early research on creativity was dominated by a personality approach (Amabile 1983) that considered creativity to be a function of individual traits, such as intelligence, curiosity, risk taking, and internal drive (Kristensen 2004), more recent perspectives on creativity have tended to focus on how contextual factors can influence an individual's creativity. This theory posits that the individual obtains concepts and the ability to reason logically through exposure to various sources of environmental stimulus (Hirschman 1980). In this view, creativity is considered an interaction of personal characteristics, cognitive processes, domain, and physical and social contexts (Amabile 1983). In line with this view, Amabile (1983) suggested that creativity is influenced by a combination of domain-relevant skills (facts, principles, opinions about various factors in the domain, knowledge of paradigms, social "scripts"), creativity-related skills (cognitive style), and task motivation.

In a similar vein, Csikszentmihalyi (1999, p. 314) argued that "creativity is a process that can be observed only at the intersection where individuals, domains and fields interact", and developed a system model of creativity, which was then further developed by Kerrigan (2013) as illustrated in Figure 2. Csikszentmihalyis's (1999) model is based on the idea that creativity is a social system made up of individuals, knowledge domains, and institutional structures. From this perspective, domains are interconnected knowledge systems that transmit original information to individuals. They operate on a set of already existing objects, rules, representations, or notations. This is separate from fields that represent the social organization of the domain. Fields are constituted by all social actors who are part of this knowledge system (or the overall domain). To various degrees, social actors within the field influence, stimulate, and select novelty for a specific domain. The third element is the individual, who consists of personal background and resources in the form of knowledge, skills, and experience. Csikszentmihalyi (1995) also highlighted that creativity occurs when individuals act. This aspect was developed by Kerrigan (2013), who argued that creativity occurs in creative practices and should therefore have a central position. Taking this view, individual creativity and creative practices must always be understood in relation to the 
specific context. Kerrigan (2013) argued that creative practice occurs at the intersection of the system's components, and highlighted that creativity is an iterative process that can be internalized by an individual actor.

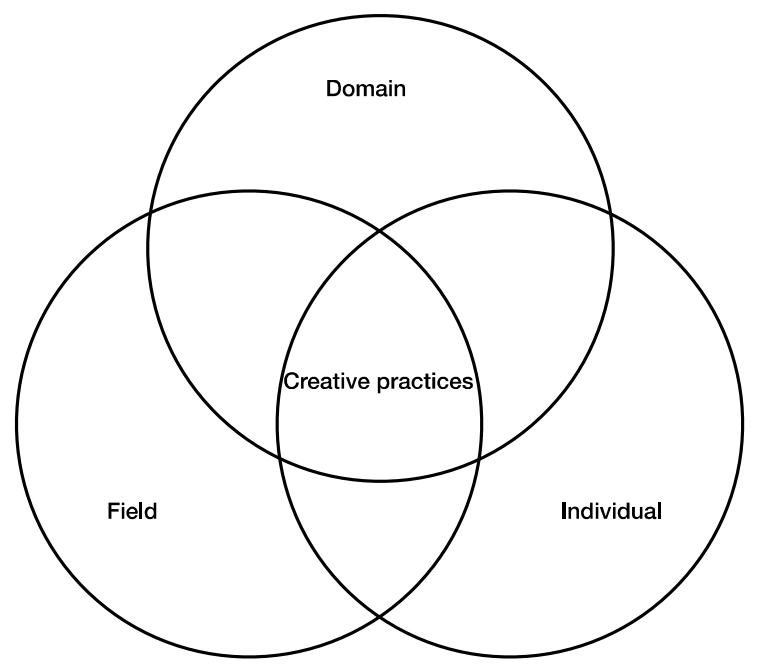

Figure 2 A system model of creativity (adapted from Csikszentmihalyi 1999; Kerrigan 2013)

\subsection{Relating service innovation, value creation, and customer creativity}

Based on the above discussion of this thesis's main concepts, I suggest that customer creativity, value creation, value-creation practices, and service innovation are different but closely related, and sometimes overlapping, concepts, as illustrated in Figure 3. In this thesis, I take the view that innovation is not a root activity in and of itself. Innovation builds on and requires creativity in some form; however, creativity alone does not automatically lead to or alone explain or predict innovation. Runco (2007) stated that creativity is sometimes selfexpression, and that there is no concrete product. Often, as in the case of customer creativity, creativity is invisible to everyone other than the individual who engages in it. Although creativity may lead to an outcome, it may not. Even in cases where creativity results in an outcome, such as a new product or service, it does not automatically transform into an innovation. In this sense, the output of creativity is more related to what Schumpeter (1934) defined as an invention (Giannopoulou, Gryszkiewicz, and Barlatier 2014). However, not all inventions are creative, and not all inventions become innovations As such, inventions have no value in themselves, unless they are used and someone finds value in them. 


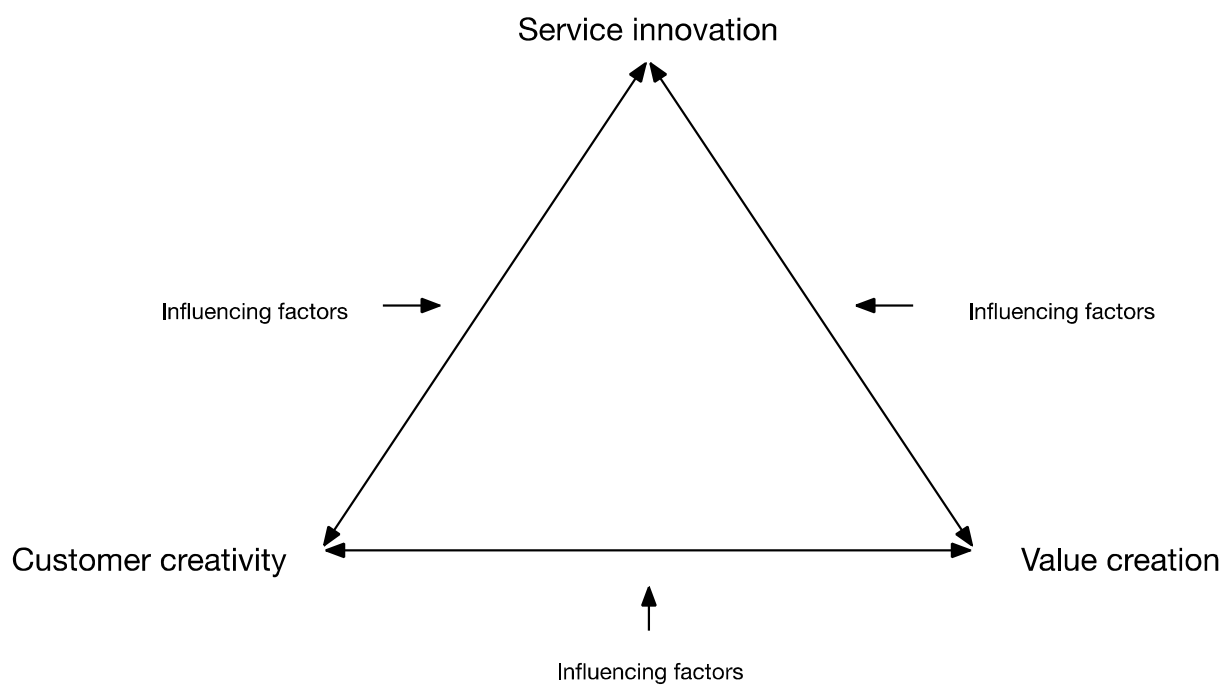

Figure 3 Connections between theoretical concepts

When considering the three concepts in simultaneous relationship with each other, definitions and boundaries of the concepts may require revision and rethinking. Creativity may result in an outcome (e.g., product, service, process, idea), but it may not. Inventions may become innovations, but they may not. In a similar vein, all practices that create value for the customer are not automatically to be defined as creative. Just because an individual engages in activities and interactions that create value for them, it does not imply that the individual is creative. Instead, value can be considered both as a motivator and a goal of creativity, meaning we do what we do in order to create value for ourselves. This value can be implicit, or tacit, rather than explicit, but it nevertheless underlies our motives and behaviors. Rarely, if ever, is creativity displayed unless it is motivated and valued, and never does something become an innovation unless someone finds it valuable. This also conveys the very definition of an innovation that was discussed earlier; for something to be considered as an innovation, it must generate value for some actor.

Considering these three concepts together can hold a numerous potential sub-concepts and relationships. Most likely, they are also influenced by a number of external factors. What these factors are and in what direction they influence, alter with perspective and specific context. Depending on the concept used as the starting point and level of analysis (individual, group or organization, society), different influencers will be in play. Similarly, depending on the direction of these relationships, different external and internal factors will be operating. For example, one can take service innovation as a starting point and investigate how it influences customer creativity. You can also investigate how customer creativity influences service innovation, how creativity influences value creation, and how value creation influences creativity. In this sense, all of the concepts can be outcomes, and all can be influencers. 
To make these concepts' relations even more complex, they must always be defined and analyzed in relation to the specific context. The factors influencing these relationships will depend on context. The individual factors that lead to creativity in physics are most likely not the same as in painting. Similarly, practices of value creation that reinforce creativity for customers in health care are unlikely to be the same factors as are relevant for customers using a kitchen device. While there are some factors that have been identified as more or less general influencers of creativity, they will be different in each domain, as will their effects.

\subsection{Influencers of customer creativity}

Current service development and innovation research has promoted the use of proactive methods based on customer co-creation (Witell et al. 2011). Involving customers has been shown to improve system quality and understanding of customer needs, and may result in more innovative ideas (e.g., Alam 2002; Ives and Olson 1984; Witell et al. 2011). Involving users also provides opportunities to obtain "sticky" information that is otherwise hard to grasp (Hippel 1994). However, as most of the research has been carried out in relation to the development of new products and services in an experimental setting, we have limited understanding of when, why, and how customers act creatively; that is, the creative practices that customers engage in (Burroughs, Moreau, and Mick 2008).

While customer creativity is considered to be a special type of creativity, it also has similarities with theories of creativity in general. Therefore, to understand customer creativity, it can be suggested that an integrative view will be useful. In this section, I combine and elaborate identified factors and findings from different theoretical perspectives and explanations of creativity to explain the important factors that explain creativity among individual customers. I use the term "factor" here to refer to various elements, circumstances, or conditions that contribute to a process or outcome (Amabile 1983). This is a similar view to that of Woodman and Schoenfeldt (1990), who suggested that creativity is the complex product of a person's behaviors in a given situation. The situation is characterized in terms of the contextual (domain) and social influences that either facilitate or inhibit creativity. The person is influenced by various factors, such as characteristics of domain and type of service, and this person brings to both cognitive abilities and personal traits. It has also been recognized that characteristics develop over time as a result of an individual's actions and interaction with environmental influences (Mumford and Gustafson 1988). In the following, I describe these main factors, starting with individual factors, then contextual, and lastly situational factors. Individual factors refer to all aspects connected to the individual customer, such as personality, knowledge and experience, and cognitive style. Contextual factors refer to aspects of the domain and subdomains. Situational factors refer to aspects of the immediate situation in which customer practices and customers' creativity take place. 


\subsubsection{Individual factors}

Personality can be defined as "that pattern of characteristic thoughts, feelings, and behaviors, that distinguishes one person from another and that persists over time and situations" (Phares 1997, p. 6). Most likely, factors connected to the individual are important for creativity (Amabile 1983; Burroughs, Moreau, and Mick 2008). These factors concern personal traits, cognitive aspects, knowledge, and motivation. However, which of these factors are important and the strength of their relation is likely to differ depending on context and situation.

\section{Personality}

During recent decades, empirical research has put forth a rather convincing argument that creative people behave consistently over time and across situations, and in ways that distinguish them from others (Feist 1998). Mumford and Gustafson (1988, p. 34) concluded that "many reasons exist for an individual's failure to develop ideas or to translate ideas into action, but one of the more important influences appears to be the individual's unique personality". Commonly, intelligence is considered important for creativity (Barron and Harrington 1981; Hirschman 1983). For example, studies of creative artists, scientists, mathematicians, and writers have found them scoring high on tests of general intelligence (Barron and Harrington 1981). Early studies focused on whether creativity can be seen as equal to intelligence; that is, if intelligence alone can predict creativity (Runco 2007). However, when measuring the effect of intelligence on creativity, the results have been conflicting, ranging from strong effects to moderate or even negative effects (Burroughs, Moreau, and Mick 2008). For example, Hirschman (1983) found a moderate correlation $(\mathrm{r}=.37, \mathrm{p}<.01)$ between general intelligence and creativity among customers. This suggests that general intelligence alone cannot explain creativity. Even so, it should be noted that people who are considered creative are often perceived as more intelligent than less creative people are (Barron and Harrington 1981; Runco 2007).

Other personal traits that have been found to positively relate to creativity are risk taking and novelty seeking (Amabile 1988; Burroughs, Moreau, and Mick 2008). The argument is that in order to be creative, individuals must be willing to move outside their comfort zone and undertake initiatives in which the outcome is uncertain. Other traits that have been investigated and found to be positively related to creativity are autonomy, intuition, selfconfidence, problem seeking and attraction to complexity, persistence, curiosity, and playfulness (Amabile 1988; Oldham and Cummings 1996; Barron and Harrington 1981). In addition, in relation to customers, Hirschman (1980) argued that novelty seeking is important, and is an internal drive or motivating force that is activated to seek out novel information, which improves problem solving. 


\section{Knowledge and experience}

A key factor that affects the individual's ability to be creative is knowledge (Amabile 1983). If creativity involves the formation of new conceptual linkages, then a body of knowledge of concepts is required. Knowledge of a field or domain is generally regarded as essential to be able to produce something new within it (Amabile 1983; Weisberg 1999). This includes understanding and factual knowledge of the domain in question; that is, facts, principles, opinions about various questions in the domain, knowledge of paradigms, performance "scripts" for solving problems in the domain, and aesthetic criteria (Amabile 1983). This also includes domain-relevant technical skills, such as laboratory techniques. Weisberg (1999) argued that while knowledge may provide the basic elements and the building blocks to form new ideas, knowledge alone is not enough. For example, experts develop large bases of domain-specific knowledge, and also have the ability to interconnect and use their knowledge to solve problems in a specific domain (Amabile 1983). However, too much knowledge in an area has also been found to hinder creativity, as it can limit the individual's ability to think in new ways (Weisberg 1999). At some point, creativity necessarily involves breaking free of past ways of thinking and old knowledge (Burroughs, Moreau, and Mick 2008). However, studies have found that creative individuals require an extensive amount of time between their initial exposure to the domain and the production of their first significant work, suggesting that deep engagement and experience within the specific field is essential (Weisberg 1999; Mumford and Gustafson 1988).

\section{Cognitive processes}

It has long been recognized and documented that cognitive processes play a prominent role in the acquisition and retention of new behavior patterns (Bandura 1991; Bandura 1977). Cognitive theories are focused on thinking skills and intellectual processes, and most cognitive approaches to creativity focus on problem-solving, where individuals want or need something and face obstacles that must be solved in order to reach the desired goal (Runco 2007). Individuals can vary both in cognitive ability and cognitive style, and a number of cognitive processes have been found to influence creativity. The ability to think divergently is considered an important factor (Guilford 1967; Barron and Harrington 1981). Divergent thinking is the ability to form numerous and unusual associations regarding a topic; these associations typically spontaneously occur in a non-linear manner, where many possible solutions are explored in a short amount of time. This is opposite to convergent thinking, where problems are identified and solved following a particular set of logical steps to arrive at one solution (Runco 2007; Oldham and Cummings 1996). In contrast to divergent thinking, others have emphasized the skill of analogical thinking, which can be defined as the ability to identify the relationship between elements in one situation to those in another, and transfer this information from the habitual context to a different context (Dahl and Moreau 2002). Thus, this implies not only identifying similar patterns, but also identifying and transferring them in a way that forms new concepts, new systems, and new information (Runco 2007). This requires the individual to have imaginative or metaphorical abilities. Related to this, researchers have had substantially more interest in the ability of creative 
individuals to use images and metaphors as a basis for solving complex problems (Mumford and Gustafson 1988).

Cognitive style refers to how individuals form and maintain these cognitive processes. Selfefficacy entails an individuals' capacity to execute behaviors necessary to the specific situation (Bandura 1977). This theory posits that individual levels of self-efficacy will determine whether the individual will take action, how much effort they will put in, and how long the action will be sustained when the individual is challenged by obstacles and adversity. Individuals vary in their analogical ability and divergent thinking; while some are restricted in their ability to transfer information and form unusual connections, others are more likely to do this and are thus more likely to form novel ideas (Burroughs, Moreau, and Mick 2008). In studies of customer creativity, cognitive processes have, for example, been investigated in relation to idea generation (Hirschman 1983; Dahl and Moreau 2002). For instance, Burroughs and Mick (2004) found that metaphorical thinking ability and locus of control affect creativity in the consumption process.

\section{Motivation}

Amabile (2001, p. 335) put forward that "raw talent, a clever imagination, and a "creative personality' aren't nearly sufficient to ensure creative success. Creativity theorists must recognize that hard work and love of a craft can be at least as important." Tierney and Farmer (2002) suggested that creativity requires some internal sustaining force that propels individuals to persevere in the face of the challenges native to creative work. This implies that creativity also requires fixation and endurance.

This is closely related to motivation and the individual's motivation to engage. Motivation concerns energy, direction, and persistence as aspects of intention and activation (Ryan and Deci 2000). Individuals have different motivations for performing a task; while some activities are performed in order to reach an outcome that is separate from the activity, others are performed for the inherent satisfaction of the activity itself (Ryan and Deci 2000). Generally, individuals are extrinsically motivated when they engage in work in order to obtain a goal that is separate from the work itself (Amabile 1996). In contrast, intrinsic motivation be described as the tendency to seek out novelty and challenges, and to extend, explore, and learn (Ryan and Deci 2000); that is, when individuals seek enjoyment, interest, challenges, or self-expression in the work they undertake (Amabile 1996). Not surprisingly, individuals are found to be most creative when they experience high levels of intrinsic motivation (Amabile et al. 1996; Oldham and Cummings 1996). In the case of customer creativity, intrinsic motivation has been found to be especially important. Von Hippel (2005) argued that creative customers find value and pleasure in the process of creating, because of the enjoyment and learning it brings to them. For these individuals, it is the problem solving itself, rather than just the outcome, that motivates them. Intrinsic motivation also relates to persistence; if an individual values not only the outcome, but also the process, they will be more likely to engage over a longer period of time. This is also reinforced by Berthon et al. 
(2007) who argued that customers, in relation to employees, invent not only from unfulfilled needs, but for the love of experimentation.

\subsubsection{Contextual factors}

Individual customers exist in a broader context, which influences their creative potential (Runco 2007). Creativity does not exist in a vacuum, but is always to be considered in relation to a specific domain (Amabile 1983). A domain can be defined as a specific area or field, such as health care or computer science, and can also consist of several sub-areas. Creativity and factors influencing creativity are believed to be highly context or domain specific (Baer 2014). Simply put, the factors influencing creativity in the arts will not be the same as those in engineering or health management. Therefore, in the following, the influence of the specific domain, type of service, and customer roles will be considered.

\section{Domain}

Creativity and innovation occur within a knowledge and social system that possesses a set of values and norms (Gatignon and Robertson 1985). On a macro level, it is suggested that certain political environments and power structures affect the degree of creativity manifested by the corresponding population (Simonton 2000). Cultural beliefs and values within a domain are suggested to influence the individual's cognition, motivation, and behavior (Perry-Smith and Shalley 2003). Domain or organizational characteristics consist of culture, strategy, level or hierarchy and power distance, and structure (Woodman, Sawyer, and Griffin 1993). Often, these factors have been investigated in relation to the employee creativity in an specific firm (e.g., Amabile 1988; Oldham and Cummings 1996). It is believed that organizations that are receptive to and absorb new knowledge are better at assimilating innovation (Greenhalgh et al. 2004). However, even though these factors have often been analyzed in relation to a specific firm, they are influenced by the overall norms and values in the specific domain to which they belong. This implies that firms exist in networks (the overall domain), and that these networks often promote innovations only after they are generally perceived as the "norm" (Greenhalgh et al. 2004), which implies that these networks will effect creativity indirectly in that domain.

Different domains handle creative customers differently. In some domains or fields customer creativity is highly encouraged, while in others it is considered a threat and is suppressed by all possible means (Berthon et al. 2007). In domains that are highly regulated and conservative regarding change, such as health care, creativity and new ways of doing things can be challenging (Herzlinger 2015). For example, the health care sector is highly regulated by law and government and has a number of stakeholders with different agendas that all influence the overall norms and values in that domain. Often, these stakeholders exert substantial resources and have the power to influence public policy and opinion by attacking or helping the innovator (Herzlinger 2015).

Researchers have suggested that creativity is positively influenced by high autonomy and sense of ownership and control (Runco 2007). That is, individuals are more creative when 
they perceive themselves to have choices in how to go about accomplishing the tasks that they are given (Oldham and Cummings 1996). It has also been suggested that internal conflict, conservatism, and rigid, formal management structures will inhibit creativity (Runco 2007). In domains that are associated with high risk, such as nuclear power or health, creative behavior from individuals might be a source of potential danger to themselves and/or others (Berthon et al. 2007). The specificities of the domain also influence (directly or indirectly) customer creativity. As these structures influence employees' behaviors and creativity (Oldham and Cummings 1996), they are also likely to influence the customer's practices and creative ability. Within different domains, the roles of professionals also have crucial importance for customer creativity. Professional roles and image - how professionals view their profession and how they believe outsiders view their profession - influence the way the public, and ultimately their clients, interact with them (Vough et al. 2013).

\section{Type of service}

A domain can include a range of different services characterized by different characteristics and conditions. In relation to customer creativity, it is also important to consider type of service as an influence of creativity. As different services inherently require different degrees of participation, problem-solving, and knowledge of the customers (Bitner et al. 1997), this should also influence customer creativity.

One way of characterizing different types of service is in accordance to their complexity and divergence (Shostack 1987). Complexity refers to the number of steps and sequences that constitute the process, and divergence refers to executional latitude and variability of those steps. Less complex services can be described as processes where the course of action is familiar and the same for every customer. Conversely, in highly complex processes, the steps and sequences can be unknown in the beginning of the process, to either the customer or the service provider. Usually, highly complex services require more of customers in terms of engagement and problem solving (Spanjol et al. 2015)

A related issue is that different services require different levels of customer participation and knowledge (Bitner et al. 1997; Gallan et al. 2013). Bitner et al. (1997) argued that some services are characterized by low levels of participation and only require the customer to be present, such as in the case of watching a concert. Other services require that the customer participate in the form of information, effort, or physical possession, which can be characterized by a moderate level of participation. This can be the case in, for example, banking services. In some services, customers have an essential role and are required to have a high level of participation that, if not fulfilled, will directly affect the nature of the service outcome. Examples of such services include education, health care services, and social services.

Another thing that can be considered is the inherent purpose of the service. Negative services can be defined as needed, but not necessarily desired, by customers (Berry and Bendapudi 2007; Spanjol et al. 2015). Examples of these types of services include legal and tax services or health care services. Often, people do not engage in these because of the pleasure of doing 
so, but because they have to in order to reach a different goal, such as health or financial security. Therefore, individuals' motivation to engage in these services is often not intrinsic, which has been found to limit creativity (Amabile 1983; Ryan and Deci 2000).

\section{Customer role}

Related to both the characteristics of the domain and the type of service, but also to the specific situation, is the influence of the social role of the customer. A social role can be viewed as a specific set of practices that connects one actor to one or more other actors (Akaka and Chandler 2011). It can be argued that both the characteristics of the general domain, but also the specific type of service, influence the social role of the customer. Role theory can be described as a collection of theories that predict how actors will behave depending on a given social role and situation (Biddle 1986). Salomon et al. (1986) described a role as a cluster of social cues that direct an individual's behaviors in a given setting. Applying a theoretical approach to role means emphasizing the nature of people as social actors who learn behaviors that are appropriate to the situation. The social role concerns a set of social norms that define expectations and appropriate behaviors for a person in that role (Parsons 1951). The customer role is composed of a set of learned behaviors associated with the specific role, which is dependent on the demands of the specific environment and situation. Role expectations are thus not connected to a specific person, but to a position (Sarbin and Allen 1968); therefore, the same person can take on any number of social roles. Role players always assume a position in relationships: one takes a focal position and the other assumes a counter position; for example, boss-employee, seller-buyer, or doctor-patient (Solomon et al. 1985). In general, even if a customer is a very different individual in private life, when entering a social situation, roles are strictly defined and each participant must adopt a relatively standardized set of behaviors and read from a common predetermined script (Solomon et al. 1985). Therefore, the role of the customer influences customer practices and, indirectly, their creativity.

Although it can be argued that social roles are situational, they are also determined by the overall norms and values within the domain. In different domains and in different types of services, customers (and professionals) take or are given different types of roles, with different required behaviors. Social climate and interaction are found to have significant effects on creativity, and encouraging interaction and support has been found to be essential to create empowered customers with high autonomy and confidence in problem solving (Ouschan, Sweeney, and Johnson 2006; Creer and Holroyd 2006). Therefore, social roles act as resources for change because they can lead to change of social norms and establish social positions, or sets of value-creating relationships and practices connected to a particular actor (Akaka and Chandler 2011). In some domains and types of services, individuality and originality are acceptable, and perhaps even rewarded. These domains are more likely to accept variety in role behaviors, and will therefore enable creativity (Amabile 1996). 


\subsubsection{Situational factors}

In addition to personal and domain-related factors, creativity is influenced by the specific environment and situation in which it takes place (Kristensen 2004; Burroughs, Moreau, and Mick 2008; Runco 2007); that is, the problem environment. It has long been considered that a variety of situational factors influence the creative process. Kristensen (2004, p. 91) argued that "much cognitive work is 'situated', once we are there, we must act out the plan and make all kinds of situational adaptations as problems occur". More precisely, creativity takes place in a physical and social environment, which allows for different cognitive processes, behaviors, and social roles. This, of course, involves the task at hand, or the nature of a specific problem that needs to be solved. However, it can also relate to time and resources that the individual has at hand. Nevertheless, the impact of environment and situational factors must be understood in relation to the individual. Different situational influences and environments have different effects on different people (Runco 2007). This explains why some factors stimulate creativity for some, but not for others. It is also expected that the effect of situational factors will vary over time, even for the same person. Therefore, it is important to consider the interaction between the individual and the specific environment and context in which the creativity takes place.

\section{Physical and social environment}

Customer creativity can take place in a number of physical spaces, ranging from the service provider to the home context of the customer. Kristensen (2004) stated that creativity takes place in a physical environment and that this facilitates certain cognitive processes and restricts others, which may reduce or enhance the individual's creativity. For example, physical space has been suggested to have an effect on individual well-being (Rosenbaum and Smallwood 2013) and affect the channels of information and the sets of tools and resources available (Kristensen 2004). Resources can refer to people, materials, facilities, and information. McCoy and Johnson (2014) found that characteristics of the settings associated with perceived creative potential include spatial complexity, visual detail, natural views, use of natural material, societal design, cool colors, and use of manufactured or composite material. Consequently, a physical environment with high creativity potential should be visually interesting and tend towards high complexity, both spatially and visually (McCoy and Johnson 2014).

It has been shown that social environments which support autonomous, active task engagement can enhance creativity, while highly controlled social environments can be unfavorable for motivation and creativity (Amabile 2001). In addition, Perry-Smith and Shalley (2003) emphasized the social aspects of creativity and stated that it is enhanced by increased interaction and communication with diverse actors, not solely the service provider. However, the value of communication and interactions depends on the kind of exposure and information that is communicated. It has also been suggested that social support reinforces creativity (Amabile 1988), meaning that social environments that give recognition, build on cooperation, and are empathic and non-judgmental will encourage creativity. 
In relation to customers, it has been found that professionals' service orientation influences customers' tendency to give ideas for improvement (Henrike and Schultz 2014), and that communication and interaction between customers and professionals directly affects customer behaviors (Gallan et al. 2013; Street et al. 2009). Environmental factors investigated in relation to the process of customer creativity have been limited. However, there are some exceptions. Rosa et al. (2014) investigated how vision and touch inputs influenced the creativity of customer-derived product concepts. In similar vein, Luo and Toubia (2015) suggested that when generating ideas, concrete cues are more beneficial to customers with low domain knowledge, and high-knowledge customers are better served with abstract cues. However, it must be considered that most customer creativity takes place during consumption in the customer sphere. Therefore, to a large extent, the service provider has no influence over the social and physical environment. Instead, other customers, Internet communities, family and friends, and other social actors in combination will influence the social environment in which the customers act. In a similar vein, the physical environment and resources will vary depending on the customer.

\section{Emotions and situational involvement}

There are a number of examples of creativity as a reaction to personal challenges. Situational involvement refers to the individual's preoccupation with an activity out of concern for its direct consequence (Burroughs and Mick 2004). This means that an individual can, in some situations or in relation to a specific problem, engage in activities that they normally would not be interested in, so long as the situation has substantial implications for the individual. For example, someone who usually is not interested in medical issues might have an increased interest and involvement if, for example, their child becomes seriously ill. This is also related to arguments that tensions in general trigger new ideas (Van de Ven, Angle, and Poole 1989). When people reach a limit of dissatisfaction with their current situation and are placed in confrontation with sources of the problem, this forces people to act and think in new ways. In general, emotions and affective state are important individual-level factors that can significantly shape one's cognition, intentions, and behavior (Runco 2007). While positive affect allows individuals to access associated memories and frame their thoughts around related concepts, a negative affective state inhibits one's ability to process incoming information. A new problem or too much tension can trigger negative emotions. Conversely, under conditions of prevailing negative affect, individuals perceive that everything seems more difficult, which leads to the inhibition of creativity. Closely related to this is the level of stress the customer experiences in the situation. Stress influences social relationships, intellectual functioning, and emotional stability, often negatively, which can influence cognitive abilities and problem solving (Runco 2007). Another factor tied to the situation can be time pressure. Most research has suggested that time pressure strains creativity (Runco 2007; Amabile 1988). However, others have stated that time pressure, when not extreme, can in fact stimulate creativity (Burroughs and Mick 2004).

Situational factors have been investigated in relation to customers. For example, Moreau and Dahl (2005) studied how input and time constraints influence the way in which 
customers process information during consumption, and how those processes, in turn, influence the creativity of the solution. Similarly, Burroughs and Mick (2004) found that situational factors, such as time constrains and situational involvement, affect creativity during consumption. In relation to emotions, it has been found that positive moods enable creative thinking (Burroughs, Moreau, and Mick 2008).

\subsection{Customer creativity in context}

In the following section, I present factors influencing creativity summarized in Table 2. These consider personal factors, contextual factors, and situational factors.

Table 2 Factors influencing customer creativity

\begin{tabular}{llll}
\hline & Personal factors & Contextual factors & Situational factors \\
\hline Factors & Personal traits & Domain & Social and physical \\
influencing & Cognitive process & Type of service & environment \\
customer & Knowledge and & Customer role & Type of situation \\
creativity & experience & & Situational involvement \\
& Motivation & & Emotions \\
\hline
\end{tabular}

Some might take the view of the individual customer's creativity as binary - you either are creative, or you are not. However, a more common view is that creativity is something that can be reinforced and developed over time (Amabile 2001; Cummings and Oldham 1997; Burroughs, Moreau, and Mick 2008). Therefore, by changing conditions in the context or situation, you can influence the creativity of customers.

As mentioned earlier, creativity and customer creativity are highly context specific, and factors influencing creativity differ depending on overall domain, type of service, and the individual customer (Simonton 2000; Baer 2014). Types of personal traits and cognitive styles that enhance creativity in one context can restrain it in others. For example, compare a creative customer who modifies a motor vehicle with one who redesigns their clothing. While these people might have some personal factors or skills in common, they also need additional traits, knowledge, and skills in relation to the specific task. 


\section{Research methodology}

This thesis builds on five separate papers and an overall summary and synthesis of the findings in the papers. In this chapter, the methodological approach, research design, data collection, and analysis underlying the results of this thesis are explained in detail. First, the assumptions and considerations connected to the methodological approach are discussed. This includes a discussion of theory generation and differences between qualitative and quantitative research approaches. Second, the research process and design is presented and the individual studies are explained and characterized. As an important part of this thesis is its discussion of the literature, the rationale for, and process of, conducting a literature review will be explained in detail. Finally, the quality of this research is discussed.

\subsection{Methodological approach}

The traditional goal of science is to find truth through the generation of knowledge (Okasha 2002), and identify fundamental laws, principles, and general facts of the world. This view of science means that scientific questions and structures of knowledge include statements of regularities among data that takes the form of causal laws. However, this view of science has been challenged due to the fact that theories and laws are difficult or even impossible to prove or justify in an absolute way (Okasha 2002; Sayer 1992). This is especially true when considering social sciences, which are often multi-dimensional, and when many things are happening all at once it is challenging, if not impossible, to isolate particular processes and behaviors (Sayer 1992). In addition, within the social sciences, it has often been argued that knowledge is contextual and is constantly changing due to developments, cultures, and perspectives (Muis, Bendixen, and Haerle 2006). However, even if theories cannot be justified and science cannot be relied on to give us absolute objective truths, it can still give us better and better candidates for truths. Therefore, in this thesis I take the position that science is not a question of proving something once and for all, but rather a means to continuously improve theories. Importantly, this does not mean that there is no truth or that everything is constructed, just that (current) scientific methods cannot fully account for and be relied on to generate the truth. As a consequence, researchers within a discipline should be critical of their own theories and open to new possibilities and new evidence, even when these come from other research fields (Nordin 1988). This view stresses that knowledge and assumptions must be continually tested and research disciplines must be somewhat tolerant of ambiguity and pluralism and recognize that knowledge is relative, fallible and changing over time, rather than absolute.

Within the social sciences, the objectives of research take a variety of forms with a wide range of accepted scientific methods. Research within the social sciences can aim towards explaining, predicting, understanding, describing, or investigating a certain issue or phenomenon (Alvesson and Sandberg 2012). In the following, I explain the methodology underlining this thesis as it relates to the contexts outlined above. 


\subsubsection{Research strategies}

Research as a process usually concerns two domains: theoretical and empirical (Okasha 2002). Theory consists of constructs, definitions, and proposed relations between different constructs. Constructs can be viewed as hypothetical concepts that are defined with the aim of being operationalized or measured (MacInnis 2011). However, defining constructs alone does not constitute a theory. This happens by conceptualizing their proposed relationships that specify why one or more constructs affect other constructs and specify why (conditions) and how (process) outcomes are affected. On this view, theories can be seen as attempts in part to understand and conceptualize how things are and why they are what they are. Thus, the empirical domain is where theories are tested or generated, and in this thesis that domain is health care.

In this thesis, I primarily use a deductive approach. Deduction or deductive logic entails scientific reasoning based on theory to explain or predict reality (Okasha 2002). If the theories are accurate, the conclusions must be correct. Deductive logic in research starts with theories and concepts, and based on these formulates hypotheses or predictions that are subsequently tested. Induction or inductive logic, on the other hand, means that scientific reasoning is based on observations that help the researcher to draw conclusions about reality (Okasha 2002). Therefore, an inductive approach in research starts with empirical data or observations to build constructs, patterns, and models that eventually result in predictions and theories. However in practice, a strict and pure deductive or inductive strategy is rare, if not impossible. Even if a study can be characterized as being either inductive or deductive, both inductive and deductive reasoning are usually a part of the analytic process of any study. As Glăveanu (2014) argued, taking a strict inductive approach ignores "the role of theoretical assumptions underlying even the most simple (if not precisely the most simple!) segmentations that allow empirical research [...] research doesn't end with theory: it starts from it and is guided by it throughout" (p. 273).

The divison of deductive and inductive resoning is usally connected to the division between qualitative and quantitative research (Bryman 2001). These two research traditions have different origins and are often described as distinct with regards to both methods and questions of truth, and what can pass as acceptable knowledge within a scientific discipline (Bryman 2006). The quantitative strategy usually relies on a deductive approach, in which the purpose of theory is to generate hypotheses that can be tested to allow for explanations and knowledge (Bryman and Bell 2007). It can be viewed as a strategy for collecting numerical data and emphasizes quantification of both data collection and analysis. The qualitative approach involves understanding and interpretation, rather than testing hypotheses. It typically has an inductive approach, in which the research process starts with the study subject or phenomena to generate theory (Alvesson and Sköldberg 2009). There are several valid reasons for applying qualitative research. For example, qualitative methods can be used to uncover and understand underlying patterns of new phenomena, as well as give deeper insight and novel thinking to well-developed theories (Corbin and Strauss 2014). Qualitative and quantitative research strategies have different components with regards to 
type of data and the way data is analyzed. While quantitative research relies on numbers and measurements that are analyzed using statistical methods, qualitative research in most cases relies on data from interviews, observations, or texts that are analyzed using interpretive procedures (Bryman 2006).

A more pragmatic view of these two research strategies is to view them as complementary. Although these approaches involve somewhat competing views on generating knowledge, the differences are often just tendencies, rather than distinct divisions (Bryman and Bell 2007). Taking this view, both qualitative and quantitative research strategies and methods for data collection and analysis can be acceptable, depending on which kind of knowledge needs to be generated. Basically, the research problem in question determines what method and approach should be used. For this reason, the purpose of research can be both to test and verify existing theories, as well as to expand existing theories or generate new ones. In this thesis, the latter of these two standpoints is employed, implying that quantitative and qualitative research strategies are viewed and used as two mutually beneficial components of conducting research with the purpose of advancing both theory and practice.

The research presented in this thesis builds on different research strategies and methods. In the following, I present my research process and design and then go on to explain the research methods used, as well as the related studies.

\subsection{Research design}

During my time as a doctoral candidate, I have been part of a Vinnova-funded research project called "Service Innovations in Health Care". The project's aim has been to contribute to increased knowledge of the prerequisites for successfully involving health care customers in the development of health care services, how health care activities can be organized to facilitate and support such development, and development and dissemination of models of health care service innovations. When I joined in 2012, a large part of the project had focused on the last part of the aim; that is, to develop and test models of health care service innovations. More precisely, this had been done by developing and testing a diary-based method for involving health care customers in the development of health care services (see Elg et al. 2011; Elg et al. 2012). Although we had a good understanding and experience of customer involvement from other areas, both in service and manufacturing, our knowledge of the research field of customer involvement in health care, of service innovation, and of roles of health care customers, were limited. In addition, we had limited understanding of the specific contextual health care circumstances influencing the customers' ability to be involved and engaged in creative behaviors and problem solving.

This thesis can be described as following two steps. A major aim of the first part of this thesis is simply to identify, overview, and synthesize both empirical and conceptual research relating to the creation of a platform and a conceptual framework to further our understanding of the health care customer's role in service innovation. Based on a synthesis 
of previous research and theories of health care roles and practices, and by relating them to theory of creativity and value-creation practices, I have identified interesting gaps in knowledge and developed a framework for the empirical studies. Figure 4 illustrates the main process and activities preceding my research.

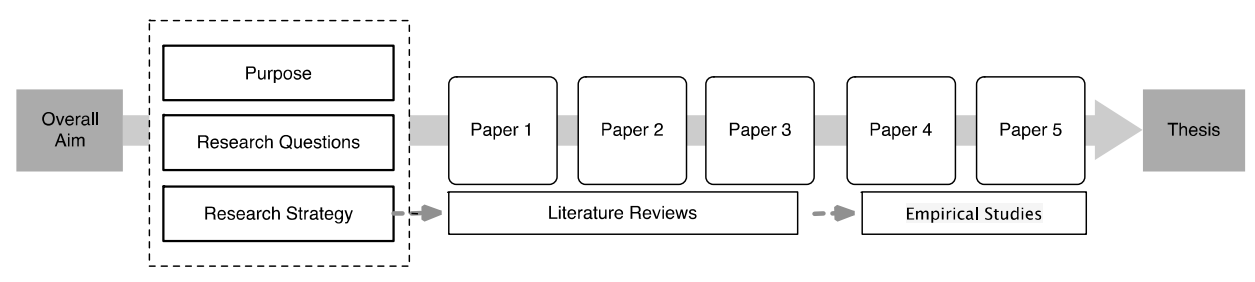

Figure 4 Illustration of the research process

As my co-authors and I were interested in methods for involving customers in health care, the aim of Paper 1 was to provide an overview and synthesize the current empirical research related to the concept of customer (patient) involvement in health care research. This approach provided a deeper understanding of what was already known and investigated, as well as different examples of methods, prerequisites, and investigated consequences related to the concept. In addition, this gave me a detailed understanding of the field of research and the development of connected subfields and subject areas. As one aim of the project was to enable service innovation, in parallel, Paper 2 aimed to define the concept of service innovation and identify different categories of service innovation. During this time and after the work with the initial reviews, it became clear that to understand how customers can be involved in development, we needed to understand the role of the customer in health care, influencers of health care behavior, and how this differs from the roles of customers in other areas. To date, research in health care has been carried out along disciplinary lines, with little sharing of knowledge with other disciplines. In addition, almost all research has been focused on involvement in the delivery of health care (for example, consultations) and isolated to specific encounters, neglecting circumstances, conditions, and practices outside the service setting. Therefore, the aim of Paper 3 was to identify and compare different perspectives on customer roles in health care research with research on customer roles and practices in the service marketing literature. An additional aim was to identify knowledge gaps and established relationships between health practice approaches and their outcomes. Using a review method enabled me to acquire a deep understanding of both the field of customer involvement as described in the health care literature, and also the different practices, approaches, and organizational systems and outlooks. Reviewing health care and service literature in parallel gave me a broadened perspective and insight into gaps in knowledge in the different fields, and ideas for cross-fertilization. Hence, the results of these reviews had a substantial impact on the focus and design of the empirical studies in this thesis.

On the basis of the results from the different reviews, it can be concluded that even though there are a large number of both conceptual and theoretical publications that have addressed methods for involving customers in both health care and service research, very few have 
investigated circumstances in which customers are creative and what influences this process, especially outside the immediate service setting. Therefore, instead of developing more methods for considering involvement, I wanted to know how different contexts and conditions influence the customer's ability to be creative and solve problems. Therefore, I integrated theory on creativity and customer practices with theory of health care practices. The aim of Papers 4 and 5 was to explore and investigate different conditions for customer creativity in health care. This was tested partially by using previously collected data from customer diaries (see Elg et al. 2011; Elg et al. 2012) in the form of patient ideas for service innovation. These studies are based on the theory of contextual factors influencing creativity, derived foremost from service innovation and customer creativity research. More specifically, in Paper 4 the aim was to explore how type of service and environment influences the customer's ability to solve problems and implement solutions to improve their situation. In Paper 5, this was extended to evaluate the influence of social and physical environments on health care customers' creative performances. The results from these studies were then integrated with previous suggestions (from Papers 1 and 3) from the literature reviews in a proposed framework for health care customer creativity. Table 3 provides an overview of the different research designs employed in the five papers appended to this thesis.

Table 3 Summary of research design in appended papers

\begin{tabular}{|c|c|c|c|c|c|}
\hline & Paper 1 & Paper 2 & Paper 3 & Paper 4 & Paper 5 \\
\hline Purpose & $\begin{array}{l}\text { Provide an } \\
\text { overview and } \\
\text { synthesize } \\
\text { the current } \\
\text { empirical } \\
\text { research } \\
\text { related to } \\
\text { patient } \\
\text { involvement }\end{array}$ & $\begin{array}{l}\text { Synthesize } \\
\text { research and } \\
\text { categories of } \\
\text { service } \\
\text { innovation }\end{array}$ & $\begin{array}{l}\text { Identify and } \\
\text { combine health } \\
\text { care customer } \\
\text { roles in health } \\
\text { care and } \\
\text { service } \\
\text { research }\end{array}$ & $\begin{array}{l}\text { Explore how } \\
\text { customer creativity } \\
\text { is influenced by type } \\
\text { of service and } \\
\text { environment }\end{array}$ & $\begin{array}{l}\text { Investigate how } \\
\text { customer } \\
\text { creativity is } \\
\text { influenced by } \\
\text { physical and } \\
\text { social context }\end{array}$ \\
\hline $\begin{array}{l}\text { Research } \\
\text { approach }\end{array}$ & $\begin{array}{l}\text { Literature } \\
\text { review }\end{array}$ & $\begin{array}{l}\text { Literature } \\
\text { review }\end{array}$ & $\begin{array}{l}\text { Literature } \\
\text { review }\end{array}$ & $\begin{array}{l}\text { Qualitative/ } \\
\text { quantitative }\end{array}$ & $\begin{array}{l}\text { Qualitative/ } \\
\text { quantitative }\end{array}$ \\
\hline Data & 214 articles & 43 articles & $\begin{array}{l}300 \text { articles and } \\
\text { books }\end{array}$ & $\begin{array}{l}\text { Customer ideas for } \\
\text { improvement }\end{array}$ & $\begin{array}{l}\text { Customer ideas } \\
\text { for improvement }\end{array}$ \\
\hline Subjects & $\begin{array}{l}\text { Academic } \\
\text { articles from } \\
\text { health care } \\
\text { research }\end{array}$ & $\begin{array}{l}\text { Academic } \\
\text { articles on the } \\
\text { topic of service } \\
\text { innovation }\end{array}$ & $\begin{array}{l}\text { Academic } \\
\text { articles and } \\
\text { books from } \\
\text { health care, } \\
\text { service, } \\
\text { marketing and } \\
\text { operations } \\
\text { research }\end{array}$ & $\begin{array}{l}53 \text { customers from } \\
\text { rehabilitation and } \\
\text { orthopedic surgery }\end{array}$ & $\begin{array}{l}33 \text { customers } \\
\text { from orthopedic } \\
\text { surgery }\end{array}$ \\
\hline
\end{tabular}




\subsubsection{Literature review as a research method}

As stated earlier, a large part of this thesis is based on literature reviews. Consideration of prior, relevant literature is essential for all research disciplines and all research projects. When reading an article independent of discipline, the author begins by describing previous research to map and assess the research area in order to motivate the aim of the study and justify the RQs and hypotheses. This is generally referred to as the "literature review", "theoretical framework", or "research background". However, these traditional ways of describing the literature often lack thoroughness and are not undertaken systematically (Tranfield, Denyer, and Smart 2003). This results in a lack of knowledge of what the collection of studies is actually saying. If effective and well conducted, reviews as a research method create a firm foundation for advancing knowledge and facilitating theory development (Webster and Watson 2002). They also help to overview areas in which the research is disparate and interdisciplinary. In addition, a literature review is an excellent way of synthesizing research findings to show evidence on a meta-level and uncover areas in which more research is needed. This is a critical component of creating theoretical frameworks and building conceptual models. In the appended papers in this thesis, I have used different approaches; these are first described at a general level and then presented in relation to the appended papers.

\subsubsection{Different approaches to conducting a literature review}

As with all research, the value of academic reviews depends on what was done, what was found, and the clarity of reporting (Moher et al. 2009). Depending on the purpose of the review, researchers can use a number of strategies, standards, and guidelines developed especially for conducting literature reviews. These approaches can be qualitative, quantitative, or have a mixed design depending on the phase of the review. In the following, I describe three broad types of approach commonly used, as summarized in Table 4. However, it should be noted that there are a number of other forms of literature review, and that elements from different approaches are often combined.

Table 4 Approaches to literature reviews

\begin{tabular}{|c|c|c|c|}
\hline Approach & Systematic & Semi-systematic & Integrative \\
\hline Purpose & \multicolumn{3}{|c|}{$\begin{array}{l}\begin{array}{l}\text { Synthesize and compare Overview research area and track Critique and synthesize } \\
\text { evidence } \\
\text { development over time }\end{array}\end{array}$} \\
\hline Research questions & Specific & Broad & Narrow or broad \\
\hline Search strategy & Systematic & May or may not be systematic & Usually not systematic \\
\hline Sample characteristics & Quantitative articles & Research articles & $\begin{array}{l}\text { Research articles, books } \\
\text { and other published texts }\end{array}$ \\
\hline Analysis and evaluation & Quantitative & Qualitative/Quantitative & Qualitative \\
\hline Synthesis & $\begin{array}{l}\text { Evidence of effect } \\
\text { Research directions } \\
\text { Inform policy and } \\
\text { practice }\end{array}$ & $\begin{array}{l}\text { Descriptive summary } \\
\text { Describing the evolution of a } \\
\text { discipline }\end{array}$ & $\begin{array}{l}\text { Taxonomy or } \\
\text { classification } \\
\text { Theoretical model or } \\
\text { framework }\end{array}$ \\
\hline
\end{tabular}




\section{Systematic literature review}

Systematic reviews have foremost been developed within medical science as a way to synthesize research findings in a systematic, transparent, and reproducible way. A systematic review can be explained as a research method and process for identifying and critically appraising relevant research, and collecting and analyzing data from the studies that are included in the review (Liberati et al. 2009). The aim of a systematic review is to identify all empirical evidence that fits pre-specified inclusion criteria to answer a specific RQ. By using explicit and systematic methods when reviewing articles, bias can be minimized, thus providing reliable findings from which conclusions can be drawn and decisions made (Moher et al. 2009).

Often, but not always, statistical methods such as meta-analysis are used to integrate the results of included studies. Meta-analysis is a statistical method for combining results from different studies to weigh and compare results and identify patterns, disagreements, or relationships that appear in the context of multiple studies on the same topic (Davis et al. 2014). With the meta-analysis approach, each primary study is abstracted and coded, and findings are subsequently transformed into a common metric to calculate an overall effect size (Glass 1976). Together with a systematic review method for selecting articles, performing a meta-analysis can clarify the state of a field of research, determine whether an effect is constant across studies, and discover what future studies are required to demonstrate the effect. Techniques can also be used to discover which study-level or sample characteristics have an effect on the phenomenon being studied; for example, whether studies conducted in one cultural context show significantly different results from studies conducted in other cultural contexts (Davis et al. 2014). However, to be able to perform a meta-analysis, the included studies must have statistical measures that are shared among the studies (effect size) in order to compare results (DerSimonian and Laird 1986). Therefore, it is challenging to perform meta-analysis on studies with different methodological approaches (Tranfield, Denyer, and Smart 2003).

Even though the systematic review method was developed in medical science, attempts have been made to adapt it into areas within the social sciences, such as management (e.g., Tranfield, Denyer, and Smart 2003). However, in these areas, which not are restricted to randomized controlled trials, a major challenge lies in assessing the quality of research findings. As a result, more qualitative approaches have been developed to assess the quality and strength of findings from different types of studies and compare results (e.g., Thomas et al. 2004; Greenhalgh et al. 2004). This is often referred to as a qualitative systematic review, which can be described as a method for comparing findings from qualitative studies (Grant and Booth 2009). Another approach is systematic review, which uses a more integrative, critical or thematic method when synthesizing the findings, and utilizes the strengths of a comprehensive search process to address other aspects than strengths of effects. 


\section{Semi-systematic review}

The semi-systematic or narrative review approach is designed for topics that have been conceptualized differently and studied by different groups of researchers and within different disciplines that hinder a full systematic review process (Wong et al. 2013). Besides the aim of overviewing a topic, a semi-systematic review often looks at how research within the selected area has developed over time. In general, the review seeks to identify and understand all potentially relevant research traditions that have implications for the studied topic, and to synthesize them using meta-narratives instead of measuring effect size (Wong et al. 2013). This provides an understanding of complex areas. However, while covering broad topics and different types of studies, this approach holds that the research process should be transparent, with a developed research strategy that enables readers to assess whether the arguments for the judgments made were reasonable, both for the chosen topic and from a methodological perspective.

A number of methods can be used to analyze and synthesize findings from a semi-systematic review. These methods often have similarities to approaches used in qualitative research in general. For example, thematic or content analysis is a commonly used technique and can be broadly defined as a method for identifying, analyzing, and reporting patterns in the form of themes within text (Braun and Clarke 2006). This type of analysis can be useful for detecting themes within a specific research discipline (e.g., Jones, Coviello, and Tang 2011) or identifying components of a theoretical concept (Ward, House, and Hamer 2009). Although this type of review is usually followed by a qualitative analysis, there are exceptions. For example, Borman and Dowling (2008) used a narrative method for collecting literature, but combined this with a statistical meta-analysis approach.

\section{Integrative review}

Closely related to the narrative review approach is the integrative or critical review approach. An integrative literature review aims to assess, critique, and synthesize literature on a research topic in an way that enables new theoretical frameworks and perspectives to emerge (Torraco 2005). Most integrative literature reviews are intended to address mature topics or new, emerging topics. In the case of mature topics, the purpose of using an integrative review method is to overview the knowledge base, to critically review and potentially reconceptualize and expand the theoretical foundation for the specific topic as it develops. For newly emerging topics, the purpose is rather to create initial or preliminary conceptualizations and theoretical models, rather than review old models. In both cases, an integrative review method should result in advancement of knowledge and theoretical frameworks, rather than just overviewing or describing a research area. Although an integrative review can be conducted in a number of ways, researchers are still expected to follow accepted conventions for reporting how the study was conducted (Torraco 2005).

The data analysis part of an integrative or critical review is not particularly developed or specified according to a specific standard (Whittemore and Knafl 2005). However, while there is no strict standard, the general idea of data analysis in an integrative review is to 
critically analyze and examine the literature and the main ideas and relationships of an issue, or to critique an existing area. It should be noted that this requires advanced skills of the reviewers, such as advanced conceptual thinking (MacInnis 2011). Often, reviews labeled as integrative are simply summaries of studies, and not truly integrative.

\subsubsection{The process of conducting a literature review}

While conducting the three literature studies in this thesis, I spent a fair amount of time reading up on and developing and refining the process of conducting a review. In the following, I present the basic steps in this process and some of the important choices to consider in the process, as summarized in Figure 5. This process was developed in relation to the practical experience of designing and conducting the reviews included in this thesis, and is influenced by various standards and guidelines suggested for literature reviews (e.g., Liberati et al. 2009; Wong et al. 2013; Torraco 2005; Tranfield, Denyer, and Smart 2003).

\section{Phase 1: Designing the review}

Ideally, the first step when designing a literature review is to clearly define the purpose of the review and which questions should be addressed. This is important because it helps to identify which approach is appropriate. For example, if the review aims to summarize or overview a large field of research, a strict systematic review approach may not be suitable, or even possible. Instead, a narrative or integrative review approach is preferable. In the same way, if the purpose of the review is to investigate and synthesize evidence of the effect of a specific treatment, an integrative review is not trustworthy. The stated RQs should then guide the rest of the review. However, in practice, the RQs are often developed and refined during the review process.

Once research questions have been selected and an overall review approach considered, a search strategy for identifying relevant literature should be developed. This includes selecting search terms and appropriate databases, and deciding on criteria for the inclusion and exclusion of literature. This is important as, independent of the type of approach, the quality of the literature is dependent on, among other aspects, what literature is included and how it was selected (Tranfield, Denyer, and Smart 2003; Wong et al. 2013; Liberati et al. 2009; Torraco 2005). Thus, the authors must be transparent in a way that enables the reader to understand how the literature was identified, analyzed, synthesized, and reported. This should be done carefully and prior to actually conducting the review. 


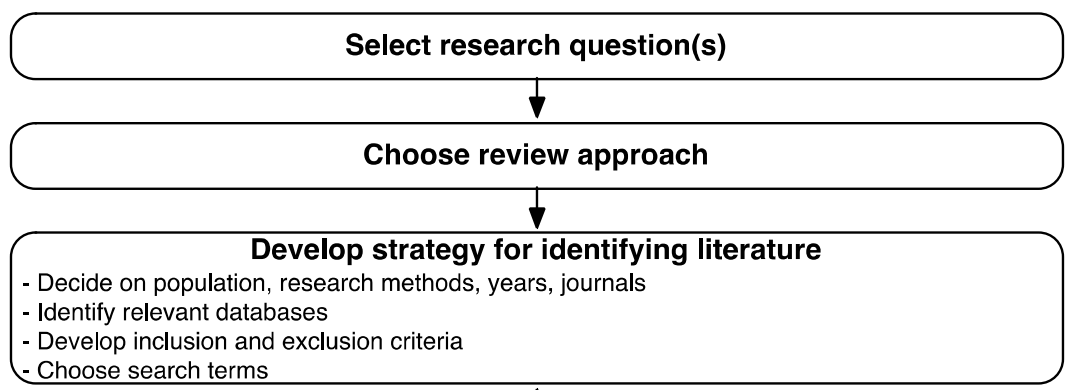

\section{Conduct the initial review}

- Test the review strategy

- Document the review process

- Initial scan to identify articles that are revelvant

- Asses reliability for the search process

- Select articles for further analysis

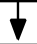

- Read articles in detail

- Collect additional articles

\section{Select articles for final sample}

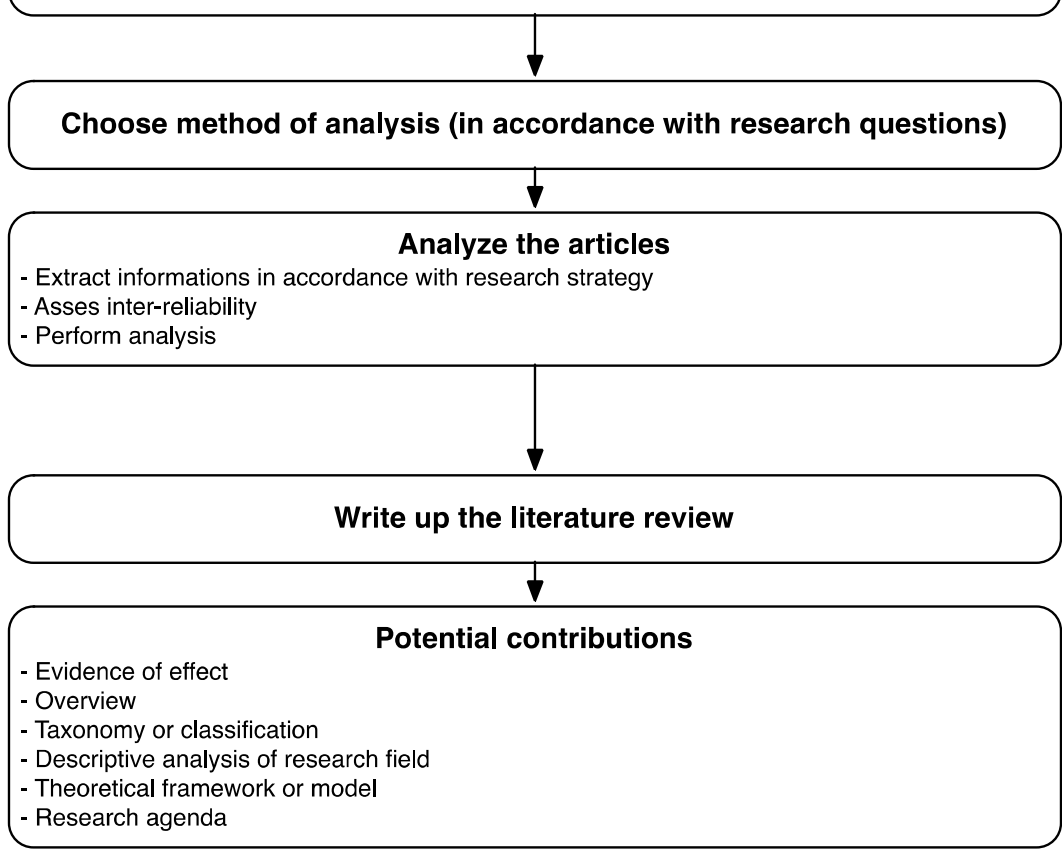

Figure 5 Process of conducting a literature review 
Search terms can be words or phrases that are used to access appropriate articles, books, and reports. These terms should be based on words and concepts that are directly related to the research questions. Depending on the aim of the review and the research questions, these search terms can be broad or narrow. Importantly, it could be wise to consider including additional limitations. As almost all initial literature searches yield many articles, a strategy is needed to identify which of these are actually relevant. Inclusion criteria for the review should be guided by the selected research questions. Criteria that can be considered and are commonly used are, for example, year of publication, language of the article, or type of article (such as conceptual, randomized controlled trail) and journal.

\section{Phase 2: Conducting the review}

When conducting the review, a pilot test of the review process and protocol is appropriate. By testing the search terms and criteria for inclusion on a smaller sample, the process can be adjusted before performing the main review. During the review process, depending on purpose, reviewers may read each piece of the literature, analyze the research method or findings, or conduct the review in stages (reading abstracts first and full articles later). Once this is done, and the initial articles (or other relevant literature) have been collected, articles should be screened in full to ensure that they all meet the criteria for inclusion. As an additional strategy, references of the selected articles can be scanned to find other articles that may potentially be relevant. During this time, the process of inclusion and exclusion should be documented.

\section{Phase 3: Analysis}

When selecting a final sample, a standardized means of abstracting appropriate data or information from each article should be used. Data abstracted can be in the form of descriptive information, such as authors, years published, topic, or type of study, or in the form of effects and findings. It can also take the form of conceptualizations or theoretical perspective. In this step, it is important to consider training the reviewers (if there is more than one) and monitoring the data abstraction carefully during the process of the review to ensure quality and reliability. Often, if the aim is to publish in an academic journal, this will require a detailed description of the process or a measure of reliability between reviewers.

Depending on the review, different methods of analysis can be used and are more or less appropriate. Nevertheless, independent of the method of analysis, it is important to ensure that it is appropriate to answer the selected research questions. For example, if the purpose is to evaluate evidence for the effect of a certain treatment of cancer, this implies the use of meta-analysis. On the other hand, if the purpose were to develop a theoretical model or framework for a topic based on literature, a strict meta-analysis would not be a good choice.

\section{Phase 4: Writing up the review}

Depending on approach, the final review article can be structured in different ways and requires different types of information and different levels of detail. There are a number of standards and guidelines that explicitly address how literature reviews should be reported 
and structured. For example, PRISMA, developed for systematic literature reviews and meta-analyses (see Liberati et al. 2009); RAMSES, developed for systematic narrative reviews (see Wong et al. 2013); and guidelines for integrative reviews (see Torraco 2005). However, some generalizations can be made. For all review articles, it is necessary (or should be) to transparently describe the process of designing the review and the method for collecting literature; that is, how the literature was identified, analyzed, synthesized, and reported by the author. Doing this properly gives the reader the chance to assess the quality and trustworthiness of the findings. The findings and contribution of the articles can take a number of forms. For example, literature reviews can result in a historical analysis of the development within a research field (e.g., Carlborg, Kindström, and Kowalkowski 2014), an agenda for further research (e.g., Neely, Gregory, and Platts 2005), a conceptual model (e.g., Smith et al. 2008), or evidence of an effect (e.g., Buchwald et al. 2004).

In the following, the specific design and methodological considerations in the review papers $(1,2$, and 3$)$ are explained.

\section{Paper 1}

Paper 1 was motivated by the difficulties of overviewing the research area concerning patient involvement in health care research as it was scattered between different concepts and research disciplines. Therefore, the purpose was to map and overview empirical research connected to various issues and methods for involving customers in health care delivery and development. As the purpose was very broad, we employed a semi- systematic review method (Wong et al. 2013). This method enabled us to capture as many aspects of patient involvement as possible while at the same time limiting the number of articles to a manageable number. A specialist on medical literature helped with selecting suitable search terms and databases, which were carefully chosen to ensure that we captured the research concerning patient involvement accurately. During the process, the search terms were revised and adjusted several times after conducting initial test searches. As an additional strategy, we scanned the references and citations within the selected articles to capture further articles. The review followed different stages, with an initial scan of abstracts and then further analysis of full text articles.

The articles were then subject to thematic content analysis (Braun and Clarke 2006). The research subject of patient involvement comprises a wide range of research methodologies, subjects, and topics, which makes statistical meta-analyses impossible, and also unsuitable for the purpose of the review. Instead, reading the articles in full and creating themes based on the content of the articles enabled us to derive an overview of the field. During this process, we discussed interpretations and disagreements throughout to increase reliability and reduce preconceptions. As a second step, we synthesized the different themes and their possible connections, resulting in a tentative model that illustrated the empirical field of patient involvement. 


\section{Paper 2}

Paper 2 was motivated by the lack of consistency in the view and definition of service innovation and the outcome of involving customers in development and delivery. Therefore, the purpose of this study was to identify and define the various categories of service innovation and analyze the role of categories in understanding service innovation. For this reason, we used a systematic review method to capture different categories of service innovation as used in literature. As this topic and purpose, in comparison to the topic of patient involvement, is narrower, we were able to scan all articles that included some form of the term "service innovation" in the abstract, title, or keywords.

As with the previous paper, this review was conducted in different stages, with an initial scan of abstracts and then further analysis of full-text articles. A total of 1046 articles appeared in the initial search, 255 of which were selected for further analysis. These were read by two independent authors and resulted in 43 texts that provided a conceptualization of service innovation using categories. The analysis followed an integrative approach suggested by MacInnis's (2011) process of conceptual thinking. Two authors sorted the identified articles into different categorizations that focused on the main categories. This process continued until the two authors had agreed on the identified categorizations. To be eligible for categorization, the categories must have been used in more than one paper. As a final stage of analysis, four alternative conceptualizations of categories addressing service innovation were identified.

\section{Paper 3}

Paper 3 was motivated by the lack of overlap in approaches to customer roles in health care research and health care customer roles as conceptualized in service research. As was concluded in Paper 1, to date, research in health care has been carried out along disciplinary lines, with little sharing of knowledge between medicine, nursing, and allied health on one hand and service research on the other. Therefore, the purpose of this paper was to identify and synthesize findings from medicine, nursing, allied health professions, and related areas with those in service research in order to identify key conceptualizations of the role of the health care customer. To review two samples of research articles- the first being published health research (medicine, nursing, and allied health professions), and the second published service research - two review approaches were used. Health care research in general is a large field with many sub-fields, such as medicine, nursing, and allied health, which all publish research relevant to health care customer roles. We used a more qualitative narrative method for identifying articles. This was done by tracking early articles (when the concept first appeared), the most cited articles, and more recent articles. However, when analyzing health care customer roles in service, marketing, and operations research, a systematic review method could be used for identifying articles that conceptualized the role of the health care customer.

We applied thematic analysis to identify and categorize articles depending on conceptualization of the customer. Two authors independently coded the conceptualizations 
and associated practices into preliminary working themes of practices, and then conferred using a process of constant comparison (Strauss 1987). Following established practice, the two authors discussed all of the cases on which they disagreed and used a third author as judge to resolve any discrepancies. Discussions continued until agreement was reached regarding the classifications. In each of the identified themes, we captured the author(s)' conceptualization, main contribution, and the described roles and associated activities of both the health care customer and health care professionals. Based on the analysis of conceptualization of customer roles, we also provided an agenda for further research.

\subsubsection{Use of empirical data}

The empirical data used in Papers 4 and 5 were collected through customer diaries (Elg et al. 2012), which is a method that was developed to capture authentic ideas and experiences as they appear in situ (Edvardsson et al. 2012). To summarize, patients were asked to introduce themselves and present reasons for their contact with the health care system. For each day, the diary was separated into two different parts: first, an open recounting of the day's events and care contacts, and second, a three-item list in which patients filled in specific improvement ideas based on everyday situations. All participants were exposed to the same instructions and were requested to write down reflections and ideas for improvement about their own health problem and contact with care providers for 14 consecutive days (Elg et al. 2011).

In these studies, theoretical sampling was used to select service settings with different requirements (Eisenhardt 1989). To capture context, participants were undergoing orthopedic surgery (hip replacement) or rehabilitation from chronic pain. These groups were chosen for different reasons. The first care process, hip replacement, is a highly standardized procedure with a sequential pattern, and is typically only experienced once. This process usually has a low degree of participation and in this care process the clinical knowledge is high and standardized procedures are widely used. As this is typically a onetime procedure, all customers experiencing it are new to the situation. Therefore, all participants shared a similar experience, unlike the case of a more compound care process. The second care process, pain rehabilitation, is complex and has a high degree of variance in terms of both experience and contact with health providers. In addition, this process covers both contact with health care and recovery at home, which enabled the capturing of experiences from both the medical service setting and the home context.

Because the objective was to identify health care customer concepts from the diaries, all ideas were abstracted from the diaries. In total, 353 ideas were abstracted. A large majority of these were explicitly written in the idea field, while others were identified in the text. Two researchers, in parallel, examined all diaries. In the following, the specific research method of Papers 4 and 5 is discussed. 


\section{Paper 4}

The purpose of Paper 4 was to explore how customer creativity is influenced by physical and social environments (health care/home) and type of service (low complexity/high complexity). The data used in this study was customer ideas and customer diaries (as described above). As the purpose was to investigate type of service and environment, we divided the sample into four groups.

- Low-complexity services in the interaction sphere (hip-replacement, health care)

- High-complexity services in the interaction sphere (rehabilitation, health care)

- High-complexity services in the customer sphere (rehabilitation, home)

- Low-complexity services in the customer sphere (hip-replacement, home)

On the basis of these four groups, the analysis was performed in several steps. First, we performed content analysis on the ideas in order to get an overview of the various topics represented in the ideas. On the basis on this, we sorted the ideas into four different categories: practical strategies, organizational aspects, social aspects, and medical care. In the next step, the proportions of these categories were calculated within each of the four groups, and compared. Chi-2 tests were used to investigate if patients within the different groups came up with specific types of ideas. Based on the differences and characteristics of each group, we read all diaries in full and selected four diaries to illustrate each condition.

\section{Paper 5}

The purpose of Paper 5 was to investigate how customer creativity is influenced by physical and social contexts, as well as the customer's role. The data used in this study was customer ideas (as described above). To enable this study, we chose to evaluate customer ideas from orthopedic surgery patients. This choice was made for two reasons: first, this health care service covers different contexts (spheres) both within health care (provider and joint spheres) and the home environment (customer sphere). Second, orthopedic surgery is typically a onetime procedure; all customers experiencing it are new to the situation as they are experiencing it for the first time and, thus, share similar experiences. This is in comparison to more complex health care services (such as rehabilitation), where the experience and the contact with the health care provider have greater variation.

In the first step, to enable statistical analysis, all customer ideas from orthopedic surgery $(n=201)$ were coded according to context for their realization (service provider sphere/joint sphere/customer sphere) and associated customer role (passive/active); namely, if the idea aimed at enabling a more active role for the customers or if the customers themselves were responsible for realization of the idea. To investigate how context affects customer creativity, we used the Consensual Assessment Technique proposed by Amabile et al. (1996), which is suitable for comparing ideas, judging them independently, and rating them relative to other ideas. In line with creativity theory, this technique draws on the notion that parties other than the originator must evaluate the degree of creativity. In Paper 5, customer ideas were evaluated using a group of nurses $(n=5)$ as expert judges. This was deemed 
suitable as nurses have both medical knowledge and knowledge and experience of caring for patients. All nurses specialized in orthopedic surgery and had at least three years of practical experience. In line with previous studies (Magnusson et al. 2003), the ideas were rated on a 10-point scale from 1 (lowest) to 10 (highest). The rating procedure was organized as a workshop in which all experts received the same set of instructions and explanation of the scale. The judges rated all the ideas according to one dimension at a time and performed the rating individually.

All ideas were evaluated based on three different dimensions: originality (the newness or uniqueness of the idea), user value (the value of the idea for the customer using the service), and clinical value (the value of the idea for the customer's health and recovery status). The first two dimensions were selected based on criteria for evaluation creativity (Amabile et al. 1996) and were verified by several similar studies on idea evaluation (e.g., Magnusson et al. 2003; Witell et al. 2011). The third dimension, clinical value, was added especially to evaluate ideas that aimed at improving clinical health. In line with other empirical studies on creativity (Burroughs and Mick 2004; Rosa et al. 2014), the dimensions were evaluated separately. To enable statistical analysis, all ratings were averaged. To determine whether health care customers' ideas concerning different spheres (provider, joint, customer) differed in outcome evaluation scores of originality, user value, and clinical value, we used one-way ANOVA. This is a statistical test used to determine whether there are any significant differences between the means of three or more independent groups (Bryman and Bell 2007).

\subsection{Evaluation of the methodological approach}

This thesis is based on studies by different constellations and according to different research traditions. This section contains some reflections concerning the quality of the research. A research design represents a logical set of statements that enable others to judge the quality and trustworthiness of the research (Yin 2009). While I discussed and presented the specific method used in each paper above, in this section I discuss the overall research design and some potential limitations with the research approach.

\subsubsection{Validity and reliability}

In general, validity refers to the extent to which a concept, conclusion, or measurement corresponds accurately to reality and is based on the whole research design (Bryman and Bell 2007). Often, validity is divided into different types, such as construct validity, internal validity, and external validity. Construct validity determines whether the measurement being used is accurate, whereas internal validity refers to whether the independent variable causes the changes seen in the dependent variable. Most often, this quality criterion applies when the researcher seeks to establish causal relationships and some conditions believed to lead to other conditions (Yin 2009). Lack of internal validity indicates that there are alternative explanations for relationships between two variables (Bryman and Bell 2007). External validity concerns the degree to which the results of a study can be generalized beyond the 
context in which the research was conducted (Bryman and Bell 2007); in other words, whether the findings can be transferred across time and to other populations.

Reliability is the means by which a study can be replicated, and refers to the consistency of the measure of a concept (Bryman and Bell 2007). The role of reliability is to reduce errors and bias (Yin 2009). Reliability can be divided into external and internal categories. If a study is repeated following the exact same procedure, the results should be the same (Yin, 2009). This is more difficult to assess for qualitative studies, because the same conditions can almost never be fully duplicated, so results can turn out differently (Bryman and Bell 2007). Internal reliability refers to the means by which observers (if there is more than one) agree on the observation (Bryman and Bell 2007).

\subsubsection{Discussion of research design}

As stated earlier, a large part of this thesis is based on literature reviews. This approach was motivated by the lack of synthesized knowledge on the topic of customer involvement and customer roles in health care research. While there are numerous of empirical studies scattered across several fields of research, few attempts have been made to synthesize the collected knowledge of these studies. However, this approach does not put any less emphasis on methodological quality; as with all research, consideration of what was done is needed, along with what was found and the transparency and clarity of reporting (Moher et al. 2009). In each of the literature reviews (Papers 1, 2, and 3), all steps were thoroughly described and explained in order to allow other researchers to replicate the study.

I was responsible for designing the review strategies in all three literature reviews, along with selecting samples, and I was highly involved in the analysis of articles. When conducting literature reviews, there is always a possibility that important articles have been omitted; thereby failing to accurately capture what was intended. To ensure that the right articles and concepts were used, search terms were carefully selected in collaboration with health care experts (in Papers 1 and 3). In all of the reviews, I purposely used a broad research strategy when considering journals, type of study, and time periods to avoid systematically excluding relevant literature and findings. In addition, in all reviews, several authors were consulted and involved in both the selection of articles and the analysis to improve reliability in the process. As the purpose of Paper 3 hindered a full systematic approach, we consulted a medical panel that evaluated the findings and analysis to ensure that we captured the research accurately.

During the work with this thesis, I have conducted both primary and secondary data analysis. A limitation in this thesis is that I was not involved in the design of the diaries investigated in Papers 4 and 5. Therefore, I had no influence over decisions leading to the data collected (diary design, participant selection), and I do not possess all insight into the methodological choices and research process. However, I was involved in design, and coding of all the variables, as well as qualitative and quantitative data analysis. I also designed and conducted 
the workshop with health care professionals when evaluating health care customer ideas in Paper 5.

With regards to validity, there are some limitations regarding the selection of participants. As the empirical studies in this thesis only investigated two types of health care service, orthopedic care and chronic pain were used as a proxy for different types of health care services to explore customer creativity. It should be noted that there are significant differences in both physical and social contexts, as well as requirements with regard to highly standardized care (such as a hip replacement), conditions involving high-level multiple encounters over a number of years (as in the case of chronic diseases), and primary and acute care. Therefore, regarding external validity, further empirical research is needed to validate, test, and extend the findings of the empirical studies to other health care settings.

In terms of construct validity, in Paper 5 we measured creativity using the dimensions of originality and value. Though theoretical support for these dimensions is well established, in empirical studies this becomes problematic. Simply determining creativity by totaling the ratings of each dimension has been criticized (Burroughs and Mick 2004), as this implies that creativity is a linear combination of originality and user value. However, sometimes these aspects are contradictory. Amabile et al (1996) stated that useful ideas are generally valued, but the more original they are, the more questions are raised regarding their usefulness and appropriateness. Therefore, in line with other empirical studies, the dimensions were examined separately. In addition, this study evaluated the customers' creative performances from the perspective of health care professionals. Even though this approach is well grounded in theory for assessing creativity (Amabile et al. 1996) and in empirical studies (e.g., Kristensson et al. 2002; Witell et al. 2011), the objectivity and accuracy of health care professionals' evaluations can still be questioned.

Due to the conceptual nature of the research approach, this thesis also faces limitations in terms of the number of investigated factors and their effect on customer creativity. The proposed framework can be considered as integrative, but without the ambition to predict and explain customer creativity across all domains, at all times, and among all people. As stated earlier, creativity and the process of creativity must always be analyzed in the specific domain or subdomain (Baer 2014). As such, this presented framework is quite general; to be operationalized and tested it must be adapted to specific factors surrounding that domain, and the interrelationships among these factors. Therefore, there are many opportunities to refine and extend the results and suggestions of this thesis.

\section{Ethical considerations}

Papers 4 and 5 were approved by the Regional Ethical Review Board in Linköping (Ref. nos. 20029-09). All participants provided written informed consent. All participants were over the age of 18. Participants' autonomy was acknowledged in text, a cover letter, and the diary, which stated that participation was voluntary and participants could withdraw from the study at any stage. Participants were also informed that confidentiality would be maintained when presenting the results. 


\section{Overview of appended papers}

This chapter summarizes the papers appended to this thesis. In the theoretical framework, I have summarized my theoretical points of departure and my main theoretical concepts, and how they are connected. On the basis of this conceptual understanding and discussion, I present an overview of the five articles and their main contributions.

\subsection{Paper 1: The Antecedents, Forms and Consequences of Patient Involvement: A Narrative Review of the Literature.}

Authors: Hannah Snyder and Jon Engström

Status: Published in the International Journal of Nursing Studies (2016), 53, pp. 351-378.

\subsubsection{Background}

The empirical research of patient involvement on the micro-level of health care is diverse, with studies focusing on specific contexts, diseases, and health situations in isolation. This diversity makes it difficult to draw firm conclusions based on findings across studies. Therefore, the purpose of Paper 1 was to synthesize and provide an overview of the diverse streams of health care research on patient involvement, and their respective RQs. The empirical sample of 214 articles contained papers from over 50 journals. These were primarily nursing and health care journals, but a number of interdisciplinary journals were also identified. Using thematic analysis, we identified nine themes in the patient involvement literature in health care research, divided into three main categories: enablers for patient involvement, types of patient involvement, and consequences of patient involvement (illustrated in Figure 6).

\subsubsection{Findings and contributions}

Three of the identified themes concern different types of patient involvement practices: in decision-making, in delivery of health care, and in development of care. Patient involvement in decision-making relates to engaging the patient in decisions about treatment. Patient involvement in health care delivery includes different ways to actively engage patients in delivering care, such as self-care and medication. Patient involvement in development concerns attitudes and methods to include the patients' perspective in the development of health care. Five themes concern enablers, or antecedents, related to the three forms of involvement. We identified themes among patient factors (patient education, patient empowerment), staff factors (communication, training), and organizational factors (service systems). Patient empowerment entails studies that focus on psychological aspects of supporting patients to gain control over their situations and become more capable of managing their illness. Patient education includes studies that examine how patient education and training can enable involvement and engagement. Staff training includes 
studies that emphasize the need to train staff to support patient involvement. Communication concerns how medical professionals' communication skills can alter patient behavior and promote proactivity and involvement. Service systems concern how technical and organizational systems can support patient involvement practices. Finally, one theme concerns the investigated consequences, such as patient satisfaction, health outcomes, and reduced costs.

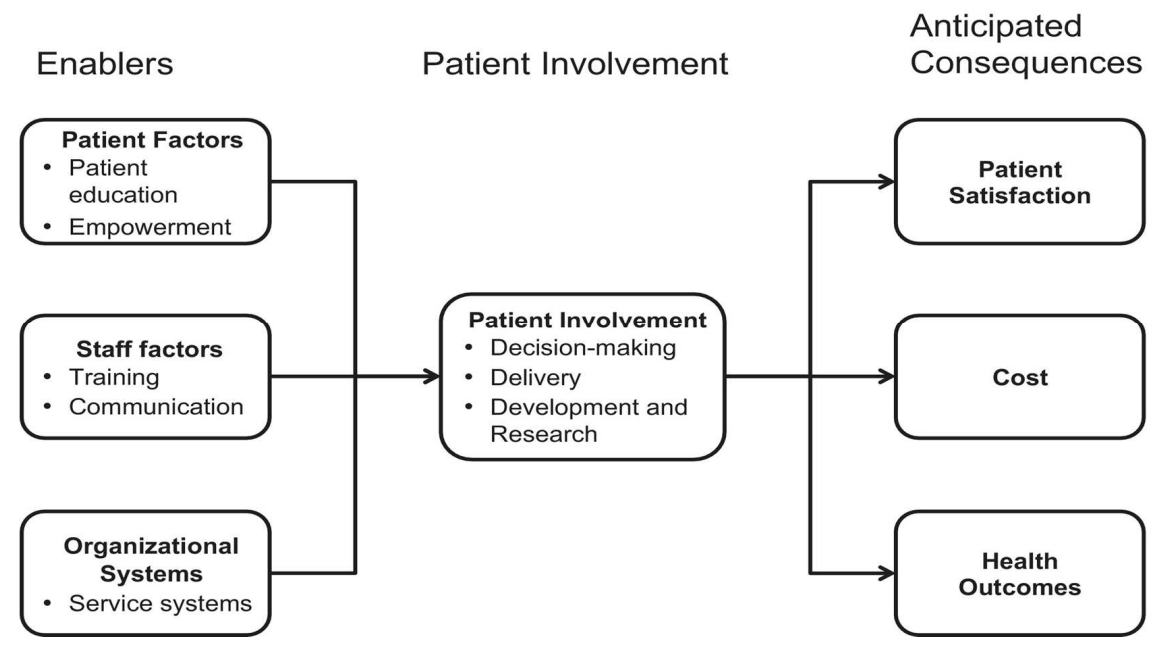

Figure 6 Model for patient involvement

We concluded that within the literature on patient involvement, there has been a steady increase in articles published in a large number of outlets within various streams of health care research. Notably, a large proportion of studies relate to chronic diseases, especially cancer and diabetes. This is not surprising, as an increase in such ongoing diseases requires a more active patient role. Despite the development of several theoretical models for involving patients, the connection and parallels between theoretical models for involvement and the study design and findings were weak in this review. While early studies in the reviewed sample dealt with issues such as attitudes towards involvement and whether patients should be involved in decision-making and treatment, later studies have focused more on how patients should be involved.

This study reveals that research on this topic is scattered across different sub-disciplines, and often concerns specific diseases or aspects of care, such as decision-making or selfmanagement. Paper 1 offers an integrative approach to the concept and practice of patient involvement and highlights the commonalities between sub-topics. Importantly, patient involvement should be viewed not only as isolated activities, but also as a result of educating and preparing patients, staff, and systems. This review includes a wide variety of studies on patient involvement in decision-making, delivery, and development, provides an integrative perspective on involving patients in various health care activities, and identifies customer practices in health care. 


\subsection{Paper 2: Identifying categories of service innovation: A review and synthesis of the literature}

Authors: Hannah Snyder, Lars Witell, Anders Gustafsson, Paul Fombelle, and Per Kristensson

Status: Published in the Journal of Business Research (2016).

\subsubsection{Background}

It has been suggested that service innovation creates value for customers, employees, business owners, alliance partners, and communities through new and/or improved service offerings, service processes, and service business models. Despite the importance of service innovation, it is still a fuzzy and poorly defined concept. The purpose of Paper 2 was to investigate the meaning of service innovation through an extensive literature review and synthesis of the concept's various categorizations. Using a systematic review method to assess 1046 research articles, we identified four types of categorizations.

\subsubsection{Findings and contributions}

From these 43 service innovation categorizations, four unique themes emerged: (1) degree of change, (2) type of change, (3) newness, and (4) means of provision, as summarized in Table 5. We suggest that most service innovation categorizations focus inwardly and view service innovation as something that is internally new to the firm. Crucially, the literature has poorly addressed how service innovations affect customer value and financial performance.

Table 5 Overview of the categorizations of service innovation

\begin{tabular}{|c|c|c|c|c|}
\hline & Degree of change & Type of change & Newness & Means of provision \\
\hline $\begin{array}{l}\text { Main } \\
\text { categories }\end{array}$ & $\begin{array}{l}\text { Radical, } \\
\text { incremental }\end{array}$ & Product, process & $\begin{array}{l}\text { New to the } \\
\text { market, new to } \\
\text { the firm }\end{array}$ & Technology, organization \\
\hline Explanation & $\begin{array}{l}\text { A service } \\
\text { innovation is based } \\
\text { on new core } \\
\text { characteristics or } \\
\text { improvements to } \\
\text { existing core } \\
\text { characteristics. }\end{array}$ & $\begin{array}{l}\text { A service } \\
\text { innovation is } \\
\text { based on changes } \\
\text { in the core } \\
\text { characteristics } \\
\text { related to the } \\
\text { output or service } \\
\text { provision. }\end{array}$ & $\begin{array}{l}\text { A service } \\
\text { innovation that } \\
\text { has not been } \\
\text { provided by } \\
\text { competitors or } \\
\text { is a new service } \\
\text { for the specific } \\
\text { service } \\
\text { provider. }\end{array}$ & $\begin{array}{l}\text { A service innovation is } \\
\text { provided in a new way } \\
\text { through technology or new } \\
\text { organizational arrangements. }\end{array}$ \\
\hline $\begin{array}{l}\text { Core } \\
\text { references }\end{array}$ & $\begin{array}{l}\text { Gallouj and } \\
\text { Weinstein (1997) }\end{array}$ & Pearson (1997) & $\begin{array}{l}\text { Mansury and } \\
\text { Love (2008) }\end{array}$ & $\begin{array}{l}\text { van der Aa and Elfring } \\
\text { (2002) }\end{array}$ \\
\hline
\end{tabular}

One main finding of the study is that a service innovation should be viewed as changes in value. However, previous research has largely neglected the effect on the customer's perception of value. Although previous research has briefly referenced this notion (see 
Michel et al. 2008), most research has focused on aspects connected to the offering's characteristics. Because value creation and customer focus are central, service innovation seems to naturally focus more on the value-creating experiences of the benefitting party(s). Similarly, the financial value captured by service-innovating firms has rarely been considered. Therefore, definitions of service innovations seem to be misleading because of an inward focus on changes in service characteristics for a specific firm. Therefore in Paper 2 we suggest that reinstating the notions that service innovation should be viewed as an outcome and imply "newness" of value creation to the market or the world (in other words, customers) and that financial value extends from the introduction of a service to success in the market, is needed to identify and understand true service innovations.

\subsection{Paper 3: Changing Role of the Health Care Customer: Review, Synthesis and Research Agenda}

Authors: Janet McColl-Kennedy, Hannah Snyder, Anu Helkkula, Mattias Elg, Lars Witell, Sue Hogan and Laurel Anderson.

Status: In review for the Journal of Service Management.

\subsubsection{Background}

The role of the customer is particularly relevant in health care, as the customer can contribute in different ways and to varying extents, not only to the design and the delivery of a health service, but to their own health and well-being. In this article, the role of the health care customer, which is an important but understudied topic, is critically reviewed. The purpose of Paper 3 was threefold. It aimed to: (1) synthesize findings from medicine, nursing, allied health professions, and related areas with those in service research identifying key conceptualizations of the role of the health care customer; (2) examine research and identify gaps in theory, and outline established relationships between health practice approaches and their outcomes; and (3) propose an agenda to guide future health service research. In this study, we combined a meta-narrative review of health care research and a systematic review of service research. In total, a sample of 300 articles was chosen from both health care and service, marketing and operations research. To capture the role of the health care customer, as well as the associated practice approached, we used thematic analysis.

\subsubsection{Findings and contributions}

Results from Paper 3 suggest that the role of the health care customer has been conceptualized and studied under a number of different practice approaches. Ten practice approaches - nine originating in health research and one in service research - were identified and are illustrated in Figure 7. These were: (1) traditional medical model; (2) biopsychosocial model; (3) patient centeredness; (4) patient participation; (5) shared decision-making; (6) patient empowerment; (7) person-centered care; (8) collaborative care; (9) self-managed care; and (10) health care value co-creation. This paper presented the overall philosophy, origins, key focuses, and roles of the health care customer and health 
professional, and the directing of the distinctive characteristics and parallels with the other practice approaches.

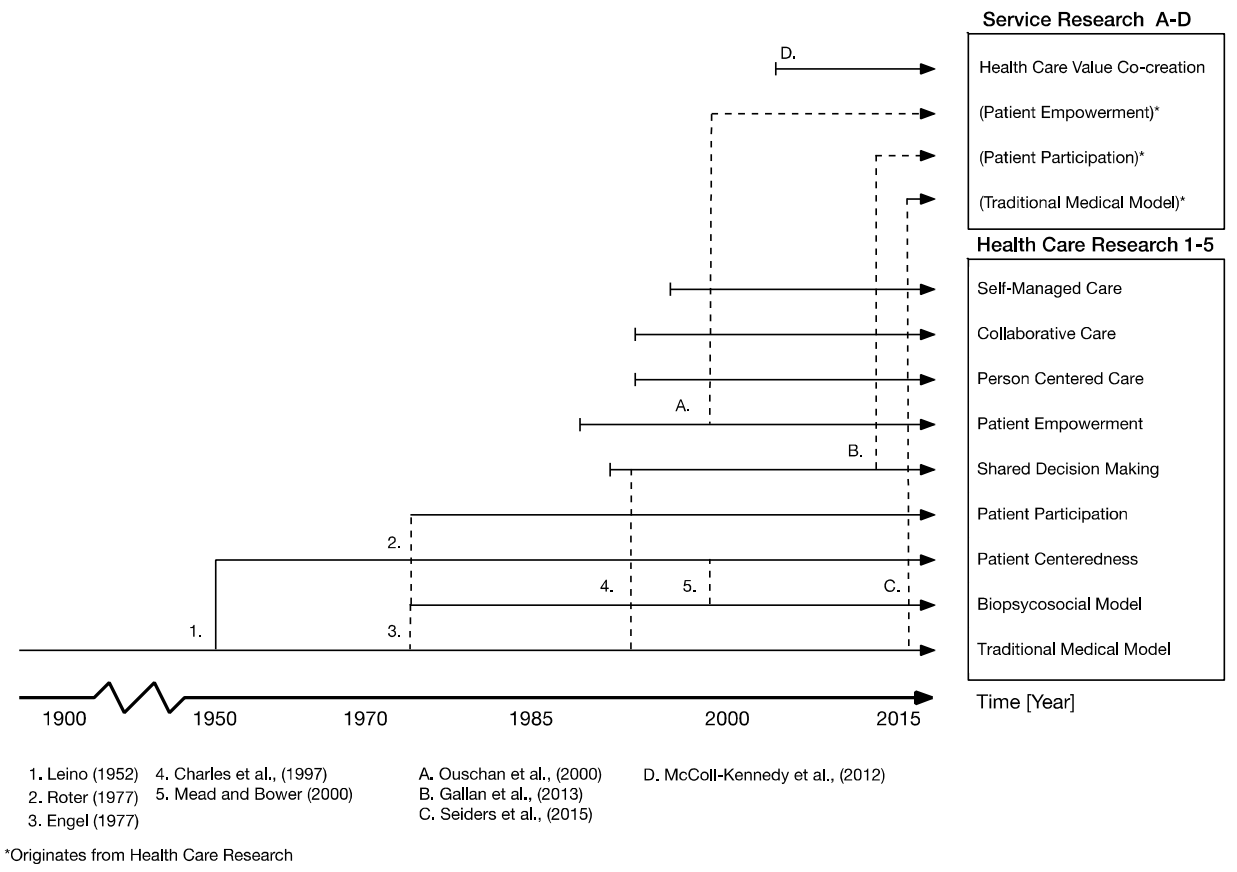

Figure 7 Health care customer practice approaches

There are several findings from this study. Besides identifying practice approaches in health care, this paper also identifies an increased activation and change in the role of the health care customer over time. This paper stresses a reorientation of customer activities and interactions and a move towards an active customer role, in which customers co-create value with the service providers and other actors. It also suggests that the special characteristic of health care services makes it a particularly interesting area for service research. Building on previously identified literature, and by analyzing and discussing the changing roles, we also put forward an agenda for further research. 


\subsection{Paper 4: Customer Creativity: Exploring the Influence of Type of Service and Environment in a Health Care Context}

Authors: Jon Engström, Hannah Snyder, Mattias Elg and Lars Witell

Status: Submitted to the Journal of Services Marketing.

\subsubsection{Background}

While previous research on customer creativity has mostly focused on the output of customer ideas, especially targeting creative customers in "positive" or neutral services, Paper 4 aimed to increase understanding of the potential of customer creativity in health care services and how customers can enable service innovation. The overall purpose of this study was to explore how type of service (standardized vs. complex) and environment (at the service setting vs. in the customer sphere) influences health care customer creativity. Taking the overall view that health care is best seen as a complex category of services and that the customer will be able to contribute in different ways depending on the characteristics of the specific service. Additionally, health care practices take place not only in the service provider sphere, but also (and sometimes primarily) in the home environment of health care customers. To investigate how these conditions influence customer creativity, we examined health care customers' ideas for service innovation and how these ideas emerged.

\subsubsection{Findings and contributions}

The results of this study suggest that health care customer creativity is influenced by both environment and type of service. Building on this analysis, we propose that level of complexity and divergence of the service process in relation to environment create different conditions for customer creativity:

- Low-complexity services in the interaction sphere (hip-replacement care in health care environment)

- High-complexity services in the interaction sphere (chronic pain care in health care environment)

- High-complexity services in the customer sphere (chronic pain care in home environment)

- Low-complexity services in the customer sphere (hip-replacement care in home context

Results suggest that health care customer creativity in high complexity services in the interaction sphere will foremost focus on identifying solutions for improving organizational aspects and medical care. In contrast, in the customer sphere, focus is on identifying practical strategies that will improve the customers' life. For health care customer creativity in low complexity services in the interaction sphere, the focus was foremost on identifying either problems or solutions to organizational aspects. In the customer sphere, the focus was to identify and develop solutions to on practical strategies and social aspects. 
Based on these conditions, this study suggests different roles for health care customers in the development of health care services (Figure 8): feedback provider, problem solver, codeveloper, and expert. In addition, we suggest different methods for customer involvement depending on these proposed roles.

High Complexity Service

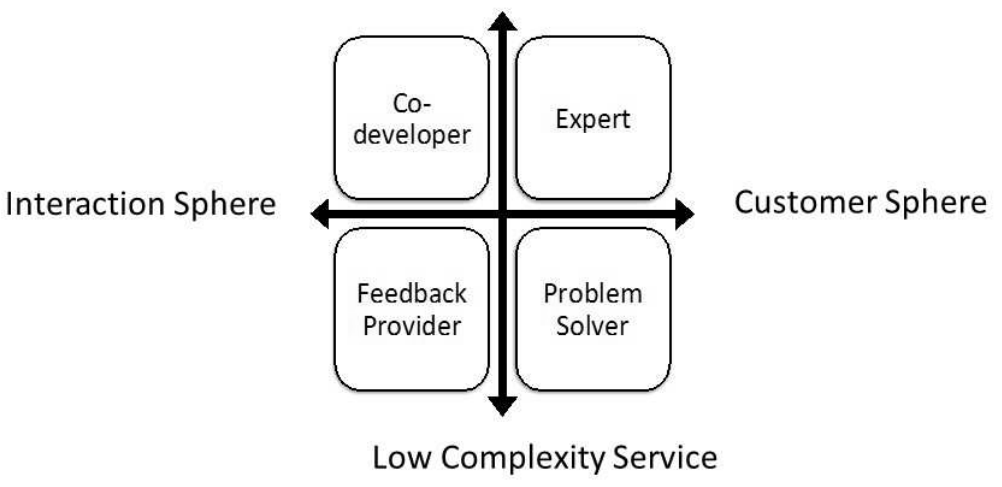

Figure 8 An overview of customer co-creation roles in service innovation

\subsection{Paper 5: Health care customer creativity: The role of physical and social context}

Authors: Hannah Snyder, Lars Witell, Mattias Elg, and Janet McColl-Kennedy.

Status: In review for the Journal of Service Management.

\subsubsection{Background}

Health care customers play an essential role in creating service outcomes, and it is suggested that thinking creatively and solving problems is part of a health care customer's daily life. Despite this, little attention has been given to what factors influence such creative processes. Therefore, the purpose of Paper 5 was to investigate the influence of physical and social environments on health care customer creativity. This study expanded previous research by shifting focus towards the health care customer as a source of creativity and innovation. Building on Grönroos and Ravald (2011), Amabile (1983) and Burroughs et al. (2008), we investigated a previously underexplored area of health care service innovation by exploring health care customer creativity.

In this study, we developed and tested a framework for customer creativity illustrated in Figure 9. The framework is based on the central assumption that health care customers' creativity is influenced by physical and social contexts. Based on theory of creativity and innovation, we used the dimensions of access, domain knowledge, and traditional [social] role to describe central physical and social dimensions and conditions related to each sphere. With a background in previous literature, we propose that health care customers' creativity 
will differ with regards to originality, user value, and clinical value in the different spheres of health care.

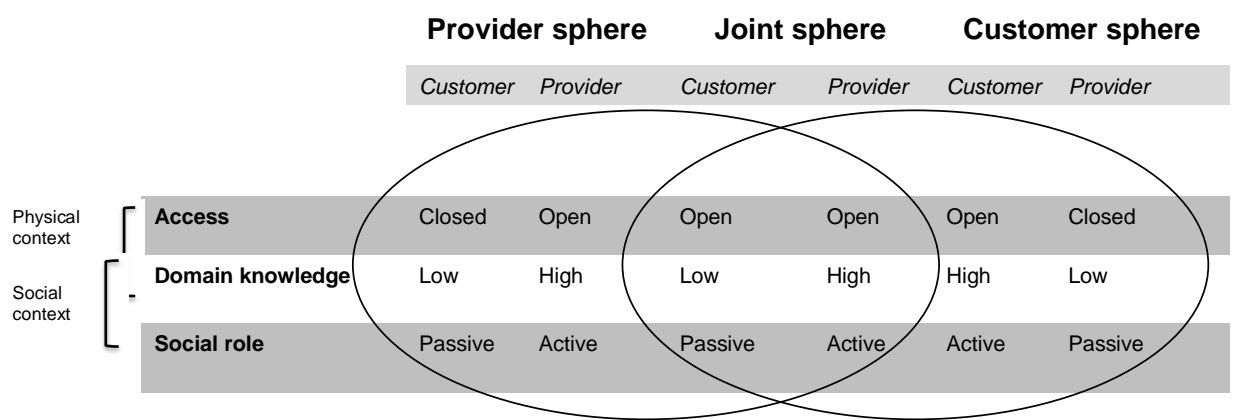

Figure 9 Physical and social contexts for health care customer creativity (adapted from Grönroos and Ravald 2011)

\subsubsection{Findings and contributions}

Paper 5 expanded on previous research by investigating what contextual factors influence creativity, and furthers the understanding of the concept of customer creativity by investigating it in a different service setting. As suggested from our proposition, the results revealed significant differences between health care customer creativity in different spheres of health care. This study changed the traditional perception of the health care customer to one that sees the customer as a source of creativity and innovation.

We found that customers were influenced by the physical and social context when generating ideas for improvement. Depending on the sphere of health care (provider, joint sphere, or customer sphere) customer creativity differed with regards to the dimensions of originality, user value, and clinical value. This suggests not only that physical and social contexts affect creativity, but also that different dimensions of customer creativity are influenced differently depending on physical and social contexts. For example, certain contextual factors have a larger influence on originality, while others have a larger influence on user value. 


\section{Discussion}

This section explains and discusses the RQs guiding this thesis, and presents a conceptual model for health care customer creativity. Specifically, in this chapter I discuss how to characterize the role of customers and customer creativity in a health care context, as well as considering various influencers of health care customer creativity. Building on this discussion, an integrated conceptual framework for health care customer creativity is presented. The proposed model is derived from theories of creativity (as presented in Chapter 2) and further refined by the results of this thesis. The model is illustrated, and empirical support for this framework in the health care literature, as well in the appended papers, is discussed. Finally, I outline the potential for health care customers to enable service innovation.

\subsection{The role of the health care customer}

Early conceptualizations of the customer in traditional medicine had a clear focus on the disease, and not the person. In this sense, the purpose of health care services was to detect deviations from the normal and "cure" the customer. This view emphasized the role of health care professionals and their knowledge and skills to determine the patient's medical condition, medical tests required and treatments to be administered (Emanuel and Emanuel, 1992). To a large extent, the customer in traditional medicine has been viewed as a passive recipient of care, and has been regarded as a subject that doctors can observe, and on whom they can operate and practice their medicine. In essence, patients have been required to show up to medical consultations, cooperate with the doctors (answer questions), and follow instructions for treatment. This role was developed in an era when acute infectious diseases and injuries were dominant and the progression of a disease generally ran its course in a short period of time (Wagner et al. 2005). This view of the customer role works rather well in isolated encounters when there is a simple cure, such as treating an infection or performing a standard surgical procedure. However, as health care changed from not only curing infectious or acute diseases but also to preventing and managing chronic diseases, it has become increasingly important to acknowledge a more active role of health care customers. This shift, together with other health care sector challenges, such as an aging population, rapidly increasing cost, calls for changes in the conceptual and practical role of the customer in health care.

The potentials and benefits of a more active health care customer role have been increasingly acknowledged in various domains of health care (McColl-Kennedy et al. 2012; Anderson and Funnell 2010; Courtney et al. 1996). In line with the discussions in Papers 1 and 3, the role of the health care customer has been portrayed and conceptualized in a number of ways. The results and findings from these reviews reveal that there has been a reorientation in the conceptualization of the role of the health care customer, from the health care professional setting rules and delivering treatment and the customer merely complying with orders, to 
the customer actively contributing and co-creating value with service providers and other actors in their service network. During recent decades, health care researchers have been developing a variety of practice approaches to promote a more active health care customer across a range of diseases. Methods, tools, and techniques for involving health care customers in practice, as well as theoretical approaches, have been developed. The findings of Paper 3 suggest that such a change in the role implies a change of both health care customers and health care professionals. From a distinct separation between service providers and customers, where the health care provider sets the rules and delivers the treatment, and the patients comply with orders, to customers who actively contribute and co-create value with the service provider and other actors in the network. When health care services are no longer considered merely a transaction between the professional and the individual patient, but rather collaboration between actors (such as family, friends, health information sites, and online health communities), the roles, traditional tasks, and responsibilities of customers and professionals have to change accordingly.

A challenge and a central question in this change is how to prepare and meet this changing role, especially since variation in the behavior of health care customers will increase at both the individual level and for different types of health services. As suggested by research from various illness contexts (Klein and Lippa 2008; Krisjanous and Maude 2015; Bélanger, Rodríguez, and Groleau 2011; McColl-Kennedy et al. 2012) and supported by the result from Papers 3 and 4, type of illness has an impact on the customer role. Results from Paper 4 indicate that the customer role and conditions for creativity differ depending on type of health care service. In the treatment of episodic illnesses (such as hip surgery) customers are subject to a standardized care process where the service provider, to a large extent, defines the process and the duration is limited in time and scope. Customers experience the health problems only temporarily, and their understanding of the illness and treatment procedures is often limited and fragmented. In contrast, when dealing with ongoing and chronic illnesses, customers are often experts in their own disease or conditions and have a more active role and greater influence on their care (Bodenheimer et al. 2002; McColl-Kennedy et al. 2012; Spanjol et al. 2015).

Understanding what processes, tools, and practices are useful in defining, motivating, and managing health care customer and employee roles is key to success with service provision in health care. Despite interest in both research and practice over the last few decades in making health care more customer-centered, models in health care remain "fundamentally the same" (Gibson, Britten, and Lynch 2012, p. 531). While it has been suggested that health care services are co-created by health care practitioners and customers who collaborate in treatment, Creer and Holroyd (2006) stated that in reality, health activities are mostly the sole responsibility of the individual customer. For example, in chronic illness, customers are "executing complex medication regimens that may include acute (as needed) and daily (maintenance) medications, lifestyle changes that often involve modifying a number of difficult-to-change behaviors (e.g. diet and exercise), monitoring symptoms, and taking different actions depending on self-monitoring results" (Creer and Holroyd 2006, p. 8). This new role, where customers are active and drivers of their own health and well-being and 
health care services are "outsourced", moves the customer into a complex participative system, putting more responsibility on the individual customer (Mifsud et al. 2015). These specific circumstances can create complications when customers have to carry out unwanted, complex tasks over long or indefinite periods of time (Spanjol et al. 2015). Therefore, shifting responsibility to the health care customer might be problematic, especially in certain types of health care service. For example, health care customers who suffer from specific combinations of illness, pain, uncertainty, and fear might not be willing or able to take an active role (Berry and Bendapudi 2007; Matthieu et al. 2015). Managing this successfully requires an ability to recognize personal, environmental, social, and knowledge-based barriers, and an ability to implement effective solutions to overcome those barriers (Hill-Briggs 2003). This requires a strong motivation from the individual customer (Lorig and Holman 2003). In addition, as findings from Papers 1 and 3 show, most research has concentrated on customer participation and involvement in interaction with health care professionals, rather than in the customer sphere. Therefore, there are still unanswered questions regarding what, and how much, customers can and should do on their own, and which parts of care should be concentrated in hospitals or other care facilities, for safety and quality reasons. Moreover, the results of the empirical studies indicate that health care customers do not view their role as active, especially in interaction with health care professionals.

\subsection{Health care customer creativity}

As stated earlier, in this thesis health care customer creativity is referred to as a practice of creating solutions, which can be incremental adaptations or completely new solutions that solve a health-related problem (Henrike and Schultz, 2014; Hirschman, 1980). Customers' creative performance in health care has included inventions that have been implemented, such as adapted furniture in the category of medical products, and training programs and engagement in coordination of improvements between involved health care professionals in order to improve health care processes (Henrike and Schultz, 2014). However, more often customer creativity in health care is displayed in the daily practices of engaging in problem solving and decision-making when identifying, preventing, or recovering from healthrelated problems (Hill-Briggs 2003; Klein and Lippa 2008). This is in line with the discussion in Paper 4. Customers in health care are not always in the position to implement their ideas and solutions. This can be due to a number of factors, such as ability and illness, but also because of a health care context over which customers have little control.

Health care practices are related to human behavior, and require that customers possess the knowledge, motivation, confidence, and skills necessary to manage their condition (Creer and Holroyd 2006; Hill-Briggs 2003). Effective problem solvers engage and adjust their behaviors in response to objective (such as results from blood tests) and subjective (symptoms) input about their situation, and are able to adapt and adjust to the imposed contextual factors, which comprise individual social and physical environments, as well as situational factors that form the context of their daily life (Hill-Briggs 2003). While 
creativity is commonly associated with the practice of problem solving (Guilford, 1967; Hirschman, 1980; Burroughs and Mick 2004), problem solving in health care is often reliant on a combination of other practices (Hill-Briggs, 2003; McColl-Kennedy et al. 2012; Klein and Lippa, 2008). This is also supported by findings in both the reviews (Papers 1 and 3) and the empirical studies (Papers 4 and 5); health care customer creativity is displayed in relation to practices when solving health-related problems.

If creative processes are believed to enhance the likelihood of achieving a creative outcome, it is critical to identify and understand the factors that influence customer creativity in a health care context. As stated in the introduction, this study takes an integrative approach that explicitly recognizes health care customer creativity as a complex interplay of factors (Burroughs, Moreau, and Mick 2008). This view implies that customer creativity takes place in practice and is influenced by various antecedent conditions, such as domain and type of service, and whatever cognitive abilities, personal traits, skills, and knowledge the individual customer brings (Burroughs, Moreau, and Mick 2008). The situation is characterized in terms of the contextual and social influences that either facilitate or constrain creativity. I also take the view that customer creativity in health care is not inert, but can be developed and reinforced (Cummings and Oldham 1997; Perry-Smith and Shalley 2003). Therefore, over time the individual can develop knowledge and experience in relation to problems and situations they experience, which enables creativity.

\subsection{Towards a framework for health care customer creativity}

In this section, I propose a conceptual framework for health care customer creativity based on integrative perspectives on customer creativity (Burroughs, Moreau, and Mick 2008; Woodman and Schoenfeldt 1990) and value co-creation practices (McColl-Kennedy et al. 2012; Moeller et al. 2013; Schau and Arnould 2009), which elaborates on relationships among creativity and customer practices as illustrated in Figure 10. As befits such a complex concept, a large number of factors potentially influence a customer's propensity to be creative. In support of this conceptual structure is the recognition that customer creativity is a function of the interplay of various individual, contextual, and situational factors (Burroughs, Moreau, and Mick 2008; Hirschman 1983) that affect the way individuals think, perform, and interact. This framework departs from the individual, contextual, and situational factors proposed in Chapter 2, and is adapted to the specific context of health care. As few studies have specifically focused on health care customer creativity, this discussion illustrates and builds on findings from various influencing factors of health care customer practices identified in Papers 1 and 3, as well as empirical findings from Papers 4 and 5 .

The following model is presented in relation to individual factors, which refer to all aspects connected to the individual health care customer, such as personality, knowledge and experience, motivation and cognitive style; contextual factors, such as aspects connected to 
different types of health care service; and situational factors, which refer to aspects of the immediate situation in which customer practices and customer creativity takes place.

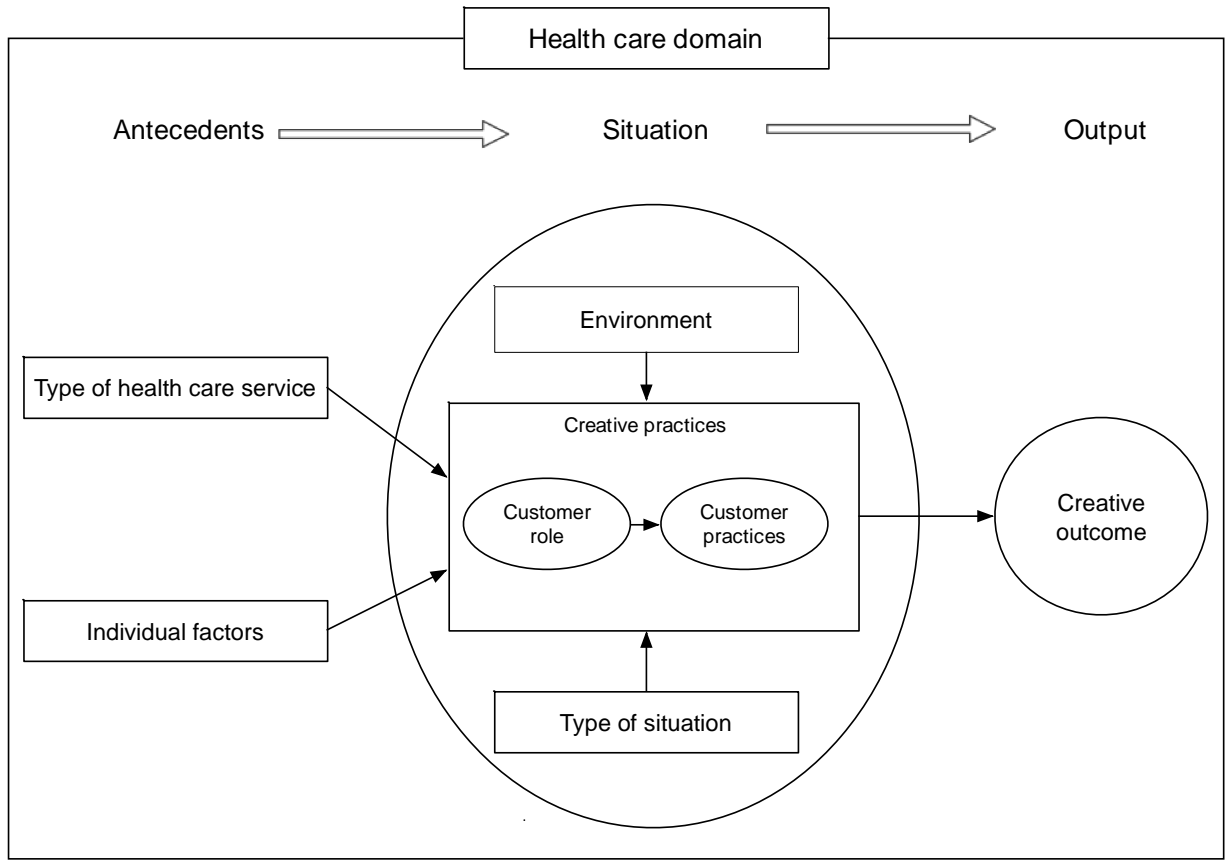

Figure 10 Conceptual framework of health care customer creativity

It should be noted that this tentative framework for health care customers is relatively general, as all of the different factors consist of underlying factors, which are interrelated and influence other factors in the same category. This model also illustrates the suggestion that customer creativity in health care is not inert, but can be developed and reinforced over time. Therefore, this model is not as linear as it is illustrated in the figure. Over time, individual factors, such as knowledge, are most likely to develop in relation to experience with the social and physical environment and situations.

\subsubsection{Individual factors}

As suggested from the framework on customer creativity, factors such as socioeconomics, personality, cognitive style, knowledge, and motivation were suggested as potential influencers. In this discussion, I compare these previously identified factors (from Chapter 2) with findings from a health care context. From Papers 1 and 3, a number of factors connected to the individual were identified as influencing health care practices.

\section{Personality}

Several studies across different illness contexts have suggested that demographic factors such as gender, age, level of education, and socioeconomic status influence the individual health care customer's engagement in health care practices, as well as their ability and 
willingness to manage their illness and participate in medical decision-making (McKinstry 2000; Murray et al. 2007; Schneider et al. 2006; Singh et al. 2010).

While there has been limited attention in health care research to how personality influences creativity, a number of studies have focused on how personal traits influence health-related behaviors and practices. For example, several studies have found the personality dimension of conscientiousness to be associated with health-related behaviors (Skinner et al. 2014; Bogg and Roberts 2004; Caspi et al. 1997). Conscientiousness refers to the individual's tendency to follow socially prescribed norms for impulse control, to be task- and goaldirected, to plan ahead, to delay gratification, and to follow norms and rules (Bogg and Roberts 2004). These studies suggest that individuals with low levels of conscientiousness will be more likely to engage in negative health behaviors. While it has been suggested that risk-taking is positively related to creativity (Amabile, 1988; Burroughs and Mick 2004), in relation to health care practices, risk-taking has been strongly connected to negative health behaviors. Other studies have found positive links between intelligence and level of education with successful health-related problem solving (e.g., Adams et al. 1998), and between emotional intelligence and adherence to treatment (e.g., Snell and White 2011).

In research that has investigated the role of personal traits on health-related outcomes, these relationships have often been seen not as direct, but as moderated by other factors, such as age, cognitive ability, and mediation by behaviors and practices (Bogg and Roberts 2004). For example, Caspi et al. (1997) proposed that certain personality traits, such as risk-seeking, were related to negative health behaviors that affected the person's overall health situation.

\section{Knowledge and experience}

Hill-Briggs (2003) stated that in order to engage effectively in health-related problem solving, an individual must have appropriate knowledge and experience from which to draw appropriate information about the problem at hand, and possible strategies. In a similar vein, Henrike and Schultz (2014) argued that customers who are knowledgeable about their own diseases can provide potentially valuable creative contributions. In general, the knowledge of customers in health care is idiosyncratic and based on the combination of personal experiences, interpretation of scientific evidence (such as that acquired through the mass media or internet), and "common sense" understandings of health and illness (Street et al. 2009). Similar to the general suggestion that customer creativity is positively influenced by knowledge and experience (Amabile 1988; Burroughs and Mick 2004), this was also an important factor found to influence individual health care practices.

There are several explanations as to why knowledge influences health care customer creativity. To be able to participate actively in medial decision-making and medical consultations, customers must have knowledge of their illness, and the risks and benefits of various treatment options. Several studies have identified knowledge as an important factor influencing the level of participation in decision making (Makoul and Clayman 2006; Joseph-Williams, Elwyn, and Edwards 2014). Outside the health care setting, knowledge and experience has been identified as important to manage illnesses and be confidant in 
performing self-care (Barlow et al. 2002; Gagliardi et al. 2008). Experience and knowledge imply greater contextual awareness of the health care customer, enabling them to be better able to detect health-related problems (Hill-Briggs 2003). For example, in a study of minor illnesses, knowledge and experience of the illness were positively associated with selftreatment and engaging in self-medication (Gustafsson et al. 2015).

Thus, knowledge and experience can influence health care customer creativity both in interactions with health care practitioners, but also outside the health care sphere. Knowledge in this sense can facilitate individual participation, and in consultations can increase the customer's ability to engage and cope with their illness (Street et al. 2009). It can also influence the types of practices the customer can use, and thus affect the degree of value and originality of the solution.

\section{Cognitive processes}

Cognitive style and capacity have been suggested as a important influencers of customer creativity (Hirschman 1980; Dahl and Moreau 2002). Similar examples have also been found in the health care literature. Klein and Lippa (2008) considered disease-related decision-making as a set of macro-cognitive functions comprising of mental activities to achieve decision goals, including problem detection (where the patient identifies anomalies and difficulties in available information) and situation assessment (where the patient identifies causes and potential remedies). This cognitive process is carried out through collecting, verifying, and assembling information and assessing how the collected information maps potential explanations.

Another important factor identified from the health care literature is the ability to transfer past experience in an appropriate manner to organize problem solving when confronted with a new problem or situation (Hill-Briggs 2003). By combining and transferring knowledge and experience, the customer is provided with essential elements to mentally represent the situational context and identify a solution to the problem. This is closely related to analogical thinking, which is generally suggested to reinforce creativity (Dahl and Moreau 2002).

These cognitive aspects are closely related to other research within health care that has focused on individual skills in coping with illness. Self-efficacy has been commonly addressed as a factor that influences the individual's engagement with medical treatment (e.g., Williams and Manias 2014; Corless et al. 2012; Snell and White 2011; Cameron et al. 2010; Boyne et al. 2014). Self-efficacy refers to an individual's capacity to execute behaviors necessary to the specific situation (Bandura 1977). Walker et al. (2014) found that higher levels of self-efficacy among diabetes patients were associated with better self-care, overall health outcomes, and quality of life. Similarly, Walker et al. (2014) found that higher levels of self-efficacy were associated with better self-care, health outcomes, and quality of life. 
Closely related to this, locus of control has been identified as a factor influencing illness management and problem solving (Bulsara, Ward, and Joske 2004; Kidd et al. 2009; Schneider et al. 2006; McColl-Kennedy et al. 2012). Kidd et al. (2009) found that patients with low perceived control were worried about "getting something wrong", and doubted the efficacy of their self-care efforts. These individuals tended to rely on the service provider, and did not want to perform self-care behaviors themselves. In contrast, Ross (1991) found that the degree to which diabetes patients perceived themselves as having a sense of control and viewing stressful events as challenges, rather than threats, was related to successfully managing their illness. This was also supported by Williams and Manias (2014), who found that patients who perceived themselves as being in control and curious about their health were more engaged in medical decision making.

In line with this discussion, it can be proposed that the individual health care customer's cognitive ability of coping with illnesses will enable or empower them, and thus facilitate creativity. In addition, the customer's cognitive capacity (transfer of information, associative thinking) will influence the practices used to create solutions, and also the degree of creativity of these solutions.

\section{Motivation}

Other studies have brought up the individual's self-regulatory ability as an important factor that influences health behaviors (Boulos et al. 2014; Kalichman et al. 2011; Fineberg 2013). This implies that for an individual to manage their illness, he or she must have the ability to resist temptation of smaller but more immediate rewards in order to receive a larger or more enduring reward later. In health-related activities, the success and reward of preventing and managing illness is often invisible or long delayed, and requires persistent behavioral changes (Fineberg 2013). These health-related changes in behavior to fit the current health situation might not immediately lead to positive effects for the individual, or can in some cases even imply a temporary decrease in well-being. An example of this was illustrated by Williams and Manias (2014), who found that patients were more likely to miss taking medications that were not seen as essential to their immediate well-being.

As stated earlier, some activities are performed in order to reach an outcome that is separate from the activity, while others are performed for the inherent satisfaction of the activity itself (Ryan and Deci 2000). Health care services are something that customers generally do not want; therefore, health-related activities are not something that people approach willingly. Rather they are something considered an obligation or responsibility (MacGregor and Wathen 2014). This is an interesting paradox in health care, and is well recognized as a motivational barrier to engage in health care activities (Fineberg 2013). Even if customers can understand the value of such activities, the motivation is often external rather than internal. Few people engage in health care activities just for the joy the activity itself brings to them. Therefore, it can be argued that most health-related activities are motivated by external, rather than internal, factors. External motivation has often been considered a barrier to creativity (Burroughs, Moreau, and Mick 2008; Amabile 1988). However, it has also been 
found that the degree to which the individual customer complies with and manages their illness is related to their mental view of how severe their situation is (Alogna 1980). This is supported by Seiders et al. (2015), who found that focusing on negative consequences during medical consultations increased customer compliance with treatment. Therefore, even if the motivation is not internal, the customer's perception of how severe their situation is, in combination with direct consequences, is likely to have a positive impact on their motivation.

In line with this discussion, it can be proposed that the individual health care customer's self-regulation ability and type of motivation will influence their health-related practices and degree of effort put forth to create solutions to problems they experience, as well the persistence of these efforts over time.

\subsubsection{Type of health care service}

As suggested from the general framework for customer creativity presented in Chapter 2, individual factors must always be understood in relation to the specific context. In this section, I elaborate further on the specific characteristics of different types of health care services. This discussion builds on previous research identified in Papers 1 and 3, as well as the empirical findings in Papers 4 and 5.

While creativity is influenced by the overall domain, it is also subject to the characteristics of the connected sub-domains (Baer 2014), which is supported by results from the empirical studies, as well as the reviews. As suggested by research on health care practices from various illness contexts (Klein and Lippa 2008; Krisjanous and Maude 2015; Bélanger, Rodríguez, and Groleau 2011; McColl-Kennedy et al. 2012), and supported by the findings in Papers 4 and 5, this thesis suggests that different types of health care services imply different conditions for customer creativity. It is not likely that diabetes services, acute services, or cancer services influence the customer in the same way. Simply explained, it is not likely that the health-related situations, problems, and necessary adaptations connected to pregnancy are the same as for asthma. Of course, these aspects vary on an individual level and also depend on how the individual experiences them; however, there are some inherent specifics connected to different illnesses and related health care services. This was supported by the results of Paper 4, where customers contributed in different ways depending on level of complexity and environment.

Different health problems and related health services differ with regards to their complexity, duration, and course of action, severity, and perceived symptoms (Shostack 1987; Bohmer 2009). With regards to previous suggestions, the following characteristics of health care services can be proposed as important to consider.

Level of complexity. While all health care services can be seen as complex, the degree of complexity varies (Shostack 1987). As illustrated in Paper 4, in low-complexity health care services, course of action is familiar, carried out in similar ways for every customer, usually has a typical start and end, and follows known procedures. Most of the actions and practices 
in these services take place in the interaction between the customer and service provider. High-complexity health care services can be described as processes, wherein the steps and sequences can be unknown in the beginning or later on, both for the customer and the service provider (Shostack 1987).

Duration. As discussed in Paper 4, Different illnesses or health care services are connected to different durations; while some are chronic or long-term (such as diabetes, hypertension, arthritis, or some types of cancer) others are short-term (such as a broken arm or minor infection) (Bohmer 2009). In addition, while some are typically only experienced once (such as removing the appendix), others can be reoccurring (such as ear infections or having the flu).

Severity. While not tested in the empirical studies in this paper, independent of complexity and duration, different types of health problems are also connected to different severities or risks (Medsger et al. 2003). Some long-term illnesses might be severe, with a large influence on the physical state and on customer well-being (such as multiple sclerosis, Parkinson's, or cancer) while others might be less severe and only influence the customer's life from time to time (such as mild allergies or asthma). This is also the case for illnesses with a shorter duration; while some are severe and painful (acute care), others are less severe (for example, an ear infection). Related to this, different types of illnesses are connected to different types of emotions and affective states of customers. While most illnesses can affect all types of emotions, some illnesses or services are more strongly connected to negative emotions and affect (such as cancer services), while others can be connected to happiness (such as childbirth), satisfaction (plastic surgery), or feelings of relief (getting a hip replacement).

Role of the health care customer. As discussed in paper 3 and paper 5, different types of health care services inherently require various degrees of participation, knowledge, activities, and interactions of customers (Bitner et al. 1997; McColl-Kennedy et al. 2012). In addition, the required role is likely to influence the customer's motivation and situational engagement.

Environment. As discussed in Paper 4 and 5, different types of health care services and stages in the processes are connected to different physical and social environments. For example, surgery takes place within the health care setting (hospital), but the recovery from the surgery often takes place in the customer's home environment. For diabetes treatment, almost all treatments and medical activities take place outside the health care setting (Cottam and Leadbeater 2004).

\subsubsection{Situational influencers}

While personal factors and contextual factors connected to the overall domain and type of health service are important influencers of creativity, the creativity of individual health care customers is also determined by the specific situation in which the problem occurs. More precisely, creativity takes place in a physical and social environment, which allows for 
different cognitive processes, behaviors, emotions, and customer roles (Kristensen 2004). In addition, creativity is influenced by the characteristics of the problem that needs to be solved. These suggestions are based on factors identified in Papers 1 and 3, and on findings from the empirical studies (Paper 4 and 5).

\section{Environmental influencers}

Several studies have suggested that elements connected to the specific environment influence health care customer practices (e.g., De Greef et al. 2011; Varekamp, Verbeek, and van Dijk 2006; Seiders et al. 2015). For example, De Greef et al. (2011) found that physical environment features such as walkability, training equipment, and environmental aesthetics influence physical activity among persons with diabetes. Others have found that aspects of communication between health care practitioners and health care customers influence customer practices (Seiders et al. 2015; Street et al. 2009; Dubé, O’Donnell, and Novack 2000; Moldovan-Johnson et al. 2014). Tansik and Routhieaux (1999) found that music in hospital waiting rooms impacts customer stress levels.

Results from Papers 4 and 5 indicate that physical and social environments connected to the situation influence customer creativity. The results suggested that where the idea was generated had an influence on both the characteristic of the idea as well as the perceived creativity of the idea. This builds on the suggestion in theory that different environments entail different social and physical conditions and requirements (Kristensen 2004; PerrySmith and Shalley 2003). In terms of interaction among health care professionals, it can be argued that in many cases, both the physical and social contexts are highly standardized, allowing for little variation. For the most part, the customer is passive, must follow the routines and standard practices, has little domain knowledge, and is dependent on the service provider.

In contrast to other services, the customer in this setting adopts a "sick role" (Parsons 1951), a situation that leaves the customer vulnerable and dependent on the actions of the health care provider. The customer is then "in need of help", and the health care professionals are there to "cure" or support the customer. In this case, the customer has little ability to modify, adapt, or transform the service to better suit them. This suggestion was supported by findings from Paper 5, where a majority of ideas generated in the health care setting focused on the action of the service provider, such as how health professionals could improve attitude, communication, and routines. In addition, this suggestion was partly supported by the results of Paper 4, where health care customers, even if they could identify problems and solutions, had problems with implementing the solution themselves. In line with previous findings (Forbat et al. 2009), these results suggest that customers do not perceive their role as being active in the health care setting; therefore, they do not generate ideas that include an active customer role or one engaged in problem solving. However, while interaction with health care professionals and the physical environment of the health care setting can strain customer creativity, it can also influence creativity in a positive direction. A number of studies have shown that communication and interaction with health care practitioners can stimulate health care customers' self-efficacy, support them in coping with their illness, and 
empower them to take action (e.g., Street et al. 2009; Boxer and Snyder 2009; Mead and Bower 2000). This is consistent with general theory on creativity that emotional support, a non-judgmental attitude, and positive interaction facilitates creativity (Amabile et al. 1996; Runco 2007).

The characteristics of the customer sphere vary depending on the overall situation of the individual and social and physical recourses. The service providers may have some influence over what the customer does (such as suggest treatments or give instructions), but have limited control over how the customer does it. In Paper 5, we found that ideas generated in the customer sphere were perceived as more original. A tentative explanation for this is that in general, this environment requires that customers themselves solve problems, tackle new situations, manage their illness, and integrate their individual recourses. This implies that the customers are more or less required to be more creative and take responsibility for their own situation. However, as suggested in previous literature, this is most likely also influenced by social support (from friends, family, and other customers) and physical resources possessed by the individual (McColl-Kennedy et al. 2012; Black and Gallan 2015). This was supported by findings in Paper 5, which showed that almost all ideas generated in the customer sphere required the customer to be active in realization of the idea, or alternatively that the goal of the idea enabled the customer to be more active in solving problems related to their daily lives. In addition, the results of Paper 4 showed that customer ideas that aimed for the customer sphere where focused on practical strategies for managing everyday life.

In line with suggestions in this discussion, it can be proposed that factors concerning the physical and social environment problem will enhance or restrain individual factors, and thus have an influence on how the customer reacts and solves problems, and eventually the degree of creativity in their solutions. However, while the physical and social environments most likely have an affect on creativity, different individuals are likely to react differently depending on individual factors. While some might require high amounts of social support to solve the current problem, others may be more creative when they are forced to tackle the problem themselves. In addition, while some are more creative when provided with more information, others are more creative when they need to seek out information themselves. This is likely to be influenced by personal factors (experience, knowledge, personality, motivation) and the type of service (complexity, duration, severity), as well as the perceived role in relation to the environment (passive, active).

\section{Type of situation}

Although not tested in the empirical studies in this thesis, in addition to the social and physical environment, there are other situational influencers to consider depending on the characteristics of the situation and the problem that needs to be solved. This is connected to aspects such as time pressure, emotions, and degree of involvement. Emotions and affective states have commonly been addressed as influencers of health care customer practices (Diener, Oishi, and Lucas 2003; Grindley, Zizzi, and Nasypany 2008; Botti, Orfali, and 
Iyengar 2009; Gallan et al. 2013; Tansik and Routhieaux 1999). Health care customers are often in anxiety-producing situations, facing significant uncertainty and risk. Gallan et al. (2013) posited affect as a motivator of behavior. This service and situational context may lead to conditions in which customer practices are inhibited rather than enabled (Hibbard 2009). Thus, health-related situations might provoke a number of negative emotions (anger, sadness, fear, worry) that can threaten emotional well-being and even physical health. In Papers 4 and 5, health care customers showed that situational involvement is an important factor connected to the health care domain. While some customers described a significant amount of involvement, this was connected to problems that have accrued due to their illness, and not because of some internal drive for solving health-related problems in general. However, it is important to note that this does not lead to the conclusion that internal motivation is not prevalent in health care customers. For example, in some sub-areas of health care such motivation is likely to be found.

While emotions and involvement are dependent on the situation, different situational influences will affect the individual health care customer differently, and they will react with different emotions depending on individual factors (for example, amount of knowledge and experience of similar situations, cognitive style, or personality). Thus, in line with suggestions in this discussion, it can be proposed that emotions, affective states, and type of task in relation to the situation in which the problems occur will enhance or constrain individual factors, and thus influence how the customer reacts and solves problems, thereby also affecting the degree of creativity in the solution. As suggested above, the influence of environmental and situational factors must be understood in relation the individual health care customer. Different situational influences and environments affect individuals differently. It is also expected that the effect of situational factors will vary over time, even for the same person. Therefore, it is important to consider the interaction between the individual health care customer and the specific environment and context in which creativity takes place.

\subsubsection{Creative practices}

As customer creativity by definition takes place in consumption - that is, in the practice of customers using and/or adapting the product or service (Hirschman 1980) - it is essential to understand these practices in their specific contexts. Sweeney, Danaher, and McCollKennedy (2015) suggested that health care customer practices require different efforts, as well as different degrees, of knowledge, skills, resources, and social support. Depending on the complexity of the problem, different factors and degrees of these factors will be needed in order to solve it; these can be connected to the individual, but also to external resources from, for example, the health care service provider and private recourses. This is in line with creativity theory, which suggests that high levels of creativity require extensive knowledge, advanced cognitive processes, and motivation (Burroughs, Moreau, and Mick 2008). What type of practices and the degree of creativity in these practices is also influences by the customer role, that can be viewed as a specific set of practices that connects one actor to one or more other actors (Akaka and Chandler 2011). As a role is composed of a set of learned 
behaviors associated with the specific role, the role of the customer influences customer practices and, ultimately, their creativity.

In both the literature studies and the empirical studies, a number of health-related practices were identified as concerning different aspects of health care within and outside the service setting. While the overall practice connected to creativity can thus be suggested to be that of problem solving, this practice requires the individual to perform a number of related activities that include cognition, actions, and interactions. Papers 1 and 3 revealed customer practices, such as answering and asking questions, sharing information, engaging in communication and connecting with health care practitioners, taking control, making decisions, solving problems, changing lifestyle, mobilizing resources, managing and taking medicines, collecting information, employing cognitive activities (such as positive thinking), combining therapies, redesigning treatment program, or reconfiguring the composition of the medical team.

These practices were also found in the empirical findings in Papers 4 and 5, where health care customers described themselves as engaging in various health-related activities and interactions in order to handle daily life and solve health-related problems. Often, different practices were combined to solve a specific health-related problem; some examples of this are displayed in Table 6. 
Table 6 Illustrations of health care customer practices

Customer practices

"Have to change the way I'm thinking ... If my son is in pre-school [for] a few hours he will play and have fun and when I pick him up I have more energy."

"But I've also learned a few things, to be more grateful for the small things and enjoy the moments when $[I]$ feel pretty good. “

"I don't think you should reject alternative medicine. Healing and meditation is something I have been working hard with since the beginning. People need to know their own responsibility in their disease. It's important to work with both body and soul. "

"When you read on the Internet, you get partially conflicting answers. Me quitting smoking [...] preceded both the present and first outbreak in 2004. The doctor and a nurse at the gastro clinic however, did not jump on my bait by asking additional questions. Therefore, I'm still in limbo about the effects of smoking."

"Maybe you should get some extra element of treatment if necessary, such as ultrasound, acupuncture, massage, etc. Much of what we do in rehab is long term. But you are often disturbed by more emergent symptoms that get in the way of your long-term goals."

"Terrible pain in the morning, had to ask the neighbor to take the dog out."

"Made a nice dinner together with my husband. Was even motivated to pick herbs in the garden. My mood gets better by spending time with my family."

"The decline continued so I took Prednisolone before midsummer instead of starting on Colifoam. As the previous times in 2004 and 2005, it was effective immediately. The blood flow almost stopped during the night. I guess, as an amateur, Colifoam has a significantly lower concentration of cortisone than my other medicines.

"Would need stronger medicine, but if I do, it's hard to manage everyday life. I'm not a good mother if I'm completely out of it. Then I would rather be tired and in more pain than to not pay attention to my two-year-old. I always think it will get better, and if it becomes worse I've taken care of most things today."

\subsubsection{Creative outcome}

As suggested from this framework, the extent of creativity will depend on the nature of the problem, the capability of the individual, and the surrounding context and situation. While customers can engage in creative practices, the degree of creativity must be judged by parties other than the originator (Amabile et al. 1996). Amabile (1983) suggested that creative outcomes should be assessed based on their novelty and value in the given context, and that an idea is creative to the extent that appropriate observers independently agree it is creative. This argument is based on the assumption that creativity is something that can be identified, judged, and agreed upon (Amabile, 1983). However, often, as in the case of customer creativity, the creativity is invisible to those other than the individual who engages in it. Although creativity may lead to an outcome, it may not. Therefore, to evaluate customer creativity, there must be some outcome.

In Paper 5, three dimensions were used to evaluate health care customer creativity based on customer ideas for service innovation. We used the dimensions of originality, user value, and clinical value. While the first two dimensions are commonly used in other literature (e.g., Magnusson et al. 2003; Witell et al. 2011), the third dimension is specific to health care services. This dimension refers specifically to the estimated value of the customer's 
health and recovery status. In Paper 5, we used a panel of health care professionals to evaluate customer creativity.

Moreover, this study evaluated the customer's creative performances from the perspective of health care professionals. Even though this approach is well grounded in theory for assessing creativity (Amabile et al. 1996) and in a number of empirical studies (e.g., Kristensson et al. 2002; Witell et al. 2011), the objectivity and accuracy of health care professionals' evaluations can still be questioned. In addition, professionals might not be able to estimate the value and originality of ideas regarding the customer sphere due to lack of knowledge Therefore, when assessing health care customer creativity, it could be beneficial to use other expert groups, such as other health care customers or other types of health care professionals.

\subsection{Health care customer as enablers for service innovation}

To address the challenges facing health care services, this thesis propose the inclusion of health care customers. Recent theory on service innovation has tended to favor a customercentric approach when developing new offerings (Witell, Gustafsson, and Johnson 2014; Alam and Perry 2002). However, customers have always been a source of insight and inspiration in business, and understanding customer creativity has the potential to be a strategic resource able to drive service innovation. To enable innovation, service providers must go beyond customers' current needs and develop methods that tap into needs for the future.

In other areas, creative customers have been suggested as being drivers of innovation, and in some contexts even at the forefront of new product and service development (von Hippel 2005). A challenge for health care service providers is recognizing that creative customers exist, identifying their action, and understanding how to capture and create value from them (Berthon et al. 2007). While the purpose of this thesis has not been to cover how to successfully use customer creativity to create service innovation, or to analyze the whole process from individual creativity all the way to a successful invention that is used and considered as an innovation, the findings can still be considered important to the area of service innovation.

Findings from Paper 2 revealed that customers and customer value have been neglected in research on service innovation. Instead, when defining service innovation, an internal focus is often used, which views service innovation as simply a "new service" and ignores the perceived customer value. While the review concluded that research on service innovation often does not separate between the process of innovation and the outcome of innovation, in this thesis I take the view that service innovation is not a root activity in and of itself. Instead, service innovation can be considered a result of creative performances achieved by individuals, groups, organizations, or markets that create value for some actor in a specific context. As stated earlier, this value may be monetary, but may also be value-in-use. This 
view implies that creativity is essential for innovation and is an integral part of service development (Zeng, Proctor, and Salvendy 2009).

In this thesis, I have argued that customer creativity is a useful concept for understanding customer practices and how health care customers can enable service innovation. This research proposed that health care customers could be a rich source of innovation. This is in line with emerging theories of service innovation that have suggested that customers must be active in the development of service offerings in order to optimize value co-creation (Grönroos 2008; Hoyer et al. 2010). Results from this thesis show that despite the negative nature of the service, health care customers are creative. Supported by previous research (Henrike and Schultz 2014; Engström and Elg 2015), the findings of this thesis show that health care customers are interested in and can contribute to service innovation. As health care outcomes in general are highly dependent on activities of the customer (Bitner et al. 1997), this view implies that to provide efficient care, customers should play a key role in planning and designing, as well as implementing, testing, and evaluating solutions (Cottam and Leadbeater 2004). The specific characteristics of health care customers and health care services make an interesting context for research on how customer creativity influences service innovation. Health care customers have unique knowledge of their own health care problems and treatments; therefore, they have unique information and experiences about how service provision can support them in their everyday lives. Thus, creative health care customers have the potential to contribute to innovation in a wide range of areas, such as medical devices, social support, information technology, and clinical processes. Many health-related and value-creation practices take place outside the patient-provider sphere, and are unknown to the health care provider (Grönroos and Ravald, 2011). By actively involving patients, health care providers can apply a whole-person perspective. Despite this potential, as shown in Paper 1, studies regarding customer involvement or activation have focused mainly on involvement in decision-making regarding treatment. Some studies have examined participation in the delivery of health care services, but only a few studies have addressed customer involvement in the development of health care. More often, the process of involving patients has concentrated on isolated encounters, such as medical consultations or a specific decision regarding treatment (Thompson 2007).

It should be noted that while involving customers in development is often a formal process that is initiated and controlled by the firm, creative customers act independently of the service provider (Berthon et al. 2007). Therefore, customer creativity is often unknown to the service provider, making it important to consider customer creativity in the customer sphere. The findings of this thesis show that context is an important influencer of customer creativity. In the empirical studies, customers provided ideas that stemmed from their experiences with health care and their daily lives. The ideas concerned a wide range of aspects of care and aimed to change both health care and their own behaviors. In many cases, ideas concerned how health care could support the customer to be more active. However, as shown in Paper 5, although customers in fact provided ideas for service innovations in all spheres of health care, the results indicate that customers differ in their ability to provide 
ideas with high originality, user value, and clinical value depending on the physical and social contexts. 


\section{Conclusion, contributions and further research}

The purpose of this thesis was to conceptualize and investigate the concept of customer creativity in health care to enhance understanding of how customer creativity can be used to enable service innovation and health care practice. Since each appended article communicated with a specific area of academic research that might be outside the scope of health care customer creativity, they each also make separate contributions to other areas of research. In this last section, I present the overall conclusions, and theoretical and managerial contributions, and point out directions for further research.

\subsection{Conclusion}

Customer creativity represents an important aspect and perspective of service innovation. Pursuing health care customer creativity in the development of new offerings can be a means of achieving service innovation that takes the customer perspective and customer creativity into account. Considerable potential exists for an enriched conceptualization of the customer's role in health care, and health care customer creativity. The results of this thesis indicate that customer creativity in health care is not an isolated activity, but takes place in practice and is influenced by a number of contextual and situational factors. This extends the view of the role of customers from just passive recipients to active contributors, and creators of value, with service providers and other actors. By developing an integrative conceptual framework for health care customer creativity based on an extensive synthesis of the current research from different disciplines, this thesis offers confirmation of existing suggestions of creativity and theory and provides new insights on how customer creativity can be interpreted and explained in health care.

Health care is a particularly interesting setting for exploring customer creativity, for several reasons. First, it is highly reliant on the customer's engagement and problem solving. Second, health care activities and practices happen both in the specific service environment and in everyday life, which makes them fit for investigating how different social and physical environments influence customer creativity. Third, health care is a negative service, which is necessary yet often unwanted and/or stressful for customers. To date, research has largely ignored contextual factors influencing customer creativity. This present study in part addresses this gap by investigating whether customer creativity is influenced by physical and social contexts in a health care setting. The results of this thesis indicate that the role of the health care customer and the customer's creative capacity may differ not only depending on individual factors, but also on the nature of illness and type of health care service. For example, customer creativity in oncology services will differ from customer creativity in orthopedic surgery. While one type of health care service might involve long-term treatment with chemotherapy, and be harmful to the person's general health, other diagnoses might be 
treated and cured through a simple surgical procedure. This implies that individual customer experiences, contexts, and types of illness play an important role in explaining creativity. As context is important for creativity, this thesis also has implications for involving health care customers in service innovation. While customers can be a valuable recourse to drive service innovation, type of health care service and individual factors should be considered when deciding on methods and designs for involving them.

Specifically, the results of this thesis suggest that customer creativity is highly relevant in the customer sphere, where the customer engages in everyday practices to solve healthrelated problems. This sphere is usually closed to the service provider, often rendering creativity invisible. Therefore, great potential lies in tapping this potential resource of creative solutions to everyday health problems to enhance the overall quality and experience of health care services. Instead of only focusing on service innovations within the actual service setting, it can be beneficial to focus on understanding the actions and creative practices and problem solving of customers in the customer sphere. After all, that is where the majority of all health-related activities take place.

\subsection{Theoretical contributions}

This thesis contributes to the services marketing and service innovation literature, and especially to the emerging stream of research that has suggested that customers are an important resources in service innovation (Witell et al. 2011; Kristensson, Magnusson, and Matthing 2002), or even drivers of innovation (von Hippel 2005; Berthon et al. 2007). In addition, this research contributes to studies within health care, evoking a more active customer role within both delivery and development (Henrike and Schultz 2014; Bodenheimer, Wagner, and Grumbach 2002; Elg et al. 2012). In the following, four main theoretical contributions are presented.

First, taking a systematic and rigorous review approach creates a firm foundation for advancing knowledge and facilitating theory development (Webster and Watson 2002). This thesis reviewed and summarized an extensive number of academic studies on the topic of customer involvement in health care, service innovation, and health care customer roles. As such, one important contribution of this thesis lies in the synthesized knowledge and implications found in these reviewed studies. Traditionally, customers in health care have been viewed as having a relatively passive role, reduced to a recipient of what an organization does for them (Berry and Bendapudi 2007). This thesis contributes to the growing stream of research by challenging this view, and suggests that health care customers can have a much more active role in both delivery and development of health care. This thesis adds to the literature by synthesizing findings from health care research with those in service research, and identifies how the role of the health care customer is changing across disciplines. It also provides an overview of current customer involvement practices in health care delivery, as well as related practices affecting health care customers and professionals. In addition, this thesis highlights the effects, and lack of effects, of the changing customer 
role as investigated in research.

Second, while numerous streams of literature within health care have promoted a more active customer role (e.g., Mead and Bower 2000; Forbat et al. 2009), few have considered the role of creativity among health care customers. Research on service innovation in health care previously focused on organizational and process innovation, or on aspects such as how to implement new practices within a health care organization (e.g., Kimberly and Evanisko 1981; West and Wallace 1991). Although some studies have addressed the role of the health care customer in health care development and service innovation (Elg et al. 2011; Henrike and Schultz 2014), this thesis extends this by contributing to the overall understanding and influences of customer creativity, suggesting that customers can be an active resource in service innovation. The empirical studies in this thesis extend previous research on customer creativity by investigating contextual factors influencing creativity during consumption. In previous research, it has been demonstrated that customers are valuable and creative resources for innovation (Alam 2006; Gustafsson et al. 2012) and provide creative ideas (Witell et al. 2011; Magnusson, Matthing, and Kristensson 2003). First, these studies have foremost been undertaken in experimental settings and not in consumption contexts, where most customer creativity takes place. Second, while these studies have concluded that customers can generate creative ideas, they have not accounted for contextual factors. This thesis contributes to furthering understanding by considering contextual factors that influence customer creativity in the environment where it primarily occurs - namely, during consumption and in the practices where customers use the product or service. Capturing creativity in the situation and context in which it occurs can enhance overall understanding of the concept. Results from this thesis show that customers are influenced to different degrees by their physical environment and social contexts, as well as type of health care service. In the customer sphere, customers' contributions scored high on both originality and clinical value, indicating that the role of the customer changes in different contexts. Concerning the high scores on originality, in line with previous work (Amabile, 1983), the results suggest that customers generate original ideas in their own contexts where they possess domain knowledge and their role is not constrained. One explanation for this is that the outcome and value they perceive is highly dependent on their own actions.

Third, previous studies on customer creativity have focused almost exclusively on "positive" or "neutral" settings; this study extends beyond that by investigating customer creativity in a negative service; that is, a service that customers need, but do not necessarily want (Berry and Bendapudi 2007). The results of this thesis show that despite the negative nature of the service, health care customers are creative, especially with regard to solving health-related problems in the customer sphere. Given the opportunity, customers in health care can provide valuable ideas and solutions on a multitude of aspects, both within and outside the health care setting. Health care practices occur in specific service environments, but also in everyday life, making health care a highly interesting setting for investigating how different contexts influence customer creativity. Customer creativity is most likely not merely a function of customer-provider interaction alone, but rather of various actors in the dynamic environment surrounding the customer. However, the results indicate that health care 
customers do not view their role as active, especially when interacting with health care professionals, and this influences their creativity and the characteristics of their ideas.

Fourth, in this thesis I have proposed that customer creativity is a useful concept for understanding the customer role in service innovation. One important theoretical contribution of this thesis is the introduction and proposed conceptual framework for customer creativity in health care. The strength of this model lies in the integration of components that reflect a holistic conceptualization of customer creativity in health care. This model elaborates on relationships among creativity and customer practices and includes individual, contextual, and situational factors. This framework provides a concept and a comprehensive model from which to generate and test hypotheses regarding health care customer creativity. This model attempts to specify the factors on which customer creativity depends, with the intention of suggesting research directions and developing an enriched theory of health care customer creativity. There are multitudes of relationships between the identified factors and sub-concepts that could potentially be explored and tested to further understanding. As such, this model is still quite general. To be operationalized, it needs to be further adjusted to specific illness contexts. The suggested relationships in the model can be both direct and indirect, but also reciprocal or bidirectional. An extension of this model would imply (1) operational definition of the factors presented, and (2) multiple measures of these factors.

\subsection{Managerial contributions}

This thesis also makes important managerial contributions. First, while this framework serves foremost as a starting point for further research, the factors presented in the model can be used to facilitate the identification of customers whose motivation, problem-solving skills, and use of prior learning may make them vulnerable, thus stimulating early intervention and reinforcing factors found to stimulate problem solving.

Second, this thesis provides insight into the fact that the actions of the service provider only have partial influence over effective disease management. Thus, instead of just focusing of the efficiency of internal structures and the quality of care within the health care setting, it might be beneficial to investigate how to support customer practices within the customer sphere and encourage customer creativity. Considering the whole service experience from the customer's perspective will enable insight and better understanding of health care customer needs and illness-related problems, as the practice of health care is not over when the customer leaves the service setting. Clearly, customers manage their illnesses and most health-related activities in everyday life. If health care providers view the experience through the customers' eyes and take part in their creativity in spheres where the providers traditionally have had no access, they can respond more effectively to customer needs and thereby enhance the service experience and service quality. 
Third, when involving customers in both the delivery and development of health care services, service providers should take physical and social contexts, as well as types of service, into account when deciding on methods of involvement. The results show that customers are able to provide valuable ideas that can potentially enhance the service experience, especially in the joint sphere of health care. However, in order to obtain access to original ideas, service providers should consider methods of involvement that enable the customer to take an active role and not be constrained by the traditional health care setting.

\subsection{Further research}

There are many opportunities to refine and extend the results reported here. While Paper 3 provided a comprehensive research agenda, there are some additional avenues for further research. The current study may be viewed as a first attempt to understand customer creativity in a health care context and present a conceptual framework. This study is subject to significant limitations with regard to the number of investigated factors and their effects on creativity. In addition, the study has only investigated two types of health care services. Therefore, the proposed framework should be further developed and tested in different health care settings. There are myriad relationships and sub-concepts that could potentially be explored and tested to further our understanding of the customer's role, practices, and creativity in health care.

As stated, this study only investigates two types of health care services. Therefore, research to further this work in other health care settings should be encouraged. While this study relies on the results of other studies regarding potential personal factors that affect customer creativity, further studies should investigate these factors in more detail. This research could investigate specific traits, knowledge, experience, and motivation of customers, in addition to contextual factors. In addition, other studies should address the entire process from customer creativity to service innovation. This could include methods for revealing customer creativity and the process of turning this creativity into something that could be introduced on the market.

Therefore, further studies on health care customer creativity should consider different level of analysis. For example, creativity can be discussed and analyzed on the macro-level as well. Interesting investigations on a macro-level could, for example, include how the health care system and related policy and legislation restrain or reinforce creativity in general, and customer creativity in particular. On the meso-level, creativity and customer creativity can be discussed in relation to specific health care organizations, or perhaps even health care customer associations or groups. Taking a specific firm as a focus, important issues can include, for example, how to adopt and handle creative customers and support creativity in practice. This type of analysis can focus on capabilities and strategies to incorporate customer creativity as a recourse in internal development, as well as how to reinforce creativity in consumption or use of the service and methods for involving customers in 
delivery of care. These perspectives can provide valuable insights and further the theoretical models for health care customer creativity as well as health care practice. 


\section{References}

Aarikka-Stenroos, L., \& Jaakkola, E. (2012). Value co-creation in knowledge intensive business services: A dyadic perspective on the joint problem solving process. Industrial Marketing Management, 41(1), 15-26.

Adams, S. H., Cartwright, L. K., Ostrove, J. M., Stewart, A. J., \& Wink, P. (1998). Psychological predictors of good health in three longitudinal samples of educated midlife women. Health Psychology, 17(5), 412-420.

Agarwal, R., \& Selen, W. (2011). Multi-dimensional nature of service innovation: Operationalisation of the elevated service offerings construct in collaborative service organisations. International Journal of Operations \& Production Management, 31(11), 1164-1192.

Akaka, M. A., \& Chandler, J. D. (2011). Roles as resources: A social roles perspective of change in value networks. Marketing Theory, 11(3), 243-260.

Akaka, A. M., Vargo, L. S., \& Schau, H. J. (2015). The context of experience. Journal of Service Management, 26(2), 206-223.

Alam, I. (2002). An exploratory investigation of user involvement in new service development. Journal of the Academy of Marketing Science, 30(3), 250-261.

Alam, I., \& Perry, C. (2002). A customer-oriented new service development process. Journal of Services Marketing, 16(6), 515-534.

Alogna, M. (1980). Perception of Severity of Disease and Health Locus of Control in Compliant and Noncompliant Diabetic Patients. Diabetes Care, 3(4), 533-534.

Amabile, T. M. (1983). The social psychology of creativity: A componential conceptualization. Journal of Personality and Social Psychology, 45(2), 357-376.

Amabile, T. M. (1988). A model of creativity and innovation in organizations. Research in Organizational Behavior, 10(1), 123-167.

Amabile, T. M. (1996). The motivation for creativity in organizations. Harvard Business School.

Amabile, T. M. (2001). Beyond talent: John Irving and the passionate craft of creativity. American Psychologist, 56(4), 333-336.

Amabile, T. M., Conti, R., Coon, H., Lazenby, J., \& Herron, M. (1996). Assessing the Work Environment for Creativity. The Academy of Management Journal, 39(5), 1154-1184.

Anderson, R. M., \& Funnell, M. M. (2010). Patient empowerment: Myths and misconceptions. Patient Education and Counseling, 79(3), 277-282.

Anell, A., Glenngard, A. H., \& Merkur, S. M. (2012). Sweden: Health system review. Health Systems in Transition, 14(5), 1-159.

Axelsson, R. (2000). The organizational pendulum Healthcare management in Sweden 1865 -1998. Scandinavian Journal of Public Health, 28(1), 47-53.

Baer, J. (2014). The Crisis in Creativity Research Stems From Too Little Fragmentation, Not Too Much. Creativity. Theories - Research-Applications, 1(2), 200-205. http://doi.org/10.15290/ctra.2014.01.02.04 
Bandura, A. (1977). Self-efficacy: Toward a unifying theory of behavioral change. Psychological Review, 84(2), 191-215.

Bandura, A. (1991). Theories of Cognitive Self-RegulationSocial cognitive theory of selfregulation. Organizational Behavior and Human Decision Processes, 50(2), 248287.

Barlow, J., Wright, C., Sheasby, J., Turner, A., \& Hainsworth, J. (2002). Self-management approaches for people with chronic conditions: a review. Patient Education and Counseling, 48(2), 177-187.

Barron, F., \& Harrington, D. M. (1981). Creativity, intelligence, and personality. Annual Review of Psychology, 32(1), 439-476.

Beibei Dong, \& K. Sivakumar. (2015). A process-output classification for customer participation in services. Journal of Service Management, 26(5), 726-750.

Bélanger, E., Rodríguez, C., \& Groleau, D. (2011). Shared decision-making in palliative care: A systematic mixed studies review using narrative synthesis. Palliative Medicine, 25(3), 242-261.

Berry, L. L., \& Bendapudi, N. (2007). Health care: A fertile field for service research. Journal of Service Research, 10(2), 111-122.

Berthon, P. R., Pitt, L. F., McCarthy, I., \& Kates, S. M. (2007). When customers get clever: Managerial approaches to dealing with creative consumers. Business Horizons, 50(1), 39-47.

Biddle, B. J. (1986). Recent Development in Role Theory. Annual Review of Sociology, 12, 67-92.

Biemans, W. G., Griffin, A., \& Moenaert, R. K. (2015). New Service Development: How the Field Developed, Its Current Status and Recommendations for Moving the Field Forward. Journal of Product Innovation Management, n/a-n/a.

Bitner, M. J., Faranda, W. T., Hubbert, A. R., \& Zeithaml, V. A. (1997). Customer contributions and roles in service delivery. International Journal of Service Industry Management, 8(3), 193-205.

Black, H. G., \& Gallan, A. S. (2015). Transformative service networks: cocreated value as well-being. The Service Industries Journal, O(0), 1-20.

Bodenheimer, T., Lorig, K., Holman, H., \& Grumbach, K. (2002). Patient selfmanagement of chronic disease in primary care. JAMA : The Journal of the American Medical Association, 288(19), 2469-2475.

Bodenheimer, T., Wagner, E. H., \& Grumbach, K. (2002). Improving primary care for patients with chronic illness. JAMA, 288(14), 1775-1779.

Bogg, T., \& Roberts, B. W. (2004). Conscientiousness and Health-Related Behaviors: A Meta-Analysis of the Leading Behavioral Contributors to Mortality. Psychological Bulletin, 130(6), 887-919.

Bohmer, R. M. J. (2009). Designing Care: Aligning the Nature and Management of Health Care. Harvard Business Press.

Bolton, R.N., Gustafsson, A., McColl-Kennedy, J.R., Sirianni, N.J., \& Tse, D.K. (2014). Small details that make big differences. Journal of Service Management, 25(2), 253-274.

Borman, G. D., \& Dowling, N. M. (2008). Teacher Attrition and Retention: A Meta- 
Analytic and Narrative Review of the Research. Review of Educational Research, 78(3), 367-409.

Botti, S., Orfali, K., \& Iyengar, S. S. (2009). Tragic Choices: Autonomy and Emotional Responses to Medical Decisions. Journal of Consumer Research, 36(3), 337-352.

Boulos, M. N. K., Brewer, A. C., Karimkhani, C., Buller, D. B., \& Dellavalle, R. P. (2014). Mobile medical and health apps: state of the art, concerns, regulatory control and certification. Online Journal of Public Health Informatics, 5(3), 229.

Boxer, H., \& Snyder, S. (2009). Five communication strategies to promote selfmanagement of chronic illness. Family Practice Management, 16(5), 12-16.

Boyne, J. J., Vrijhoef, H. J., Spreeuwenberg, M., De Weerd, G., Kragten, J., Gorgels, A. P.,. (2014). Effects of tailored telemonitoring on heart failure patients' knowledge, self-care, self-efficacy and adherence: a randomized controlled trial. European Journal of Cardiovascular Nursing, 13(3), 243-252.

Braun, V., \& Clarke, V. (2006). Using thematic analysis in psychology. Qualitative Research in Psychology, 3(2), 77-101.

Bryman, A. (2001). Social Research Methods. Oxford University Press, Incorporated. Bryman, A. (2006). Integrating quantitative and qualitative research: how is it done? Qualitative Research, 6(1), 97-113.

Bryman, A., \& Bell, E. (2007). Business Research Methods. Oxford University Press. Buchwald, H., Avidor, Y., Braunwald, E., Jensen, M. D., Pories, W., Fahrbach, K., \& Schoelles, K. (2004). Bariatric surgery: a systematic review and meta-analysis. Jama, 292(14), 1724-1737.

Bulsara, C., Ward, A., \& Joske, D. (2004). Haematological cancer patients: achieving a sense of empowerment by use of strategies to control illness. Journal of Clinical Nursing, 13(2), 251-258.

Burroughs, J. E., \& Mick, D. G. (2004). Exploring Antecedents and Consequences of Consumer Creativity in a Problem-Solving Context. Journal of Consumer Research, 31(2), 402-411.

Burroughs, J. E., Moreau, C. P., \& Mick, D. G. (2008). Toward a psychology of consumer creativity. Handbook of Consumer Psychology, 1011-38.

Cameron, K. A., Ross, E. L., Clayman, M. L., Bergeron, A. R., Federman, A. D., Bailey, S. C.,Wolf, M. S. (2010). Measuring patients' self-efficacy in understanding and using prescription medication. Patient Education and Counseling, 80(3), 372-376.

Carlborg, P. (2015). On Service Innovation and Realization in Manufacturing Firms.

Carlborg, P., Kindström, D., \& Kowalkowski, C. (2014). The evolution of service innovation research: a critical review and synthesis. The Service Industries Journal, 34(5), 373-398.

Caspi, A., Begg, D., Dickson, N., Harrington, H., Langley, J., Moffitt, T. E., \& Silva, P. A. (1997). Personality differences predict health-risk behaviors in young adulthood: Evidence from a longitudinal study. Journal of Personality and Social Psychology, 73(5), 1052-1063.

Charles, C., Gafni, A., \& Whelan, T. (1997). Shared decision-making in the medical encounter: What does it mean? (or it takes at least two to tango). Social Science \& Medicine, 44(5), 681-692. 
Chesbrough, H., \& Crowther, A. K. (2006). Beyond High Tech: Early Adopters of Open Innovation in Other Industries (SSRN Scholarly Paper No. ID 904428). Rochester, NY: Social Science Research Network. Retrieved from http://papers.ssrn.com/abstract $=904428$

Cohen, D., McDaniel Jr, R. R., Crabtree, B. F., \& Ruhe, M. C. (2004). A practice change model for quality improvement in primary care practice. Journal of Healthcare Management, 49(3), 155.

Commonwealth Fund International Health Policy Survey of Older Adults in 11 Countries. (2014). Retrieved July 16, 2015, from http://www.commonwealthfund.org/publications/surveys/2014/2014commonwealth-fund-international-health-policy-survey

Corbin, J., \& Strauss, A. (2014). Basics of Qualitative Research: Techniques and Procedures for Developing Grounded Theory. SAGE Publications.

Corless, I. B., Wantland, D., Kirksey, K. M., Nicholas, P. K., Human, S., Arudo, J., ... Holzemer, W. L. (2012). Exploring the Contribution of General Self-Efficacy to the Use of Self-Care Symptom Management Strategies by People Living with HIV Infection. AIDS Patient Care \& STDs, 26(6), 335-343.

Cottam, H., \& Leadbeater, C. (2004). Red Paper 01 Health: co-creating services. Design Council.

Courtney, R., Ballard, E., Fauver, S., Gariota, M., \& Holland, L. (1996). The Partnership Model. Public Health Nursing, 13(3), 177-186.

Creer, T. L., \& Holroyd, K. A. (2006). Self-management of chronic conditions: the legacy of Sir William Osler. Chronic Illness, 2(1), 7-14.

Csikszentmihalyi, M. (1999). 16 Implications of a Systems Perspective for the Study of Creativity. Handbook of Creativity, 313.

Cummings, A., \& Oldham, G. R. (1997). Enhancing Creativity: Managing work contexts for the high potential employee. California Management Review, 40(1), 22-38.

Dahl, D. W., \& Moreau, P. (2002). The influence and value of analogical thinking during new product ideation. Journal of Marketing Research, 39(1), 47-60.

Davis, J., Mengersen, K., Bennett, S., \& Mazerolle, L. (2014). Viewing systematic reviews and meta-analysis in social research through different lenses. Springerplus, 3, 511511.

De Greef, K., Van Dyck, D., Deforche, B., \& De Bourdeaudhuij, I. (2011). Physical environmental correlates of self-reported and objectively assessed physical activity in Belgian type 2 diabetes patients. Health \& Social Care in the Community, 19(2), 178-188.

DerSimonian, R., \& Laird, N. (1986). Meta-analysis in clinical trials. Controlled Clinical Trials, 7(3), 177-188.

Diener, E., Oishi, S., \& Lucas, R. E. (2003). Personality, Culture, and Subjective WellBeing: Emotional and Cognitive Evaluations of Life. Annual Review of Psychology, 54(1), 403-425.

Dong, B., Sivakumar, K., Evans, K. R., \& Zou, S. (2015). Effect of Customer Participation on Service Outcomes The Moderating Role of Participation Readiness. Journal of Service Research, 18(2), 160-176. 
Dubé, C. E., O’Donnell, J. F., \& Novack, D. H. (2000). Communication skills for preventive interventions. Academic Medicine: Journal of the Association of American Medical Colleges, 75(7 Suppl), S45-54.

Edvardsson, B., Gustafsson, A., Kristensson, P., \& Witell, L. (2010). Service Innovation and Customer Co-development. In P. P. Maglio, C. A. Kieliszewski, \& J. C. Spohrer (Eds.), Handbook of Service Science (pp. 561-577). Springer US.

Edvardsson, B., Kristensson, P., Magnusson, P., \& Sundström, E. (2012). Customer integration within service development-A review of methods and an analysis of insitu and exsitu contributions. Technovation, 32(7-8), 419-429. http://doi.org/10.1016/j.technovation.2011.04.006

Eisenhardt, K. M. (1989). Building Theories from Case Study Research. Academy of Management Review, 14(4), 532-550.

Elg, M., Engström, J., Witell, L., \& Poksinska, B. (2012). Co-creation and learning in health-care service development. Journal of Service Management, 23(3), 328-343.

Elg, M., Witell, L., Poksinska, B., Engström, J., Dahlgaard-Park, S. M., \& Kammerlind, P. (2011). Solicited diaries as a means of involving patients in development of healthcare services. International Journal of Quality and Service Sciences, 3(2), $128-145$.

Engström, J., \& Elg, M. (2015). A self-determination theory perspective on customer participation in service development. Journal of Services Marketing, 29(6/7), 511521.

Feist, G. J. (1998). A meta-analysis of personality in scientific and artistic creativity. Personality and Social Psychology Review, 2(4), 290-309.

Fineberg HV. (2013). The paradox of disease prevention: Celebrated in principle, resisted in practice. JAMA, 310(1), 85-90.

Forbat, L., Cayless, S., Knighting, K., Cornwell, J., \& Kearney, N. (2009). Engaging patients in health care: an empirical study of the role of engagement on attitudes and action. Patient Education and Counseling, 74(1), 84-90.

Ford, R. C., \& McColl-Kennedy, J. R. (n.d.). Organizational strategies for filling the customer can-do/must-do gap. Business Horizons.

Gagliardi, A. R., Lemieux-Charles, L., Brown, A. D., Sullivan, T., \& Goel, V. (2008). Barriers to patient involvement in health service planning and evaluation: an exploratory study. Patient Education and Counseling, 70(2), 234-241.

Gallan, A. S., Jarvis, C. B., Brown, S. W., \& Bitner, M. J. (2013). Customer positivity and participation in services: an empirical test in a health care context. Journal of the Academy of Marketing Science, 41(3), 338-356.

Gatignon, H., \& Robertson, T. S. (1985). A Propositional Inventory for New Diffusion Research. Journal of Consumer Research, 11(4), 849-867.

Giannopoulou, E., Gryszkiewicz, L., \& Barlatier, J-P. (2014). Creativity for service innovation: a practice-based perspective. Managing Service Quality: An International Journal, 24(1), 23-44.

Gibson, A., Britten, N., \& Lynch, J. (2012). Theoretical directions for an emancipatory concept of patient and public involvement. Health: An Interdisciplinary Journal for the Social Study of Health, Illness and Medicine, 16(5), 531-547. 
Glăveanu, V. P. (2014). Theory and Context / Theory in Context: Towards an Expanded View of the Creativity Field. Creativity. Theories - Research-Applications, 1(2), 268-280.

Glass, G. V. (1976). Primary, Secondary, and Meta-Analysis of Research. Educational Researcher, 5(10), 3-8.

Grant, M. J., \& Booth, A. (2009). A typology of reviews: an analysis of 14 review types and associated methodologies. Health Information \& Libraries Journal, 26(2), 91108.

Greenhalgh, T., Robert, G., Macfarlane, F., Bate, P., \& Kyriakidou, O. (2004). Diffusion of Innovations in Service Organizations: Systematic Review and Recommendations. Milbank Quarterly, 82(4), 581-629.

Grindley, E. J., Zizzi, S. J., \& Nasypany, A. M. (2008). Use of protection motivation theory, affect, and barriers to understand and predict adherence to outpatient rehabilitation. Physical Therapy, 88(12), 1529-1540.

Grönroos, C. (2006). Adopting a service logic for marketing. Marketing Theory, 6(3), $317-333$.

Grönroos. C. (2008). Service logic revisited: who creates value? And who co-creates? European Business Review, 20(4), 298-314.

Grönroos, C., \& Ravald, A. (2011). Service as business logic: implications for value creation and marketing. Journal of Service Management, 22(1), 5-22.

Guilford, J. P. (1967). Creativity: Yesterday, Today and Tomorrow. The Journal of Creative Behavior, 1(1), 3-14.

Gustafsson, A., Kristensson, P., \& Witell, L. (2012). Customer co-creation in service innovation: a matter of communication? Journal of Service Management, 23(3), 311-327.

Gustafsson, A., Aksoy, L., Brady, M. K., McColl-Kennedy, J. R., Sirianni, N. J., Witell, L., \& Wuenderlich, N. V. (2015). Conducting service research that matters. Journal of Services Marketing, 29(6/7), 425-429.

Gustafsson, S., Vikman, I., Axelsson, K., \& Sävenstedt, S. (2015). Self-care for minor illness. Primary Health Care Research \& Development, 16(01), 71-78.

Hardyman, W., Daunt, K. L., \& Kitchener, M. (2015). Value Co-Creation through Patient Engagement in Health Care: A micro-level approach and research agenda. Public Management Review, 17(1), 90-107.

Haywood, K., Marshall, S., \& Fitzpatrick, R. (2006). Patient participation in the consultation process: a structured review of intervention strategies. Patient Education and Counseling, 63(1-2), 12-23.

Helkkula, A. (2010). Service experience in an innovation context. Helsinki: Hanken School of Economics :

Helkkula, A., Kelleher, C., \& Pihlstrom, M. (2012). Characterizing Value as an Experience: Implications for Service Researchers and Managers. Journal of Service Research, 15(1), 59-75.

Henrike, H.-W., \& Schultz, C. (2014). The impact of health care professionals' service orientation on patients' innovative behavior: Health Care Management Review, 
39(4), 329-339.

Herzlinger, R. E. (2006). Why innovation in health care is so hard. Harvard business review, 84(5), 58.

Hill-Briggs, F. (2003). Problem solving in diabetes self-management: A model of chronic illness self-management behavior. Annals of Behavioral Medicine, 25(3), 182-193.

Hillebrand, B., Driessen, P. H., \& Koll, O. (2015). Stakeholder marketing: theoretical foundations and required capabilities. Journal of the Academy of Marketing Science, 43(4), 411-428.

Hirschman, E. C. (1980). Innovativeness, Novelty Seeking, and Consumer Creativity. Journal of Consumer Research, 7(3), 283-295.

Hirschman, E. C. (1983). Consumer Intelligence, Creativity, and Consciousness: Implications for Consumer Protection and Education. Journal of Public Policy \& Marketing, 2, 153-170.

Holbrook, M. (2002). Consumer Value: A Framework for Analysis and Research. Routledge.

Howard, T. J., Culley, S. J., \& Dekoninck, E. (2008). Describing the creative design process by the integration of engineering design and cognitive psychology literature. Design Studies, 29(2), 160-180.

Hoyer, W. D., Chandy, R., Dorotic, M., Krafft, M., \& Singh, S. S. (2010). Consumer Cocreation in New Product Development. Journal of Service Research, 13(3), 283 296.

Jaakkola, E., \& Hakanen, T. (2013). Value co-creation in solution networks. Industrial Marketing Management, 42(1), 47-58.

Jones, M. V., Coviello, N., \& Tang, Y. K. (2011). International Entrepreneurship research (1989-2009): A domain ontology and thematic analysis. Journal of Business Venturing, 26(6), 632-659.

Joseph-Williams, N., Elwyn, G., \& Edwards, A. (2014). Knowledge is not power for patients: A systematic review and thematic synthesis of patient-reported barriers and facilitators to shared decision making. Patient Education and Counseling, 94(3), 291-309.

Kalichman, S. C., Kalichman, M. O., Cherry, C., Swetzes, C., Amaral, C. M., White, D., ... Eaton, L. (2011). Brief Behavioral Self-Regulation Counseling for HIV Treatment Adherence Delivered by Cell Phone: An Initial Test of Concept Trial. AIDS Patient Care \& STDs, 25(5), 303-310.

Kawashima, N. (2010). The rise of "user creativity" - Web 2.0 and a new challenge for copyright law and cultural policy. International Journal of Cultural Policy, 16(3), 337-353.

Kerrigan, S. (2013). Accommodating creative documentary practice within a revised systems model of creativity. Journal of Media Practice, 14(2), 111-127.

Kidd, L., Hubbard, G., O'Carroll, R., \& Kearney, N. (2009). Perceived control and involvement in self care in patients with colorectal cancer. Journal of Clinical Nursing, 18(16), 2292-2300.

Kimberly, J. R., \& Evanisko, M. J. (1981). Organizational Innovation: The Influence of 
Individual, Organizational, and Contextual Factors on Hospital Adoption of Technological and Administrative Innovations. Academy of Management Journal, 24(4), 689-713.

Kindström, D., \& Kowalkowski. K., (2014). Service innovation in product-centric firms: a multidimensional business model perspective. Journal of Business \& Industrial Marketing, 29(2), 96-111.

Kjellberg, H., \& Helgesson, C.-F. (2007). On the nature of markets and their practices. Marketing Theory, 7(2), 137-162.

Klein, H. A., \& Lippa, K. D. (2008). Type 2 Diabetes Self-Management: Controlling a Dynamic System. Journal of Cognitive Engineering and Decision Making, 2(1), $48-62$.

Krisjanous, J., \& Maude, R. (2015). Customer value co-creation within partnership models of health care: an examination of the New Zealand Midwifery Partnership Model. Australasian Marketing Journal (AMJ).

Kristensen, T. (2004). The Physical Context of Creativity. Creativity and Innovation Management, 13(2), 89-96.

Kristensson, P., Magnusson, P. R., \& Matthing, J. (2002). Users as a Hidden Resource for Creativity: Findings from an Experimental Study on User Involvement. Creativity and Innovation Management, 11(1), 55-61.

Lepak, D. P., Smith, K. G., \& Taylor, M. S. (2007). Introduction to Special Topic Forum: Value Creation and Value Capture: A Multilevel Perspective. The Academy of Management Review, 32(1), 180-194.

Liberati, A., Altman, D. G., Tetzlaff, J., Mulrow, C., Gøtzsche, P. C., Ioannidis, J. P. A., ... Moher, D. (2009). The PRISMA Statement for Reporting Systematic Reviews and Meta-Analyses of Studies That Evaluate Health Care Interventions: Explanation and ElaborationPRISMA: Explanation and Elaboration. Annals of Internal Medicine, 151(4), W-65.

Lorig, K. R., \& Holman, H. R. (2003). Self-management education: History, definition, outcomes, and mechanisms. Annals of Behavioral Medicine, 26(1), 1-7.

Ludwig AM. (1975). THe psychiatrist as physician. JAMA, 234(6), 603-604.

Luo, L., \& Toubia, O. (2015). Improving Online Idea Generation Platforms and Customizing the Task Structure Based on Consumers' Domain Specific Knowledge. Journal of Marketing.

Lusch, R. F., \& Nambisan, S. (2015a). Service Innovation: A Service-Dominant Logic Perspective. MIS Quarterly, 39(1), 155-176.

Lusch, R. F., \& Nambisan, S. (2015b). Service innovation: A service-dominant logic perspective. Mis Quarterly, 39(1), 155-175.

MacGregor, J. C., \& Wathen, C. N. (2014). "My health is not a job": a qualitative exploration of personal health management and imperatives of the "new public health." BMC Public Health, 14(1), 726.

MacInnis, D. J. (2011). A Framework for Conceptual Contributions in Marketing. Journal of Marketing, 75(4), 136-154.

Magnusson, P. R., Matthing, J., \& Kristensson, P. (2003a). Managing User Involvement in Service Innovation Experiments with Innovating End Users. Journal of Service 
Research, 6(2), 111-124.

Magnusson, P. R., Matthing, J., \& Kristensson, P. (2003b). Managing User Involvement in Service Innovation Experiments with Innovating End Users. Journal of Service Research, 6(2), 111-124.

Makoul, G., \& Clayman, M. L. (2006). An integrative model of shared decision making in medical encounters. Patient Education and Counseling, 60(3), 301-312.

Malterud, K. (2001). The art and science of clinical knowledge: evidence beyond measures and numbers. The Lancet, 358(9279), 397-400.

McColl-Kennedy, Cheung, L., \& Ferrier, E.(2015). Co-creating service experience practices. Journal of Service Management, 26(2), 249-275.

McColl-Kennedy, J. R., Vargo, S. L., Dagger, T. S., Sweeney, J. C., \& Kasteren, Y. v. (2012). Health Care Customer Value Cocreation Practice Styles. Journal of Service Research, 15(4), 370-389.

McCoy, J. H., \& Eric Johnson, M. (2014). Clinic Capacity Management: Planning Treatment Programs that Incorporate Adherence. Production and Operations Management, 23(1), 1-18.

McKinstry, B. (2000). Do patients wish to be involved in decision making in the consultation? A cross sectional survey with video vignettes. BMJ, 321(7265), 867871 .

Mead, N., \& Bower, P. (2000). Patient-centredness: a conceptual framework and review of the empirical literature. Social Science \& Medicine, 51(7), 1087-1110.

Medsger, T., Bombardieri, S., Czirjak, L., Scorza, R., Rossa, A., \& Bencivelli, W. (2003). Assessment of disease severity and prognosis. Clinical and Experimental Rheumatology, 21(3; SUPP/29), S42-S46.

Menor, L. J., Tatikonda, M. V., \& Sampson, S. E. (2002). New service development: areas for exploitation and exploration. Journal of Operations Management, 20(2), 135157.

Michel, S., Brown, S. W., \& Gallan, A. S. (2008). Service-Logic innovations: How to Innovate Customers, Not Products. California Management Review, 50(3), 49-65.

Mifsud, M., Cases, A-S., \& N'Goala, G. (2015). Service appropriation: how do customers make the service their own? Journal of Service Management, 26(5), 706-725. h

Moeller, S., Ciuchita, R., Mahr, D., Odekerken-Schröder, G., \& Fassnacht, M. (2013). Uncovering Collaborative Value Creation Patterns and Establishing Corresponding Customer Roles. Journal of Service Research, 16(4), 471-487.

Moher, D., Liberati, A., Tetzlaff, J., \& Altman, D. G. (2009). Preferred Reporting Items for Systematic Reviews and Meta-Analyses: The PRISMA StatementThe PRISMA Statement. Annals of Internal Medicine, 151(4), 264-269.

Moldovan-Johnson, M., Martinez, L., Lewis, N., Freres, D., \& Hornik, R. C. (2014). The Role of Patient-Clinician Information Engagement and Information Seeking from Nonmedical Channels in Fruit and Vegetable Intake Among Cancer Patients. Journal of Health Communication, 19(12), 1359-1376.

Moreau, C. P., \& Dahl, D. W. (2005). Designing the Solution: The Impact of Constraints on Consumers' Creativity. Journal of Consumer Research, 32(1), 13-22.

Morton, D. G. (1937). Modern prenatal care. The American Journal of Surgery, 35(2), 
225-233.

Muis, K. R., Bendixen, L. D., \& Haerle, F. C. (2006). Domain-Generality and DomainSpecificity in Personal Epistemology Research: Philosophical and Empirical Reflections in the Development of a Theoretical Framework. Educational Psychology Review, 18(1), 3-54. http://doi.org/10.1007/s10648-006-9003-6

Mumford, M. D., \& Gustafson, S. B. (1988). Creativity syndrome: Integration, application, and innovation. Psychological Bulletin, 103(1), 27.

Murray, E., Pollack, L., White, M., \& Lo, B. (2007). Clinical decision-making: Patients' preferences and experiences. Patient Education and Counseling, 65(2), 189-196.

Neely, A., Gregory, G., \& Ken Platts. (2005). Performance measurement system design: A literature review and research agenda. International Journal of Operations \& Production Management, 25(12), 1228-1263.

Nelson, E. C., Godfrey, M. M., Batalden, P. B., Berry, S. A., Bothe, A. E., McKinley, K. E.,Nolan, T. W. (2008). Clinical Microsystems, Part 1. The Building Blocks of Health Systems. Joint Commission Journal on Quality and Patient Safety, 34(7), 367-378

Nordin, I. (1988). Teknologins rationalitet: En teori om teknikens struktur och dynamik. Timbro.

OECD Health Statistics 2015 - OECD. (2015). Retrieved July 16, 2015, from http://www.oecd.org/els/health-systems/health-data.htm

Okasha, S. (2002). Philosophy of Science: A Very Short Introduction. OUP Oxford.

Oldham, G. R., \& Cummings, A. (1996). Employee Creativity: Personal and Contextual Factors at Work. Academy of Management Journal, 39(3), 607-634.

Ostrom, A. L., Parasuraman, A., Bowen, D. E., Patrício, L., Voss, C. A., \& Lemon, K. (2015). Service Research Priorities in a Rapidly Changing Context. Journal of Service Research, 18(2), 127-159.

Ouschan, R., Sweeney, J., \& Johnson, L. (2006). Customer empowerment and relationship outcomes in healthcare consultations. European Journal of Marketing, 40(9/10), 1068-1086.

Parsons, T. (1951). Illness and the role of the physician: A sociological perspective. American Journal of Orthopsychiatry, 21(3), 452-460.

Payne, A. F., Storbacka, K., \& Frow, P. (2008). Managing the co-creation of value. Journal of the Academy of Marketing Science, 36(1), 83-96. http://doi.org/10.1007/s11747-007-0070-0

Perry-Smith, J. E., \& Shalley, C. E. (2003). The social side of creativity: A static and dynamic social network perspective. Academy of Management Review, 28(1), 89106.

Peter, M. (2009). Milieus of Creativity: The Role of Places, Environments, and Spatial Contexts. In P. Meusburger, J. Funke, \& E. Wunder (Eds.), Milieus of Creativity (pp. 97-153).

Phares, E. J. (1997). Introduction to Personality. Longman.

Plsek, P. E., \& Greenhalgh, T. (2001). The challenge of complexity in health care. BMJ : British Medical Journal, 323(7313), 625-628.

Poetz, M. K., \& Schreier, M. (2012). The Value of Crowdsourcing: Can Users Really 
Compete with Professionals in Generating New Product Ideas? Journal of Product Innovation Management, 29(2), 245-256.

Rosa, J. A., Qualls, W. J., \& Ruth, J. A. (2014). Consumer creativity: Effects of gender and variation in the richness of vision and touch inputs. Journal of Business Research, 67(3), 386-393.

Rosenbaum, M. S., \& Smallwood, J. (2013). Cancer resource centers as third places. Journal of Services Marketing, 27(6), 4-4.

Ross, M. E. T. (1991). Hardiness and Compliance in Elderly Patients With Diabetes. The Diabetes Educator, 17(5), 372-375.

Runco, M. A. (2007). Creativity. [Elektronisk resurs] : theories and themes: research, development, and practice. Amsterdam ; Boston : Elsevier Academic Press, c2007.

Ryan, R. M., \& Deci, E. L. (2000). Self-determination theory and the facilitation of intrinsic motivation, social development, and well-being. American Psychologist, 55(1), 68-78.

Sarbin, T. R., \& Allen, V. L. (1968). Role theory.

Sarooghi, H., Libaers, D., \& Burkemper, A. (2015). Examining the relationship between creativity and innovation: A meta-analysis of organizational, cultural, and environmental factors. Journal of Business Venturing, 30(5), 714-731.

Sayer, A. (1992). Method in Social Science: A Realist Approach. Psychology Press.

Schau, H. J., Jr., A. M. M., \& Arnould, E. J. (2009). How Brand Community Practices Create Value. Journal of Marketing, 73(5), 30-51.

Schneider, A., Körner, T., Mehring, M., Wensing, M., Elwyn, G., \& Szecsenyi, J. (2006). Impact of age, health locus of control and psychological co-morbidity on patients' preferences for shared decision making in general practice. Patient Education and Counseling, 61(2), 292-298.

Schumpeter, J. A. (1934). The Theory of Economic Development: An Inquiry Into Profits, Capital, Credit, Interest, and the Business Cycle. Transaction Publishers.

Seiders, K., Flynn, A. G., Berry, L. L., \& Haws, K. L. (2015). Motivating Customers to Adhere to Expert Advice in Professional Services A Medical Service Context. Journal of Service Research, 18(1), 39-58.

Shostack, G. L. (1987). Service Positioning through Structural Change. Journal of Marketing, 51(1), 34-43.

Simonton, D. K. (2000). Creativity: Cognitive, personal, developmental, and social aspects. American Psychologist, 55(1), 151-158.

Singh, S., Butow, P., Charles, M., \& Tattersall, M. (2010). Shared decision making in oncology: assessing oncologist behaviour in consultations in which adjuvant therapy is considered after primary surgical treatment. Health Expectations, 13(3), 244-257.

Skålén, P., Gummerus, J., Koskull, C. von, \& Magnusson, P. R. (2014). Exploring value propositions and service innovation: a service-dominant logic study. Journal of the Academy of Marketing Science, 43(2), 137-158.

Skinner, T. C., Bruce, D. G., Davis, T. M. E., \& Davis, W. A. (2014). Personality traits, self-care behaviours and glycaemic control in Type 2 diabetes: The Fremantle Diabetes Study Phase II. Diabetic Medicine, 31(4), 487-492. 
Smith, L., Maull, R., \& Ng, I. C. L. (2014). Servitization and operations management: a service dominant-logic approach. International Journal of Operations \& Production Management, 34(2), 242-269.

Smith, M., Busi, M., Ball, P., \& Van Der Meer, R. (2008). Factors influencing an organisation's ability to manage innovation: a structured literature review and conceptual model. International Journal of Innovation Management, 12(04), 655676.

Snell, L., \& White, L. (2011). An Exploratory Study of the Role of Emotional Intelligence and Self-Efficacy on Service Quality and Adherence in a Weight Loss Setting. Services Marketing Quarterly, 32(3), 228-246.

Solomon, M. R., Surprenant, C., Czepiel, J. A., \& Gutman, E. G. (1985). A Role Theory Perspective on Dyadic Interactions: The Service Encounter. Journal of Marketing, 49(1), 99-111.

Soto, N. I., Bazyler, L. R., O’Toole, M. L., Brownson, C. A., \& Pezzullo, J. C. (2007). Starting a Diabetes Self-Management Program in a Free Clinic. The Diabetes Educator, 33(Supplement 6), 166S-171S.

Spanjol, J., Cui, A. S., Nakata, C., Sharp, L. K., Crawford, S. Y., Xiao, Y., \& WatsonManheim, M. B. (2015). Co-Production of Prolonged, Complex, and Negative Services An Examination of Medication Adherence in Chronically Ill Individuals. Journal of Service Research, 18(3), 284-302.

Sternberg, R. J. (1999). Handbook of Creativity. Cambridge University Press.

Stewart, M. (2001). Towards a global definition of patient centred care. BMJ, 322(7284), 444-445.

Street Jr., R. L., Makoul, G., Arora, N. K., \& Epstein, R. M. (2009). How does communication heal? Pathways linking clinician-patient communication to health outcomes. Patient Education and Counseling, 74(3), 295-301.

Street, R. L., \& Gordon, H. S. (2006). The clinical context and patient participation in post-diagnostic consultations. Patient Education and Counseling, 64(1-3), 217224.

Sundbo, J. (1997). Management of Innovation in Services. The Service Industries Journal, 17(3), 432-455.

Sweeney, J. C., Danaher, T. S., \& McColl-Kennedy, J. R. (2015). Customer Effort in Value Cocreation Activities Improving Quality of Life and Behavioral Intentions of Health Care Customers. Journal of Service Research.

Tansik, D. A., \& Routhieaux, R. (1999). Customer stress-relaxation: the impact of music in a hospital waiting room. International Journal of Service Industry Management, 10(1), 68-81.

Thomas, J., Harden, A., Oakley, A., Oliver, S., Sutcliffe, K., Rees, R., ... Kavanagh, J. (2004). Integrating qualitative research with trials in systematic reviews. BMJ :

British Medical Journal, 328(7446), 1010-1012.

Tierney, P., \& Farmer, S. M. (2002). Creative Self-Efficacy: Its Potential Antecedents and Relationship to Creative Performance. Academy of Management Journal, 45(6), 1137-1148.

Toivonen, M., \& Tuominen, T. (2009). Emergence of innovations in services. The Service 
Industries Journal, 29(7), 887-902. http://doi.org/10.1080/02642060902749492

Topol, E. J. (2012). The creative destruction of medicine: How the digital revolution will create better health care. Basic Books.

Torraco, R. J. (2005). Writing Integrative Literature Reviews: Guidelines and Examples. Human Resource Development Review, 4(3), 356-367.

Tranfield, D., Denyer, D., \& Smart, P. (2003). Towards a Methodology for Developing Evidence-Informed Management Knowledge by Means of Systematic Review. British Journal of Management, 14(3), 207-222.

Troye, S. V., \& Supphellen, M. (2012). Consumer Participation in Coproduction: "I Made It Myself” Effects on Consumers' Sensory Perceptions and Evaluations of Outcome and Input Product. Journal of Marketing, 76(2), 33-46.

Van de Ven, A. H., Angle, H. L., \& Poole, M. S. (1989). Research on the management of innovation: The Minnesota studies (Vol. 1). Ballinger Publishing Company.

Varekamp, I., Verbeek, J. H. A. M., \& van Dijk, F. J. H. (2006). How can we help employees with chronic diseases to stay at work? A review of interventions aimed at job retention and based on an empowerment perspective. International Archives of Occupational and Environmental Health, 80(2), 87-97.

Vargo, S. L., \& Lusch, R. F. (2004). Evolving to a New Dominant Logic for Marketing. Journal of Marketing, 68(1), 1-17.

Vargo, S. L., \& Lusch, R. F. (2008). Service-dominant logic: continuing the evolution. Journal of the Academy of Marketing Science, 36(1), 1-10.

Vargo, S. L., \& Lusch, R. F. (2015). Institutions and axioms: an extension and update of service-dominant logic. Journal of the Academy of Marketing Science.

von Hippel, E. (1986). Lead Users: A Source of Novel Product Concepts. Management Science, 32(7), 791-805.

von Hippel, E. (1989). New product ideas from lead users. Research Technology Management, 32(3), 24-27.

von Hippel, E. (2005). Democratizing innovation: The evolving phenomenon of user innovation. Journal Für Betriebswirtschaft, 55(1), 63-78.

Voss, A.C., Sousa, R., Perks, H., Witell, L., and Wunderlich, N. (2016). Reflections on the Role of Context in Service Research. Journal of Service Management.

Vough, H. C., Cardador, M.T., Bednar, J. S., Dane, E., \& Pratt, M. G. (2013). What Clients Don't Get About My Profession: A Model of Perceived Role-Based Image Discrepancies. Academy of Management Journal, 56(4), 1050-1080.

Wagner, E. H., Bennett, S. M., Austin, B. T., Greene, S. M., Schaefer, J. K., \& Vonkorff, M. (2005). Finding Common Ground: Patient-Centeredness and Evidence-Based Chronic Illness Care. The Journal of Alternative and Complementary Medicine, 11 (supplement 1), s-7.

Walker, R. J., Gebregziabher, M., Martin-Harris, B., \& Egede, L. E. (2014). Independent effects of socioeconomic and psychological social determinants of health on selfcare and outcomes in Type 2 diabetes. General Hospital Psychiatry, 36(6), 662668.

Ward, V., House, A., \& Hamer, S. (2009). Developing a framework for transferring knowledge into action: a thematic analysis of the literature. Journal of Health 
Services Research \& Policy, 14(3), 156-164.

Webster, J., \& Watson, R. T. (2002). Analyzing the past to prepare for the future: Writing a literature review. Management Information Systems Quarterly, 26(2), 3.

Weisberg, R. W. (1999). I2 Creativity and Knowledge: A Challenge t0 The0ries. Handbook of Creativity, 226.

West, M. A., \& Wallace, M. (1991). Innovation in health care teams. European Journal of Social Psychology, 21(4), 303-315.

Whittemore, R., \& Knafl, K. (2005). The integrative review: updated methodology. Journal of Advanced Nursing, 52(5), 546-553.

Williams, A., \& Manias, E. (2014). Exploring motivation and confidence in taking prescribed medicines in coexisting diseases: a qualitative study. Journal of Clinical Nursing, 23(3-4), 471-481.

Windrum, P. (2014). Third sector organizations and the co-production of health innovations. Management Decision, 52(6), 1046-1056. http://doi.org/10.1108/MD03-2012-0166

Windrum, P., \& García-Goñi, M. (2008). A neo-Schumpeterian model of health services innovation. Research Policy, 37(4), 649-672.

Witell, L., Kristensson, P., Gustafsson, A., \& Löfgren, M. (2011). Idea generation: customer co-creation versus traditional market research techniques. Journal of Service Management, 22(2), 140-159.

Witell, L., Gustafsson, A., \& Johnson. D. M. (2014). The effect of customer information during new product development on profits from goods and services. European Journal of Marketing, 48(9/10), 1709-1730.

Witell, L., Snyder, H., Gustafsson, A., Fombelle, P., \& Kristensson, P. (2016). Defining service innovation: A review and synthesis. Journal of Business Research.

Wong, G., Greenhalgh, T., Westhorp, G., Buckingham, J., \& Pawson, R. (2013). RAMESES publication standards: meta-narrative reviews. BMC Medicine, 11(1), 20.

Woodman, R. W., Sawyer, J. E., \& Griffin, R. W. (1993). Toward a Theory of Organizational Creativity. The Academy of Management Review, 18(2), 293-321.

Woodman, R. W., \& Schoenfeldt, L. F. (1990). An Interactionist Model of Creative Behavior*. The Journal of Creative Behavior, 24(4), 279-290.

Xie, C., Bagozzi, R. P., \& Troye, S. V. (2007). Trying to prosume: toward a theory of consumers as co-creators of value. Journal of the Academy of Marketing Science, 36(1), 109-122.

Yin, R. K. (2009). Case Study Research: Design and Methods. SAGE.

Zeng, L., Proctor, R. W., \& Salvendy, G. (2009). Fostering Creativity in Service Development: Facilitating Service Innovation by the Creative Cognition Approach. Service Science, 1(3), 142-153. 


\section{Papers}

The articles associated with this thesis have been removed for copyright reasons. For more details about these see:

http://urn.kb.se/resolve?urn=urn:nbn:se:liu:diva-125723 